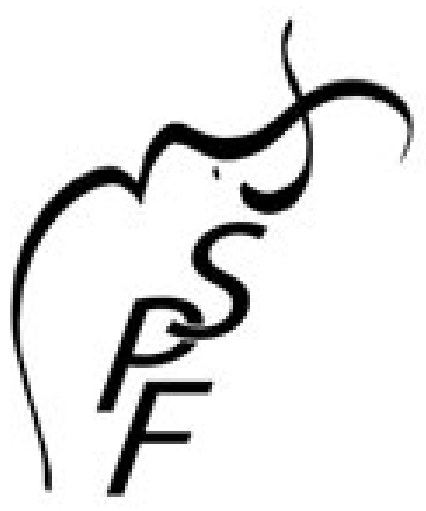

La grotte des Cloches à Saint-Martin-d'Ardèche

Author(s): Joël Vital, Jean-Luc Gisclon and Stéphanie Thiébault

Reviewed work(s):

Source: Bulletin de la Société préhistorique française, T. 83, No. 11/12, Études et Travaux (1986), pp. 503-545

Published by: Société Préhistorique Française

Stable URL: http://www.jstor.org/stable/27918992

Accessed: $27 / 08 / 201210: 33$

Your use of the JSTOR archive indicates your acceptance of the Terms \& Conditions of Use, available at http://www.jstor.org/page/info/about/policies/terms.jsp

JSTOR is a not-for-profit service that helps scholars, researchers, and students discover, use, and build upon a wide range of content in a trusted digital archive. We use information technology and tools to increase productivity and facilitate new forms of scholarship. For more information about JSTOR, please contact support@jstor.org. 


\title{
La grotte des Cloches à Saint-Martin-d'Ardèche
}

\author{
par Joël Vital
}

\section{$R E ́ S U M E ́$}

Nous présentons une étude synthétique de la grotte des Cloches et des industries qu'elle renfermait, réalisée à partir des documents des fouilles anciennes (1946-48) et récentes (1986). C'est un site d'habitat, vraisemblablement temporaire, occupé au Bronze final 2 et 3 . La cavité a accueilli quelques inhumations, dont une B.F. 2 b, et une incinération. Elle a servi d'atelier de confection et de cuisson de poteries au milieu du Bronze final. Les industries sont attribuées au B.F. 2 (phase moyenne et récente) et au B.F. 3 a et $3 \mathrm{~b}$. Les faits les plus marquants sont : - l'introduction des types céramiques et métalliques septentrionaux, et notamment du groupe Rhin-Suisse-France orientale, les productions locales originales ne disparaissant pas pour autant ; - la diminution des rapprochements avec l'Italie du Nord entre le Bronze final 2 et $3 \mathrm{~b}$, sanctionnée par l'émergence de traditions localisées au B.F. 3 b.

\section{RIASSUNTO}

Ui presentiamo una studio sintetico sulla grotta « Des Cloches » e sulle industrie in essa contenute, realizzato in base ai documenti sugli scavi vecchi (1946-48) e recenti (1986). Si tratta verosimilmente di un insediamento stagionale occupato durante l'età del Bronzo finale 2 e 3 . La cavità accalse qualche inumazione e una cremazione. Essa servi di laboratorio per la fabricazione e la cottura di terraglie nella metà dell'età del Bronzo finale. I materiali indica l'appartenenza del sito all'età dell Bronzo finale 2,
$3 \mathrm{a}$ e $3 \mathrm{~b}$. I fatti più importanti sono : - l'introduzione dei tipi di ceramica e di metallo settentrionali e in particolare del gruppo Reno-Svizzera-Francia orientale, non scompaiono tuttavia le produzioni locali ; - un minor accostamento con l'Italia del Nord tra l'età del Bronzo finale 2 e $3 \mathrm{~b}$, confermato dall'emergere di tradizioni localizzate nel B.F. 3 b.

\section{ZUSAMMENFASSUNG}

Wir legen eine synthetische Analyse der « grotte des Cloches » und ihrer Fundkomplexen dar, die aus den Dokumenten der früheren (1946-48) und neuen (1986). Grabungen ausgeführt wurde. Es handelt sich um eine wahrscheinlich zeitweilige Siedlung, die während der Spätbronzezeit 2 und 3 besetzt wurde. Die Höhle empfang einige Bestattüngen, darunter eine aus der Spätbronzezeit 2 b ( Ha A 2), und ein Brandgrab. In der mittleren Spätbronzezeit diente sie als Werkstatt für das Herstellen und Brennen der Töpferei. Das Fundmaterial ist einerseits in der Spätbronzezeitsstufe 2 (mittlere und spätere Phase), andererseits in den Spätbronzezeitsstufen 3 a und 3 b (Ha B) einzuordnen. Die wichtigsten Erkenntnisse sind :

- Das Vorkommen nördlicher Typen in der Keramik und Metalindustrie, insbesondere aus der Rheinisch-Schweizerisch-Ostfranzösischen Gruppe, dennoch verschwindet die originale Lokalproduktion nicht.

- Die Verringerung der Beziehungen zu Norditalien zwischen den Stufen 2 und 3, bestätigt durch das Entstehen lokaler Traditionen in der Stufe $3 \mathrm{~b}$ der Spätbronzezeit. 


\section{I. - INTRODUCTION}

La grotte des Cloches, sur la commune de SaintMartin-d'Ardèche, fait partie d'un groupe d'une dizaine de cavités concentrées en rive gauche de l'Ardèche au lieu-dit le Ranc-Pointu, dans la partie convexe du dernier des méandres creusés dans les calcaires urgoniens (fig. 1). Léopold Chiron (1896, pp. 20-21) signale 5 grottes - les plus importantes " qui ont toutes servi d'habitation à l'homme ". Il déclare avoir trouvé " des amas de cendres, des silex et beaucoup de débris de poterie grossière, épaisse ».

\section{II. - LE SITE}

Trente-cinq mètres au-dessus de l'Ardèche, la grotte des Cloches s'ouvre par un arc ogival sur un couloir fortement en pente vers l'extérieur. Il donne accès à une salle d'une centaine de mètres carrés au sol formé de planchers stalagmitiques en partie

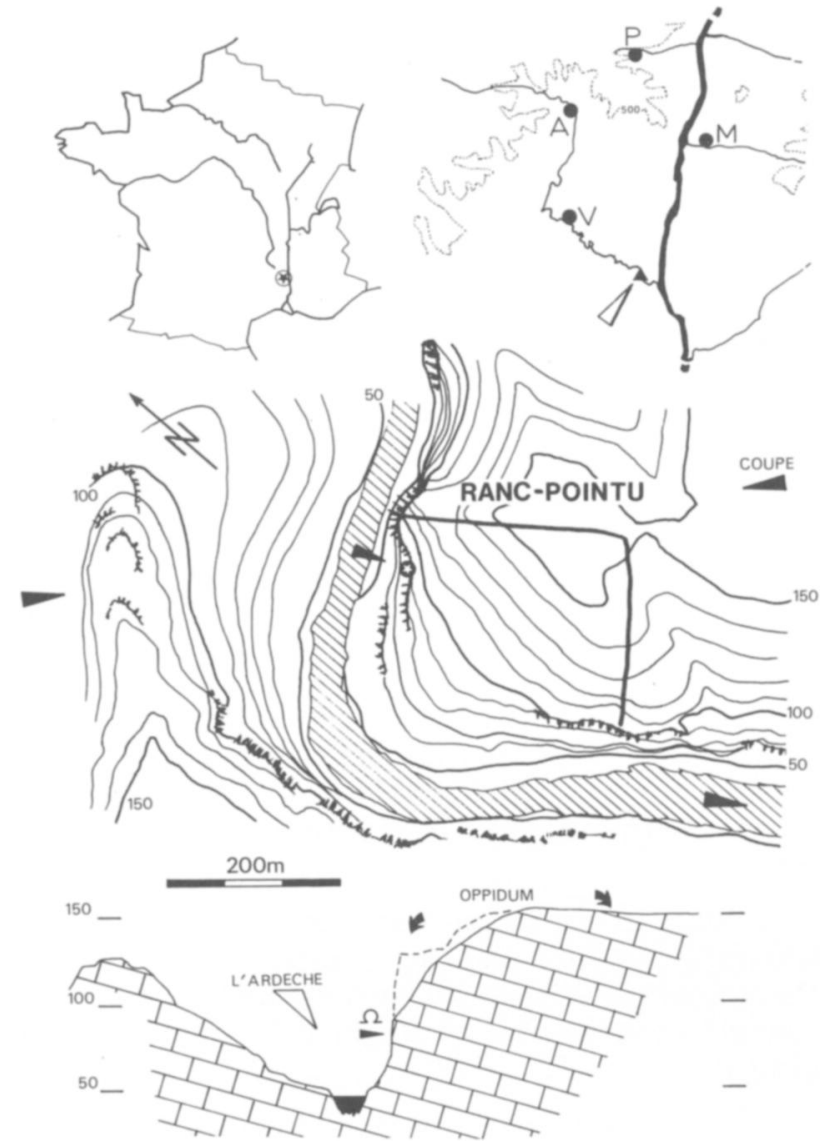

Fig. 1 - Situation de la grotte des Cloches. Villes repères : A : Aubenas ; V : Vallon-Pont-d'Arc ; P : Privas, M : Montélimar. Le rempart de l'oppidum du Ranc-Pointu est indiqué en trait gras. démantelés se succédant en escalier (fig. 2). Deux massifs stalagmitiques importants en forme de cloches sont à l'origine de la dénomination de la grotte. Celle-ci se poursuit par un couloir et une rotonde d'où diverge un court boyau. Le développement de la cavité est d'une soixantaine de mètres, pour une largeur et une hauteur variant de 3 à 10 mètres. Un diverticule s'amorce à gauche entre 7 et 12 mètres de l'entrée.

\section{III. - LES FOUILLES DE 1946-1948}

Elles ont intéressé le diverticule dans lequel furent observés "sur $1,75 \mathrm{~m}$ de profondeur, des sables et des cendres formant des couches bien individualisées ». Dix-huit couches auraient été distinguées, relevées sur une coupe théorique réalisée à l'époque

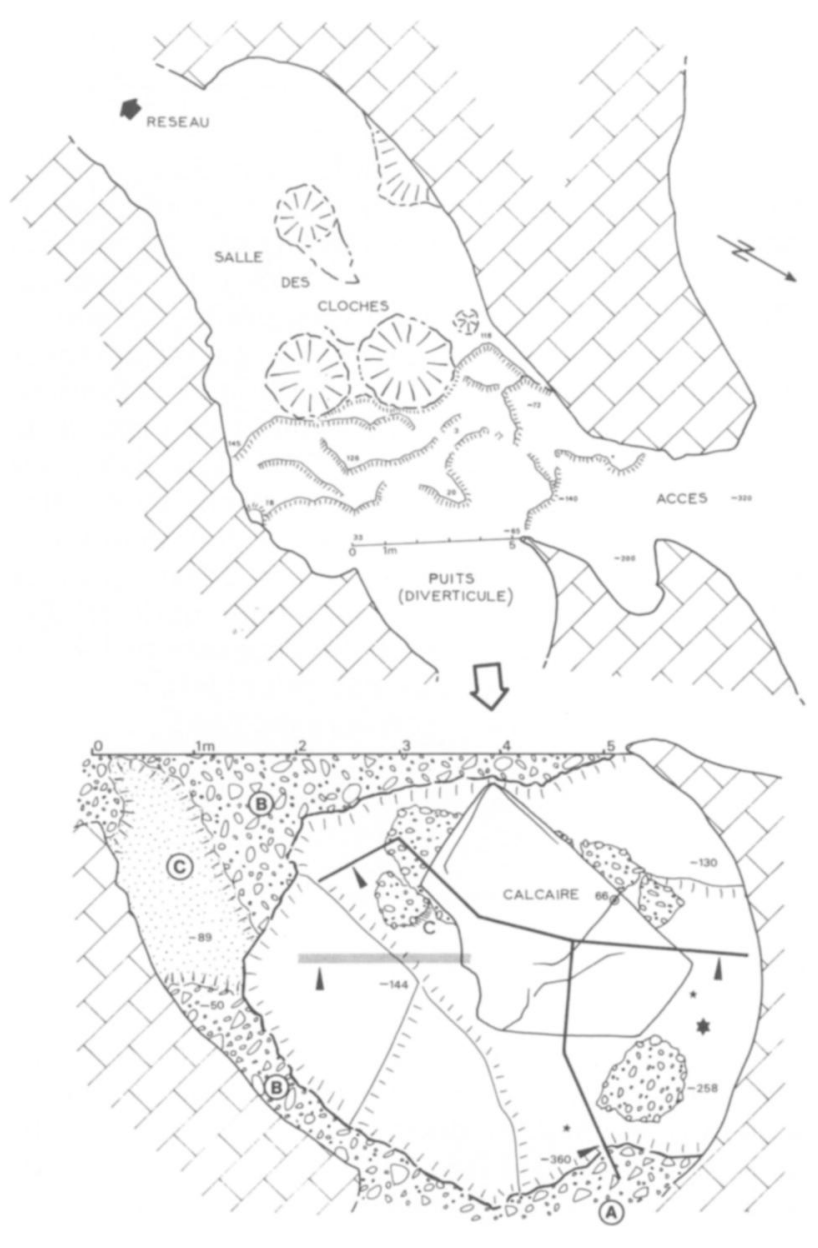

Fig. 2 - Plan de la partie antérieure de la grotte des Cloches et du secteur du Puits. Les coupes de 1986 sont indiquées en traits gras. L'emplacement probable de la coupe Louis (1946-48) est tramé. Les restes humains découverts en 1986 sont figurés par des petites étoiles. La grande étoile indique la position du squelette (Huchard et Louis, 1950). A, B et C représentent des lambeaux de formations quaternaires prises en brêche. 
par M. Louis - restée inédite depuis - et décrite ainsi de bas en haut (fig. 3) :

- XII, couche très sableuse jaune clair avec galets roulés de plus grandes dimensions ; épaisseur inconnue,

- XI, couche de terre et sables mélangés jaunâtres, avec galets roulés de dimensions moyennes, plus sableuse à la base ; épaisseur : $17 \mathrm{~cm}$,

$2 \mathrm{~cm}$,

- $\mathrm{X}$, petit foyer blanc cendreux ; épaisseur :

- IX, couche de terre brune peu sableuse, sans trace de foyers ; épaisseur : $15 \mathrm{~cm}$, stérile ?

- VIII a (base de VIII), couche mince très claire cendreuse ; épaisseur : $2 \mathrm{~cm}$,

- VIII, couche terreuse avec intercalation de bandes de foyers à -5 et $-10 \mathrm{~cm}$; épaisseur : $12 \mathrm{~cm}$,

- VII, couche épaisse très cendreuse avec charbons ; épaisseur : $15 \mathrm{~cm}$,

- VI, couche plus terreuse avec quelques charbons ; épaisseur : $5 \mathrm{~cm}$,

$-\mathrm{V}$, couche cendreuse avec foyer et charbons à la base ; épaisseur : $5 \mathrm{~cm}$, avec hélix némoralis,
- IV, couche plus foncée avec charbons ; épaisseur : $4 \mathrm{~cm}$. Vase entier hallstattien trouvé dans la couche II et empiétant dans la couche III.

- III, couche de terre brunâtre foncée avec charbons (peut-être la base des foyers de la couche II) ; épaisseur : $4 \mathrm{~cm}$.

- e, couche sablonneuse avec cendres et galets roulés ; épaisseur moyenne : $15 \mathrm{~cm}$,

- II, couche grise cendreuse avec charbons de bois ; épaisseur : $4 \mathrm{~cm}$,

- I, couche de surface : terre meuble brunâtre avec éléments calcaires anguleux provenant de la voûte, remaniée à la partie supérieure ; épaisseur : $55 \mathrm{~cm}$. Deux lignes horizontales de foyers à -23 et - $48 \mathrm{~cm}$. Col d'amphore romaine à la surface et débris d'ossements humains dans les parties remaniées.

— d, couche brunâtre avec foyer à la base ; épaisseur : $14 \mathrm{~cm}$,

- c, couche cendreuse mélangée de sable rouge à la base ; épaisseur : $17 \mathrm{~cm}$,

- b, couche cendreuse avec débris de charbons ; épaisseur : $12 \mathrm{~cm}$,

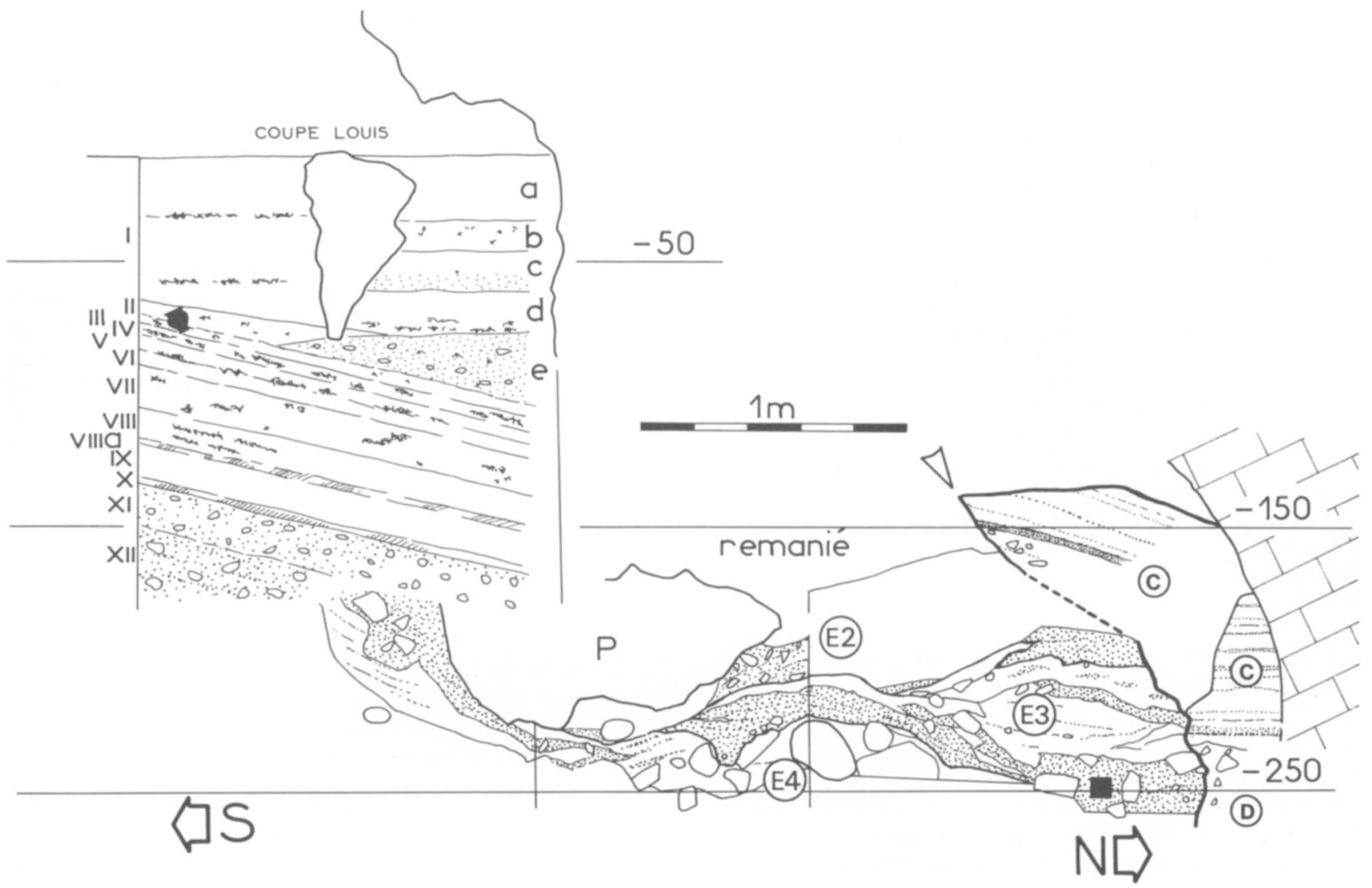

Fig. 3 - Coupe Louis replacée par rapport aux coupes S-N de 1986. C et D sont des témoins de formations quaternaires, E 4 à A des couches holocènes. 
- a, couche de surface : terre meuble brunâtre et éléments calcaires anguleux provenant de la voûte, partie supérieure remaniée ; épaisseur : $25 \mathrm{~cm}$.

Les fouilleurs regroupèrent ces couches dans plusieurs horizons dont le nombre et la numérotation varient suivant que l'on se rapporte à l'une ou l'autre des deux principales publications (Huchard et Louis, 1950 ; Louis et Taffanel, 1955). Une couche de l'âge du Bronze et 4 horizons de "l'âge de Fer » furent distingués dans un premier temps, un niveau étant ajouté en 1958 à la suite d'un redécoupage de la stratigraphie. Les indications sur la nature et les caractéristiques extrinsèques des formations, données en 1950, permettent d'établir des équivalences avec les unités retenues en 1958 et de les confronter à la coupe relevée par Louis ; on peut alors dresser le tableau de correspondance suivant :

\begin{tabular}{|c|c|c|c|}
\hline $\begin{array}{l}\text { Horizons } \\
\text { de } 1950\end{array}$ & $\begin{array}{l}\text { Niveaux } \\
\text { de } 1958\end{array}$ & Descriptions de 1950 & $\begin{array}{l}\text { Numérotation } \\
\text { coupe Louis }\end{array}$ \\
\hline & & sable stérile & XII-XI \\
\hline & & $\begin{array}{l}\text { sépulture de la cou- } \\
\text { che inférieure repo- } \\
\text { sant directement sur } \\
\text { le sable stérile }\end{array}$ & $\begin{array}{l}\text { X? } \\
\text { IX ? }\end{array}$ \\
\hline \multicolumn{2}{|c|}{ couche du Bronze } & $\begin{array}{c}\text { foyers importants } \\
\text { d'habitat }\end{array}$ & VIII a - VIII \\
\hline & & couche stérile & $\begin{array}{c}\text { sommet } \\
\text { VIII ? } \\
\text { VII? }\end{array}$ \\
\hline \multirow{4}{*}{$\begin{array}{cc}\text { H1 } 1 & \text { inf. } \\
& \text { sup. } \\
& \text { inf. } \\
\text { H II } & \\
& \text { sup. }\end{array}$} & niv. I & \multirow{3}{*}{ traces de foyers } & (VII ou) VI \\
\hline & niv. II & & $(\mathrm{VI}$ ou $) \mathrm{V}$ \\
\hline & niv. III & & (V ou) IV \\
\hline & niv. IV & $\begin{array}{l}\text { niveau le plus imp- } \\
\text { ortant, vase intact } \\
\text { empiétant sur plu- } \\
\text { sieurs couches }\end{array}$ & II et III \\
\hline HIII & niv. $\mathrm{V}$ & $\begin{array}{l}\text { couche du Fer } \\
\text { avancé }\end{array}$ & \\
\hline H IV & récent & $\begin{array}{l}\text { « couche gallo-ro- } \\
\text { maine à amphores } \\
\text { micacées » }\end{array}$ & $\mathrm{I}=\mathrm{a}, \mathrm{b}, \mathrm{c}, \mathrm{d}$ \\
\hline
\end{tabular}

Les « foyers importants d'habitat » doivent être corrélés aux couches VIII a et VIII et non pas à la couche $X$, trop ténue, malgré que le niveau stérile les surmontant puisse alors correspondre à IX. On considérera donc que le sommet de VIII et peut-être VII composé de $15 \mathrm{~cm}$ de cendres, se rapportent à la couche stérile. En conséquence, la sépulture risque bien d'être contemporaine de la couche $X$. Le « niveau le plus important à vase intact » s'identifie indubitablement aux couches II et III, les autres équivalences étant proposées hypothétiquement.

La répartition stratigraphique des rares vestiges céramiques portant une indication de provenance s'établit comme suit, leur datation étant discutée dans le $\S$ VII.

\begin{tabular}{|l|c|c|c|c|c|c|c|c|c|c|}
\cline { 2 - 10 } \multicolumn{1}{c|}{ Couches } & X & IX & VIII & VII & VI & V & IV & III & II & I \\
\hline BF 2 b & 4 & & 2 & & & 1 & & 3 & & 3 \\
\hline BF 2 b/3 a & & & & & 1 & 2 & 1 & 1 & & 1 \\
\hline BF 3 a & & & 2 & & 3 & 1 & & & 2 & 2 \\
\hline BF 3 b & & & 1 & & 2 & 1 & & 4 & 6 & 5 \\
\hline Fer & & & & & 1 & & & & & 1 \\
\hline
\end{tabular}

Ce tableau montre une ébauche de diagonalisation rendant compte d'un classement chronologique. Son imperfection est à mettre au compte des méthodes de récolte du mobilier, plus qu'à un éventuel remaniement affectant la totalité du remplissage, plusieurs témoignages en garantissant la stratification. Le tableau confirme la stérilité de la couche IX et démontre celle de la couche VII.

Selon nos prédécesseurs, le sol du diverticule était à l'origine peu incliné vers les parois. La position présumée de la coupe Louis suivant leurs indications, trouve confirmation dans l'insertion que nous pouvons proposer à partir des altitudes sommitales et basales des couches encore en place à l'extérieur, et dans le diverticule, confrontées à l'épaisseur des sédiments I à XII, ainsi que de la nature sableuse des deux derniers niveaux corrélables à la séquence que nous avons récemment étudiée. Le massif limitant la coupe Louis au nord serait alors le bloc urgonien dont la trop précaire stabilité avait causé l'arrêt de ces premières recherches, et qui était susceptible d'avoir protégé des lambeaux de couches en place (fig. 2).

\section{IV. - LES RECHERCHES RÉCENTES}

L'étude de la grotte des Cloches se devait d'être menée en référence à un cadre stratigraphique nécessitant la reprise des fouilles. Plus généralement, nos objectifs furent les suivants :

- retrouver le niveau d'arrêt des fouilles antérieures,

- étudier la stratigraphie des dépôts anthropiques (I à X) et constituer des colonnes de prélèvements, 
- rechercher la base de la séquence et la nature des sédiments de XI et XII, tation,

- mettre en évidence les vecteurs de la sédimen-

- discuter de la notion de " champ d'urnes en grottes » souvent introduite pour expliquer la grande concentration de vestiges archéologiques, à l'image de plusieurs autres cavités du Sud-Est,

- déterminer la part des traditions régionales et celle du groupe du Rhin-Suisse-France orientale dans cette série se rattachant majoritairement au milieu du Bronze final (B.F. 2-3 a),

- identifier la nature des occupations.

Après dégagement d'un volume important de sédiments fins remaniés, de blocs calcaires et de poudingue issus de l'effondrement de planchers stalagmitiques suspendus, nous constations qu'il ne subsistait pratiquement aucun témoin des formations I à IX. Nos investigations s'orientèrent alors vers les couches sous-jacentes par le relevé de plusieurs coupes dont les emplacements furent dictés par la topographie des surfaces encore en place correspondant globalement au sommet de la couche XI (fig. 2 et 3).

Les unités sédimentaires rencontrées (fig. 3 et 4 ) s'encastrent dans un important complexe de forma- tions quaternaires. Le plafond de la salle est notamment constitué d'un plancher stalagmitique suspendu entre 6 et $8 \mathrm{~m}$ du sol témoignant d'un remplissage ancien épais, et de son déblaiement. Dans le diverticule, quatre ensembles principaux fortement inclinés vers le nord et plaqués essentiellement le long des parois, montrent de bas en haut :

- un niveau composé de 50 à $60 \%$ de blocs et de galets cristallins, et de sables graveleux roux (fig. 3, D),

- une succession régulière de minces horizons sableux fins micacés, marqués parfois par des oxydes de fer (fig. 3 et $4, C$ ),

- un niveau comportant $90 \%$ de galets emballés dans des sables fins gris peu cimentés (fig. 4, B),

- un ensemble de formations cryoclastiques dont ne subsistent que des témoins concrétionnés le long des parois et sous les cloches dans la salle principale (couches A, fig. 2).

S'ouvrant au même niveau dans la falaise à 30 mètres en aval, la grotte du Ranc-Pointu $n^{\circ} 2$ offre un remplissage comparable. L'interprétation qui en a été faite permettrait de rattacher les sables basals et les niveaux à galets de la grotte des Cloches à une phase finale du Riss (Combier, 1967, pp. 132-133 ; Debard, 1976, p. 276), correspondant à une terrasse

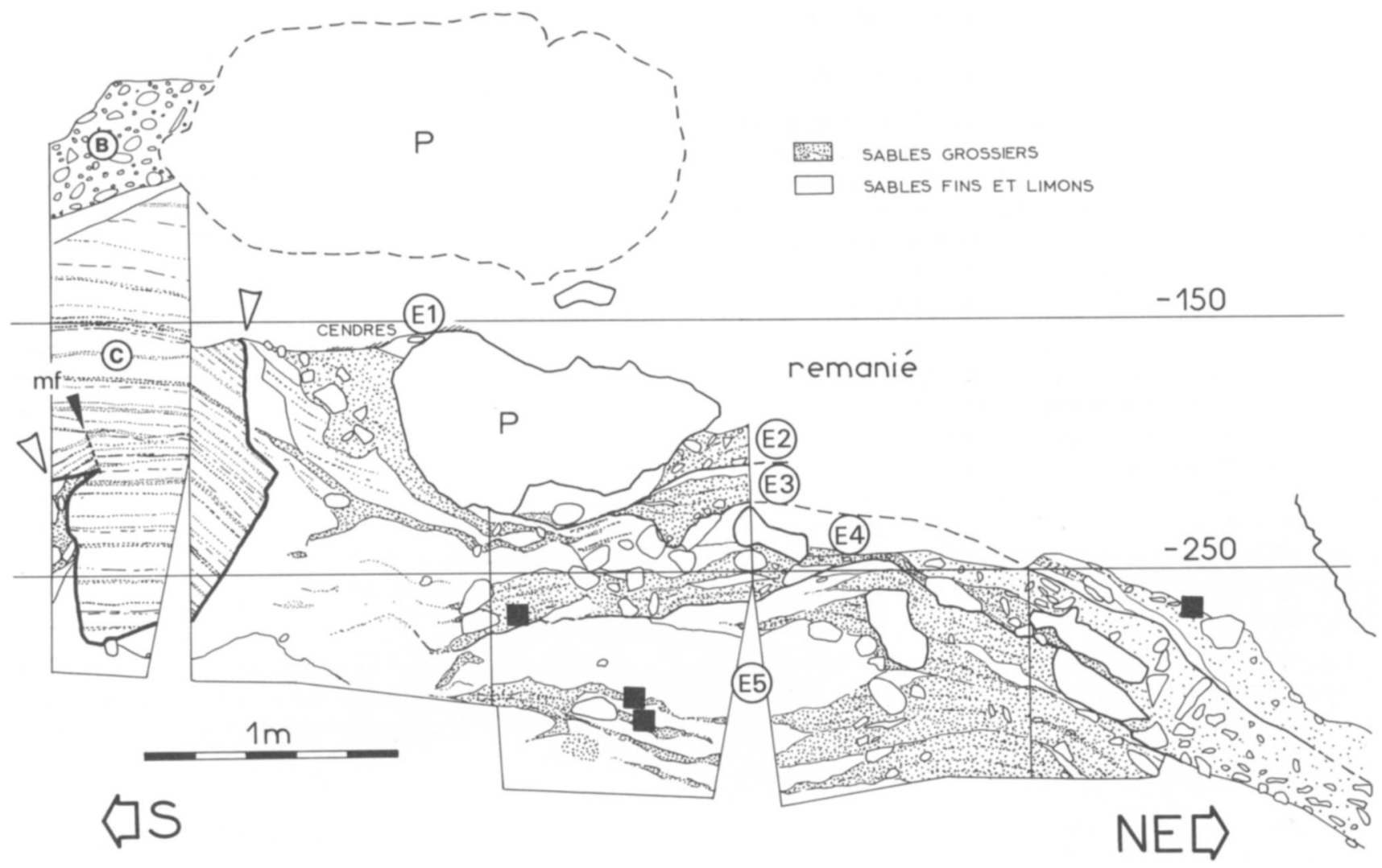

Fig. 4 - Coupes S-N et S.O.-N.E. Les carrés noirs indiquent la position stratigraphique des vestiges du Bronze final. 
reconnue $45 \mathrm{~m}$ au-dessus du cours d'eau, voire à l'interglaciaire Riss-Würm. Les lambeaux de brêches cryoclastiques représenteraient le Würm 1 , et plus probablement plusieurs phases du stade würmien, dégagés lors d'épisodes torrentiels de ravinement, tels ceux qui ont marqué de leur empreinte les remplissages des grottes du Figuier à quelques centaines de mètres en aval (Combier, 1967, p. 186), et du Ranc-Pointu ${ }^{\circ} 2$. La plupart des grottes et des boyaux de ce secteur montrent de semblables sédiments relictuels, indiquant de hauts-niveaux quaternaires de l'Ardèche.

Les couches B, C, D (fig. 3 et 4) subirent une érosion leur conférant un profil général surplombant. Cette morphologie évoque un démantellement dans lequel les phénomènes de gravité et de décompression sont les intervenants majeurs. L'évacuation des particules permet de s'interroger sur la morpholie du "diverticule » qui en fait ne constitue pas à notre avis un appendice à la galerie majeure, mais la portion avale de celle-ci sous la forme la plus probable d'un puits aujourd'hui entièrement comblé. La direction générale du réseau accrédite cette hypothèse, et le couloir d'accès est une galerie fossile parallèle recoupée par le lit de l'Ardèche. Le déblaiement des couches $\mathrm{A}$ à $\mathrm{D}$ s'est donc effectué par soustirage et une micro-faille dans la couche $C$ (fig. $4, \mathrm{mf}$ ) atteste de cette dynamique. L'amplitude des surplombs est fonction de la compacité des horizons constitutifs, à l'image du massif nord de la couche C (fig. 3) qui inclut un niveau complètement induré.

Les formations mises en place au subboréal, d'aspect lenticulaire, occupent rarement plus de quelques mètres carrés. Elles connaissent des pentes parfois accusées marquées par un granoclassement des sédiments. Quinze unités sédimentaires se regroupent dans 5 ensembles (fig. 3 et 4, E 1 à E 5), la base de la séquence n'ayant pas été atteinte :

E 5 :

- sables fins gris-marron à marron, et jaune-gris, - alternances d'horizons sableux grossiers et graveleux roux (classe $1-4 \mathrm{~cm}$ ) renfermant des débris de roches cristallines arénisées, et de sables fins grismarron; quelques vestiges céramiques au sommet,

- épais niveau de sables limoneux fins marron, et jaune-gris, entre lesquels s'intercalent au nord des sables grossiers roux piègeant une lentille de sables fins jaunes.

La puissance des sables va croissant vers le nord et ils comportent quelques galets cristallins très friables de $5-15 \mathrm{~cm}$. Les basaltes sont un peu plus compacts.

E 4, succession de couches d'épaisseurs comparables:

- sables grossiers roux incluant 30 à $40 \%$ de blocaille calcaire, des fragments volumineux de brèche ayant constitué la voûte antérieurement, et sur lesquels ont pris naissance des stalagtites ; quelques fragments de céramiques à la base,

- sables fins gris ou roux, mêlés d'une part minime de sables grossiers, de granules, de blocaille et de galets cristallins et basaltiques altérés.

Cet ensemble se singularise par la forte proportion de blocs et galets, ainsi que par un enrichissement en sables fins roux vers le nord-est, au-delà des fragments superposés de plafond. Il s'accompagne d'un granoclassement et d'une augmentation de la proportion de sédiments fins vers le sommet corrélable à un mouvement inverse de la fraction grossière.

On remarque au sud, des sables grossiers roux à blocs et galets encadrant un mélange de sables fins marron-gris et roux, en partie sous-jacents à un massif de poudingue (fig. 4). Ils se rattachent à E4 par la présence d'éléments grossiers et se biseautent rapidement sans assurer de raccord stratigraphique.

Dans le même secteur, E 5 et E 4 montrent un passage latéral de leurs sables fins à un épais niveau de sables hétérométriques et hétérogènes, sans stratification nette ni régulière.

\section{E 3:}

- sables grossiers roux et graviers se biseautant vers le nord (fig. 3),

- contre la paroi nord formée du substrat, on trouve un amas en coin de galets et poudingues (70\% du sédiment), absent au nord-est (fig. 4) ; un tesson en fut exhumé,

- sables fins gris-jaune dominant de rares sables grossiers, granulés et blocs. Le long de la paroi nord, ces niveaux inhomogènes s'enrichissent en limons et intègrent une passée de sables grossiers. Quelques éléments céramiques proviennent de $\mathrm{E} 3$, à l'aplomb de la voûte de brêche nord-est (fig. 4).

Le sommet de cet ensemble correspond à la surface d'arrêt des fouilles anciennes, à la base des sédiments remaniés. Néanmoins, la coupe Louis, et plusieurs fragments de céramiques des collections Huchard se raccordant aux nôtres, montrent que cette séquence sableuse fit jadis l'objet d'une fouille limitée. Elle se situerait en deçà de la coupe Louis, là ou débutèrent les fouilles, à l'endroit où nous avons laissé en place un témoin de sédiments bouleversés formant un palier à la cote - 144 (fig. 2).

\section{E 2:}

- devant précéder la séquence anthropique, on trouve quelques lambeaux de couches à dominante sableuse, de couleur ocre-rouge, renfermant quelques blocs.

E 1:

- placage de cendres pures et de charbons de petites dimensions, piégés dans les anfractuosités sommitales d'un bloc de poudingue (fig. 4) et sous un 
petit bloc de même nature non déplacé par nos prédécesseurs (fig. 2, C).

Nous pouvons proposer les corrélations suivantes avec la coupe Louis :

\begin{tabular}{l|l|l|l|} 
Coupe Louis : & niv. XII & niv. XI & niv. X \\
Coupe 1986 : & niv. E 4 & niv. E 3-E 2 & niv. E 1
\end{tabular} \mid

V. - LE REMPLISSAGE : INTERPRÉTATION

Par leur nature, les formations holocènes où dominent les sables et éléments grossiers originaires de massifs cristallins et volcaniques, se rattachent à la gamme des sédiments fluviatiles, mais il est bien évident qu'elles n'ont pas pour origine une des crues violentes de l'Ardèche qui coule près de $40 \mathrm{~m}$ en contrebas ; ce sont des dépôts quaternaires remaniés, d'anciennes terrasses certainement, comme en présentent nombres de cavités du Ranc-Pointu. Les phénomènes présidant à leur mise en place sont de trois ordres :

- un déblaiement par soutirage des sédiments quaternaires contenus dans l'aven, supposant un ennoiement de tout ou partie du karst permettant la circulation de courants aquifères vecteurs de déplacements en profondeur ;

- simultanément, une érosion des édifices sédimentaires quaternaires, dont subsistent actuellement de nombreux restes dans la partie antérieure de la grotte ;

- un dépôt par gravité des sédiments remaniés, en un temps très court : les céramiques sont dans un remarquable état de fraîcheur et un important fragment de vase sphérique (fig. 5/12), posé face interne vers le bas, chapeautait un vide de sédiments.

Les causes et la chronologie de ce cycle érosion/ sédimentation sont difficiles à cerner. L'absence de témoins, peut-être enfouis profondément, éclairant les premières manifestations du phénomène limite l'interprétation. Mais il ne fait pas de doute qu'une remise en charge importante du karst est à l'origine de cette dynamique. Les caractères intrinsèques des formations encaissantes (sables et galets) n'autorisent guère une décompression de longue durée. Trouvé à plusieurs niveaux, le mobilier archéologique est homogène et atteste, ainsi que la répartition spatiale des sables graveleux, d'un comblement rapide. On évoquera trois facteurs intervenant dans cette histoire sédimentaire :

- une diminution du couvert végétal. Au vu de la situation actuelle qui représente un aspect de ce retrait, il semble, seul, une cause insuffisante ;

- une péjoration climatique. Des augmentations d'humidité entre le tardiglaciaire et le subboréal ont été discernées à quatre reprises dans la grotte de Chazelles à Saint-André-de-Cruzières (Ardèche ; Laville, Nikitine et Thibault, 1969) (1) entre un mésolithique aziloïde et le Cardial, antérieurement au Chalcolithique, entre le Bronze moyen et le Bronze final et après ce dernier stade. Dans la salle IG de la grotte du Hasard à Tharaux (Gard), une couche d'argile déposée par décantation s'intercale entre un niveau sépulcral de la $2^{\mathrm{e}}$ moitié du Bronze moyen et le Bronze final (Roudil, 1972, p. 250) ;

- une crue rapide et violente de l'Ardèche alimentée par des torrents incisant un vaste bassin versant sur son cours supérieur. Ses crues atteignent rapidement plusieurs mètres, autorisant une mise en charge accélérée du karst avec de fortes pressions en profondeur, et une augmentation des vitesses de circulation à la décrue expliquant le soutirage. Il faut alors admettre que la partie supérieure du réseau, audelà de la grotte des Cloches, connaissait une activité bien plus importante que l'actuelle permettant le démantellement et le dépôt dans le puits des formations quaternaires, et qui ne peut s'envisager sans le recours à une augmentation de la pluviosité. On peut alors poser comme hypothèse l'existence d'une péjoration climatique, dont l'ampleur reste à évaluer, durant la première moitié du Bronze final.

Avec l'ensemble E 1, on assiste à un changement radical de la dynamique sédimentaire. L'homme intervient alors directement dans la mise en place de la plupart des couches $\mathrm{X}$ à $\mathrm{I}$. En accordant quelque crédit aux observations anciennes, des cendres (2), des charbons, des limons dont on ignore l'origine et de rares sables, alternent dans la stratigraphie.

VI - L'OCCUPATION DE LA GROTTE DES CLOCHES. ESSAI DE DIAGNOSE

Essai, car nous ne prétendrons pas à l'exhaustivité en l'absence de résultats précis tirés des premières fouilles, et nos propres observations sur le terrain restant limitées faute d'objet d'étude.

(1) J.-E. Brochier (1983, p. 191) souligne les problèmes d'interprétation suggérés par l'analyse des limons en grotte. Leur origine pourrait ne pas être seulement alluviale à Chazelles, remettant en cause l'interprétation paléoclimatique. On notera a contrario que la présence des limons se double dans ce cas de phénomènes mécaniques : lessivages, ravinements, illuviations.

(2) Un prélèvement de matière blanche pulvérulent obtenu sur un fond de récipient de la collection Huchard a été analysé par J.$\mathrm{E}$. Brochier. Il s'agit de cendres blanches très pures ; leur présence fut confirmée par nos travaux (couche E 1). On peut avec prudence exclure l'utilisation répétée de la cavité comme bergerie, mais on ne saurait être affirmatifs en l'absence d'observations microscopiques des limons qui semblaient alterner avec les formations liées à la combustion. 
La chronologie des dépôts anthropiques est induite dans le tableau de contingence de la dispersion stratigraphique des céramiques. Les effectifs majeurs incitent à rapporter les couches $\mathrm{X}$ et VIII au Bronze final $2 b$, les couches VI et $\mathrm{V}$ au Bronze final $3 a$, les couches III et II au Bronze final 3 b et la couche I à ce dernier et au Premier âge du Fer.

La description des sédiments et le mobilier sont les seuls domaines nous instruisant sur les types d'occupation. On suppose l'existence de structures de combustion dans les couches $\mathrm{X}, \mathrm{VIII}, \mathrm{V}$ et $\mathrm{d}$, qui font référence à des foyers. Selon $M$. Louis, les horizons cendreux VIII a, e et 2 sont peu développés ; nous les interprétons comme produits en nappe du curage de foyers. L. Chiron $(1896$, p. 21$)$ notait dans la grotte la présence d'amas de cendres, pouvant avoir été les structures génératrices de ces résidus, ou d'autres témoins de vidanges. Parmi les vestiges attribuables à un habitat, on retiendra le grand nombre de fragments céramiques, les restes osseux animaux, plusieurs meules et molettes, entières et brisées, des fragments de soles ou de parois d'aires de cuisson aménagées, lissés sur une face, des morceaux de clayonnage montrant des empreintes de branchages. Le petit outillage est représenté par une portion d'aiguisoir en grès (fig. 23/21).

L'évocation ancienne d'une « nécropole » de l'âge du Bronze (Huchard et Louis, 1950, p. 137) trouverait confirmation dans la présence de poteries intactes, mais ce sont des récipients dont les petites dimensions conditionnent directement le degré de conservation, ce qui ne permet pas d'exclure leur présence dans un habitat. Plus convaincants sont les restes osseux humains (cf. infra la contribution de J.L. Gisclon) de 3 individus inhumés, dont 1 au moins marque le dépôt de la couche $X$ (cf. supra) bien antérieure aux couches VI à II qui livrèrent les céramiques entières du Bronze final 3. Quelques fragments brûlés autorisent à dénombrer une incinération.

Toute une gamme d'objets signent indifféremment la présence d'habitat ou de tombes : fusaïoles, mobilier métallique et osseux, perles en ambre et en pâte de verre, bracelets en terre cuite et bouchons en calcaire (fig. 23 et 24). Leur abondance, leur médiocre état de conservation et leur banalité correspondraient plutôt à une utilisation au sein d'habitats.

Une activité a dû être parfaitement illustrée dans la grotte des Cloches : c'est la confection et la cuisson de céramiques. En les considérant globalement, plusieurs vestiges en témoignent : coquillage bivalve au pourtour largement poli (fig. 23/23), broyon (fig. 24/1) utilisable pour piler le dégraissant, ou en tas à l'image des potières des Fidji (Rieger, 1977, pp. 2627 et 41 à 43). La rareté des galets à polir les poteries, au nombre de deux (fig. 23/20 et 21), est pondérée par l'extrême abondance des galets dans les forma- tions quaternaires qui offrent à quelques mètres des milliers de pièces de qualité ! Deux masses de colombins accolées sont plus convaincantes (fig. 23/ 1). Leur conservation a été assurée par un simple séchage à l'air ; un fragment se décomposa en quelques heures dans l'eau en libérant des limons. L'hypothèse de cet atelier est à relier à l'existence d'un niveau de combustion stérile en restes archéologiques (couche VII), regroupant des cendres et des charbons sur une épaisseur considérable $(15 \mathrm{~cm})$ étant donné leur caractère pulvérulent. On admettra difficilement qu'il s'agit de rejets de foyers domestiques, dont nous connaissons les formes et les volumes au travers de nombreux exemples. Aussi considérons-nous que ces cendres furent produites par un foyer ouvert mettant en œuvre un combustible abondant difficile à relier à une autre activité que la constitution de meules de cuisson d'artisans potiers. On peut considérer qu'il manque un élément essentiel à cette démonstration : ce sont les ratés de cuisson, vases ou fragments tordus, fissurés ou montrant un début de vitrification. Mais rien ne permet de penser que cuisson implique altération d'une partie du stock initial. Plusieurs cas sont possibles, de la réussite totale à la perte de 25 à $30 \%$ des pots (Gallay, 1970, p. 170 ; Leroi-Gourhan, 1971, p. 226). Le puits se situe dans la pénombre. Pour contrôler la qualité des produits il semble indispensable de les présenter à l'extérieur, à l'aplomb des falaises dominant l'Ardèche et dont on entrevoit la fonction de dépotoir éventuel...

Nous concluerons à plusieurs utilisations de la grotte des Cloches, bien que nos interprétations ne puissent prétendre à la finesse et à la fiabilité qu'aurait permis l'analyse de documents de grande valeur à l'origine, mais qui furent arrachés à leurs contextes et dont le pouvoir heuristique est de ce fait considérablement apauvri. Au Bronze final $2 \mathrm{~b}$, la couche $\mathrm{X}$ accueille au moins " un squelette d'individu adulte » (Huchard et Louis, 1950, p. 138). Peutêtre tous les ossements humains proviennent-ils de cet horizon, mais il en est signalé dans la couche I, ce qui rend leur datation aléatoire. La grotte est habitée au Bronze final à plusieurs reprises et les occupations sont entrecoupées par quelques dépôts limoneux et sableux dont on ignore l'origine. Une aire de cuisson des poteries façonnées sur place à partir de matériaux disponibles dans la cavité ou à proximité, s'intercale entre deux niveaux du Bronze final 2 b et 3 a (couche VII). Il est permis de penser que les chocs thermiques causés par la combustion sont à l'origine du démantèlement des brêches surplombant la zone des fouilles (fig. 2).

La position topographique de la grotte des Cloches (fig. 1), son environnement physique, végétal et pédologique immédiat, l'irrégularité du sol des galeries, ne permettent pas de la considérer comme un 
habitat permanent. Ces caractéristiques intrinsèques sont identiques à celles retenues pour la définition de la grotte-refuge à partir de l'exemple de la grotte des Planches-près-Arbois (Jura : Pétrequin et coll. 1985, p. 220). Une interprétation semblable a été proposée concernant l'occupation du Bronze final $3 \mathrm{~b}$ tardif de la grotte de la Chauve-Souris à Donzère (Drôme : Vital, 1984), qui pourrait être l'un des termes d'une balance entre deux types d'habitats complémentaires, le second, permanent, se manifestant sur les sites de hauteur proches. Le même cas de figure est envisageable aux Cloches car le sommet du massif du Ranc-Pointu est limité sur deux côtés par un rempart, l'ensemble constituant un petit oppidum (fig. 1). Sous certaines conditions souvent liées à la réalisation de grands travaux de génie civil ou à la conduite de programmes de recherche spécifiques, des habitats permanents de plein air s'offrent à l'étude. Leur extrême dégradation, conséquence des conditions physico-chimiques de conservation, liée à la difficulté de les repérer par simple prospection au sol, rendent leur découverte difficile par rapport à celle de gisements de hauteur et de karst. Plusieurs sites de plaine alluviale sont ainsi apparus récemment dans la région lyonnaise à Montagnieu, Château-Gaillard et Béligneux (Ain : Vital et coll., 1986 a ; Vicherd, 1986 ; Vicherd, Baudrand et De Klijn, 1981), ainsi qu'à Vénissieux (Rhône : inédit). En Languedoc, la découverte des sites lagunaires de la région montpelliéraine complète la vision de l'occupation protohistorique des terroirs, jusqu'alors pratiquement limitée aux oppida et aux grottes. Il est probable en conséquence que la plaine alluviale de l'Ardèche comprise entre le dernier coude des gorges et le confluent avec le Rhône, soit une distance de 7 à $8 \mathrm{~km}$, conserve des restes de villages permanents des âges des métaux.

Les rites funéraires sont localement représentés dans la grotte $\mathrm{n}^{\circ} 1$ du Ranc-Pointu où un dépôt céramique du Bronze final $3 \mathrm{~b}$ assorti d'une tête d'oiseau et d'une calotte cranienne humaine furent rencontrés (Gilles, 1962). Un crâne d'enfant et un squelette incomplet en furent extraits ultérieurement (Lavoinne et Parisi, 1981, p. 154). L'incinération se pratique avant tout sous tumulus, parallèlement parfois à l'inhumation : tumulus du quartier de Beauregard à Saint-Remèze (Ardèche : Gourvest, 1959) et de la ferme des Aures à La Roche-SaintSecret (Drôme : Combier, 1963, p. 298). Nous rejoindrons H. Duday et J. Guilaine (1975) qui concluent pour le Languedoc et le Roussillon à l'exclusivité de l'inhumation en grotte au Bronze final, et à la présence d'incinérations en milieu ouvert (basses terres, p. 151). J.-L. Roudil soutient une proposition identique pour le Languedoc oriental (1972, p. 210). La grotte de la Clapade à Millau (Aveyron) resterait donc l'une des rares cavités ayant livré des os incinérés à l'intérieur de récipients (Temple, 1936). Il est alors impropre de parler de
« Champs-d'Urnes en grotte » à partir d'un cas, un mode funéraire étant, seul, largement insuffisant pour définir une civilisation, vocable transposé abusivement de surcroît hors de son aire de développement dans la zone qui nous concerne. Le nombre des inhumations domine celui des incinérations dans le Sud-Est et le dépôt de céramiques n'est pas l'apanage des seules populations du Bronze final. Dans la salle IG de la grotte du Hasard à Tharaux (Gard : Roudil et Soulier, 1976), plusieurs inhumés du Bronze moyen étaient accompagnés de poteries et de parures métalliques.

L'insertion de l'artisanat céramique protohistorique, tant sur les plans fonctionnel, techno-économique, que social, est mal connue. Elle pourrait être abordée par le biais de la reconnaissance des structures de cuisson, de leur nature et de leurs rapports avec le village, mais force est de constater que là aussi les données archéologiques sont peu fournies. Les aires aménagées en plein air ont du être érodées en partie. Les documents ethnographiques montrent que ces aménagements se situent à proximité des concessions ou des agglomérations, mais en sont cependant suffisamment éloignées afin d'éviter tout risque de propagation du feu. Ce qui suppose pour leur mise en évidence en archéologie, de dégager des villages sur de grandes surfaces sans négliger les abords immédiats, conditions d'observations rares. Les ateliers de confection sont encore plus malaisés à repérer étant donné la mobilité de cet artisanat, du peu d'outillage mis en œuvre et de la quasi-inexistence de déchets de fabrication. Un exemple mérite d'être cité : le village de Cannes-Écluse, détruit avant d'avoir pu faire l'objet d'une fouille rationnelle. Sur ce site, 15 fonds de cabanes ont été exhumés, dont 11 comprenaient un foyer parmi les 21 décomptés. Entre les constructions, des surfaces d'argile rouge durcie résulteraient d'une puissante combustion. Des fours de fondeurs - deux dépôts gisaient à proximité - ou de potiers expliqueraient ce phénomène (Gaucher et Robert, 1967, p. 173). Rappelons que les fours de métallurgistes offrent fréquemment des contours nets, à Saint-Germain-duPlain et à Choisy-au-Bac (Saône-et-Loire : Bonnamour, 1972, fig. 1 ; 1973 ; Oise : Blanchet, 1984, fig. 245), et une emprise au sol limitée à quelques mètres carrés, à la différence des aires rubéfiées de Cannes-Écluse bien plus étendues (Gaucher et Robert, 1967, fig. 2). Ceci renforce l'hypothèse de vastes zones de cuisson de poteries.

Plus évidents, les fours excavés ou en élévation sont, dans tous les cas autorisant une observation, plus ou moins proches de bâtiments seuls ou en groupe. C'est le cas des exemples alsaciens du Bronze final d'Achenheim et du Hohlandsberg (Hatt, 1952, fig. 1 ; Jehl et Bonnet, 1968, fig. 3). Le four du Crêt-de-Châtillon à Sévrier gisait dans le village même (Haute-Savoie : Bocquet et Couren, 
1974). Au Premier âge du Fer à Besançon-SaintPaul, stade 1, et à Hascherkeller en Bavière (Doubs : Pétrequin et coll. 1979, fig. 32 ; Wells, 1984, fig. 4), les fours de potier sont implantés à peu de distance des habitations. D'autres exemples, tel Cronenbourg, ont été l'objet de fouilles trop limitées pour servir notre démonstration. Récemment $P$. Pétrequin et coll. (1985, p. 233 et fig. 212) situaient 1 à 2 fours dans le village du Bronze final de Dampierre-sur-leDoubs, et rappelaient l'exemple comparable de Perleberg en R.D.A.

Nous constatons que des rapports topographiques étroits lient village et aire de cuisson, les exemples ethnologiques montrant qu'il en est de même fréquemment des relations avec l'officine de montage des céramiques.

La position et l'utilisation de la grotte des Cloches en font un cas particulier. La volonté d'éloignement s'explique en terme technique : éloignement feumaison, recherche de l'ombre, de matières premières ; et en termes culturels : respect d'un interdit de fabrication dans le village comme R.M.A. Bedaux en signale dans la région Sànga du Pays Dogon (Gallay, 1981, p. 81, note 9). Les facteurs limitants techniques semblent des arguments fragiles. On a vu que les aires de cuisson jouxtent les villages en général, et l'on imagine mal un transport de poteries entre les deux après le façonnage et sur de grandes distances. Le fait culturel peut être retenu à titre d'hypothèse.

VII - LE MOBILIER ARCHÉOLOGIQUE

Constituant un ensemble de référence majeur souvent évoqué et appelé dans les comparaisons (Sandars, 1957, p. 288 ; Roudil, 1972, p. 180 ; Guilaine, 1972, p. 305 ; Guilaine et Roudil, 1976, p. 465 ; Dedet et Py, 1985, p. 37), le mobilier archéologique de la grotte des Cloches n'avait jamais fait l'objet d'une présentation synthétique. Les publications livrent des informations contradictoires et les assemblages chronotypologiques ne sont pas exempts de critiques. Une mise au point s'imposait donc, rendue possible par la multiplication d'ensembles de comparaison, ce qui n'était pas le cas jusqu'alors empêchant notamment la distinction entre Bronze final 3 a et 3 b (Roudil, 1972, p. 185).

Notre reconnaissance de groupes typochronologiques résulte autant des comparaisons pièce par pièce, que de l'absence répétée de certaines d'entre elles d'horizons chronologiques donnés. Cette méthode des fossiles directeurs ne permet évidemment pas d'observer les phénomènes évolutifs traduits en pourcentages, ni les cas de perduration. Mais on jugera de la répartition géographique des types et des fréquences relatives des vestiges par époque. La recontextualisation de ces céramiques répond plus généralement à l'objectif d'analyse synthétique des productions de l'âge du Bronze de la moyenne vallée du Rhône.

Nous distinguons au moins quatre groupes typochronologiques : deux du Bronze final 2, un du Bronze final $3 \mathrm{a}$ et un du Bronze final $3 \mathrm{~b}$. Nos fouilles mirent en évidence deux stades du Bronze final 2 d'après l'étude du remplissage (ensemble $E 5$ à $\mathrm{E} 2$; ensemble E 1-X et VIII) ce qui confirme la constatation suivante : la surface exploitée par A. et $\mathrm{P}$. Huchard dans les niveaux E 5 à E 2 se compare à celle que nous avons étudiée ; plusieurs récipients se répartissent de manière égale entre les deux collections ce qui implique, à densité équivalente de vestiges, que la majorité des autres céramiques du Bronze final 2 découvertes jadis proviennent de la séquence sédimentaire anthropique postérieure.

\section{1. - La céramique : terminologie}

Nous retenons 6 types principaux pour la clarté de l'exposé, suivant leur aplatissement et leur volume, et la complexité de leur profil : non segmenté, monosegmenté, bisegmenté.

\begin{tabular}{|c|c|c|c|}
\hline \multicolumn{2}{|l|}{ VOLUME } & POT & JARRE \\
\hline \multirow{3}{*}{ APLATIS. } & \multirow{2}{*}{ COUPE } & JATTE & GOBELET \\
\hline & & COUPELLE & ÉCUELLE \\
\hline & NS & MS & BS \\
\hline
\end{tabular}

VII. 2. - Mobilier des fouilles 1986 : niveaux E 5 à E 3 (fig. 5)

On observe 3 récipients dont l'origine est à rechercher dans les productions du Bronze moyen ou du Bronze final 1 . Une jarre à col $\left(n^{\circ} 5\right)$ présente au Bronze moyen dans le tumulus de la Rente-Neuve à Couchey, et au Bronze final 1-2 a dans la grotte du Pontet à La Burbanche et dans la Cauna de Martrou (Côte-d'Or : Nicolardot, 1968, pl. 39 ; Ratel, 1961, fig. 62 ; Ain : Bonnamour, 1967, fig. 6/7 ; Aude : Gasco, 1983, fig. 6/1). Un gobelet à col muni d'une anse encadrée à la base par deux tétons côniques $\left(\mathrm{n}^{\circ} 11\right)$, connu dans la grotte du Noyer à Esclauzels 

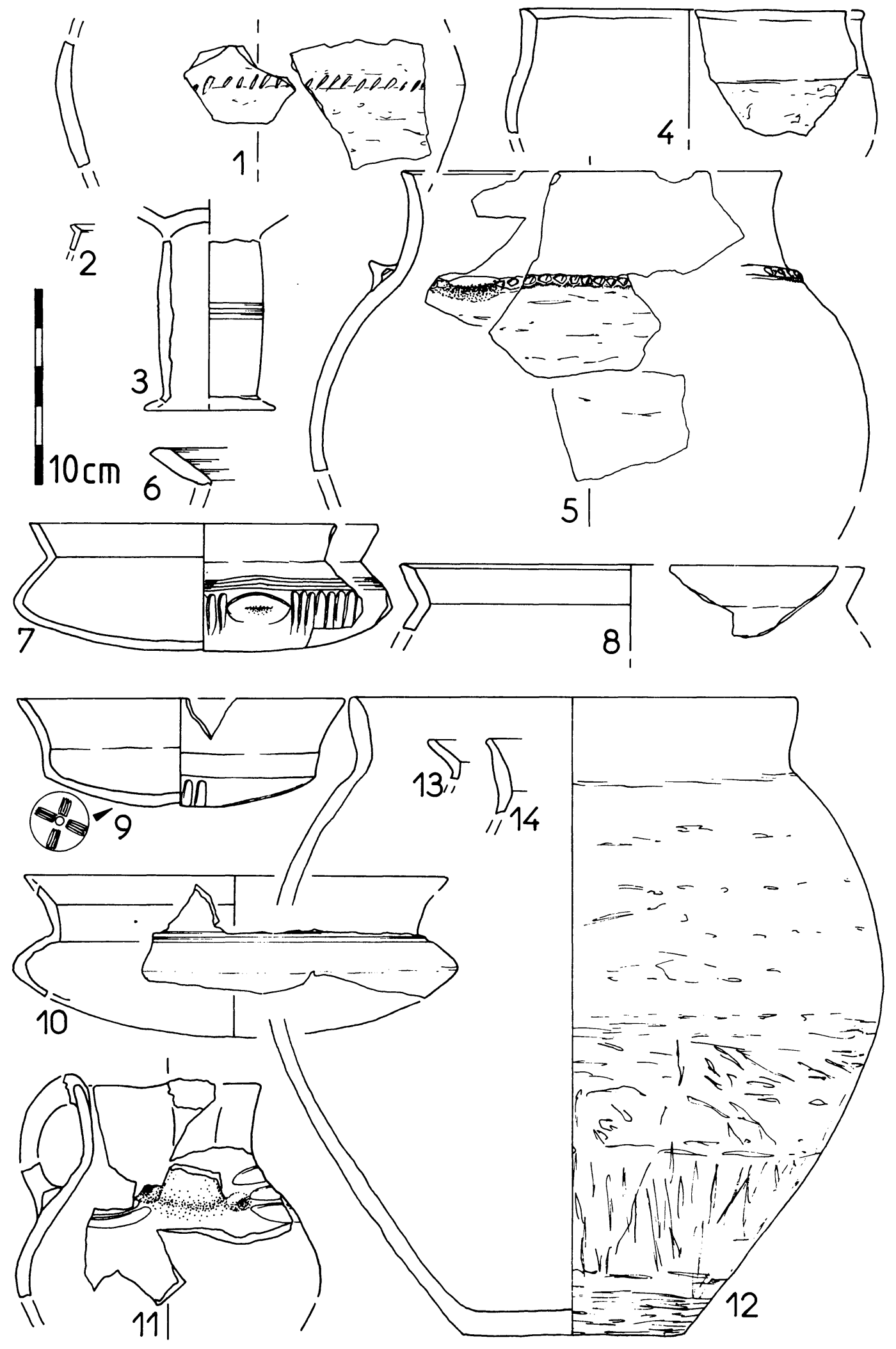

Fig. 5 - Céramiques des couches E 1 (1 et 2), E 3 ouest (3), E 3 nord (4 et 5), E 4 (6 à 8 ) et E 5 (9 à 14). 
ainsi que dans la salle IG de la grotte du Hasard à Tharaux au Bronze moyen, et au Bronze final 1-2 a dans la nécropole de La Colombine à Champlay, dans la grotte de la Baume-des-Anges à Donzère et dans celle de Baume-Sourde à Francillon (Lot : Clottes et Lorblanchet, 1972, pl. 3/1 et 4 ; Gard : Roudil et Soulier, 1976, fig. $3 / 2$ et 3 ; Yonne : Mordant, 1975, fig. 2/2 ; Drôme : Vital, 1984, pl. 82 à 85 ; Cornet, 1963, fig. A et 11/1). Une jatte à lèvre biseautée, au profil marqué par un léger ressaut $\left(n^{\circ} 4\right)$, comparable aux exemplaires de Vaux-les-Prés du Bronze final 1 (Doubs : Pétrequin et Urlacher, 1967, fig. 3/1 et 2). Une grande jarre ainsi qu'un fragment ( $\mathrm{n}^{\text {os }} 12$ et 8 ) figurent dans plusieurs séries du Bronze final 2: grotte de la Baume-des-Anges à Donzère, grotte de l'Igue Blanche à Sauliac (Vital, à paraître, Lot : Lorblanchet et Genot, 1972, fig. 27/ $3)$. Trois écuelles retiendront notre attention. L'une à méplat externe et à décor cruciforme de la base obtenu par 4 cannelures parallèles $\left(n^{\circ} 9\right)$ est une production méridionale. Le décor renvoie aux nombreux exemples d'Italie du Nord où cette tradition s'enracine dans le Bronze moyen (De Marinis, 1980, fig. III et IV), à la différence de la France méridionale qui suivra cette mode au début du Bronze final. Cette forme est connue dans la grotte du Cimetière à Tharaux et sur le gisement lagunaire de Camp-Redon à Lansargues. On peut leur rapprocher un exemplaire de la grotte Murée à Montpezat. Tous datent du Bronze final 2. (Gard : Roudil, 1972, fig. 71/8 ; Hérault : Prades et Coll., 1985, fig. 22, 23, 25/1 ; Alpes-de-Haute-Provence : Lagrand, 1976, fig. 1/7). La première des deux autres écuelles $\left(\mathrm{n}^{\text {os }} 7\right.$ et 10 ) porte un motif orthogonal encadrant 5 à 6 oves cannelées, bien connu dans la plupart des mobiliers du Bronze final 1-2 a. La forme très basse est une caractéristique de la région et plus largement d'une frange périphérique du Massif Central. Ce phénomène d'aplatissement, sur des formes approchantes, existe dans les productions italiques de la Plaine Padane à la même époque : stations de Cop Roman, Castellano-Lagusello couche A, Sabbioneta (Salzani, 1976, fig. $1 / 2$ et 5 ; Piccoli, 1982, pl. 4/A et C ; De Marinis, 1980, pl. VI/1, 3, 4, 6). Ce fait est moins sensible en Catalogne mais nettement attesté dans la grotte du Reclau-Viver au début du Bronze final (Pons I Brun, 1984, fig. 58/4 à 6). Un premier inventaire peut être dressé pour la France (fig. 6) :

1. Incinération 5 des Gours-aux-Lions à Marollessur-Seine (Seine-et-Marne : Mordant, 1970, fig. 30/5).

2. Carisey (Yonne : Unz, 1973, pl. 36/4),

3. Habitat de l'Alleu à Saint-Hilaire-Saint-Florent (Maine-et-Loire : L'Helgouach, 1979, fig. 21),

4. Nécropole de Chissay-en-Touraine (Loir-etCher : Cordier, 1961, fig. 1),

5. Nécropole du Claveau à Gièvres (Loir-etCher : Cordier, 1977, fig. $15 / 2$ et 13 ),

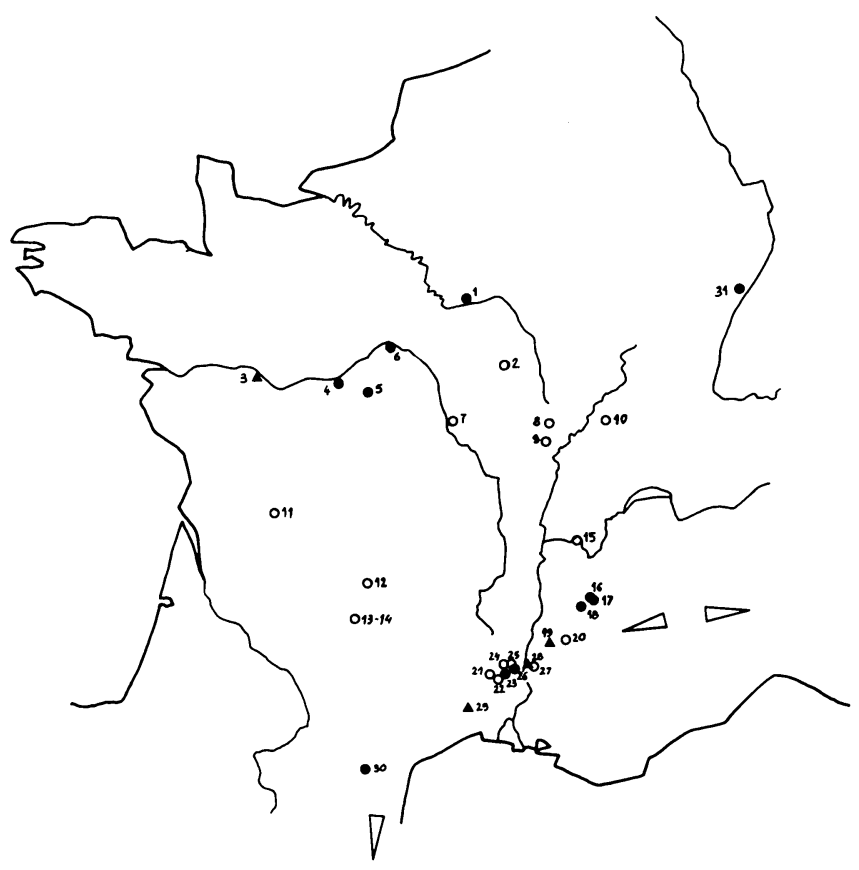

Fig. 6 - Cartographie des écuelles basses sans précision du contexte (cercles blancs), du Bronze final 2 a (cercles noirs) et du Bronze final 2 b (triangles noirs).

6. Le Parterre nord-ouest à Férolles (Ibid., fig. 3/ $5)$,

7. Inhumations 13 et 14 de la nécropole des Vicreuses à Pougues-les-Eaux (Nièvre : Jacquinot et Usquin, 1878, pl. IV/3 et 5 ; Kimmig, 1952, fig. 20/B, C ; Bouthier, Daugas, Vital, à paraître),

8. Marvelay-Sully (Saône-et-Loire : Millotte, 1959, fig. 59),

9. Camp de Chassey (Saône-et-Loire : Kimmig, 1954, fig. 10/4),

10. Grotte de la Fontaine de la Roche à Courchapon (Doubs : Richard, 1980, $\mathrm{n}^{\text {os }} 171,172,180, \ldots$ ),

11. Grotte de Rancogne (Charente : Guillien, 1968 , fig. $13 / 3$ et $14 / 7$ ),

12. Grand abri de La Roque Saint-Christophe à Peyzac-le-Moustier (Dordogne : Roussot-Larroque, 1986, fig. 1),

13. Grotte des Escabasses à Thémines (Lot : Lorblanchet et Genot, 1972, fig. 2/3),

14. Grotte de Roucadour à Thémines (Lot : Arnal, Couchard et Lorblanchet, 1969, fig. 10/2).

15. Grotte de La Balme (Isère : Bocquet et Reymond, 1976, fig. 80/1 et 2),

16. Scialet funéraire du bois des Vouillants à Fontaine (Isère : Bocquet, 1963, fig. 2/4),

17. Grotte des Sarrazins à Seyssinet-Pariset (Isère : Bocquet, 1976, fig. 52/11),

18. Grotte de la Fontaine du Renard à Villars-deLans (Isère : Bocquet, 1969, fig. 89/17).

19. Grotte de Baume-Sourde à Francillon (Drôme : Cornet, 1963, fig. 5/1), 
20. Grotte d'Antonnaire à Solaure (Drôme : fouille Héritier inédites),

21. Grotte de Chazelles à Saint-André-de-Cruzières (Ardèche : Cauvin et Nikitine, 1960, fig. 5),

22. Grotte du Hasard à Tharaux (Gard : Roudil, 1972, fig. 70/8),

23. Grotte du Prével Supérieur à Montclus (Ibid, fig. 62/2),

24. Grotte de Saint-Marcel (Ardèche : Gilles, 1984, fig. 2 à 4),

25. Grotte de Châteauvieux à Aiguèze (Gard : coll. Huchard),

26. Grotte de Cloches à Saint-Martin (Ardèche : cf. supra),

27. Grotte de la Baume-des-Anges à Donzère (Drôme : Vital, 1984, pl. 42, 51,...),

28. Grotte de la Chauve-Souris à Donzère (Ibid., inédit),

29. Grotte de la Boucle à Corconne (Gard : fouilles Duday et Cours, inédit),

30. Cauna de Martrou à Mas-de-Cours (Aude : Gasco, 1983, fig. 3/6 et 8).

31. Tumulus 57 d'Oberfeld à Haguenau (BasRhin : Unz, 1973, pl. 29/3).

Cet inventaire montre une répartition importante sur les Bassins rhodanien et ligérien. Ces formes apparaissent au début du Bronze final mais persistent au Bronze final 2 b (l'Alleu à Saint-Hilaire-SaintFlorent), parfois avec un décor au peigne à dents fines (grottes de Donzère). S'ajoutant aux ensembles rhénan et parisien (Unz, 1973 ; groupe de Marolles, Brun, 1984), elles indiquent d'autres régions aux productions originales et dynamiques. Un fragment cylindrique à décor cannelé $\left(\mathrm{n}^{\circ} 3\right)$, appartient à un piédestal. Il aurait pu supporter une coupelle ou une coupe conique. On les connaît au Bronze moyen et au début du Bronze final dans les tertres haguenoviens et dans l'inhumation 18 des Gours aux Lions à Marolles-sur-Seine (Unz, 1973, pl. $26 / 7$ et 39/5). Le fragment $n^{\circ} 6$ se raccorde à une forme (fig. 8/1) sans comparaison directe mais dont l'épaulement, le décor incisé, la technologie, ainsi que les jarres élancées de la sépulture $\mathrm{n}^{\circ} 5$ d'Orval, de la couche III de la grotte de Labeil à Lauroux, du foyer F 7 de l'abri de Saint-Étienne-de-Gourgas (Cher : Abauzit, Vannier et Thévenon, 1968, fig. 1/5 ; Hérault : Bousquet, Gourdiole et Guiraud, 1966, fig. 20/C'2 ; Hérault : Arnal, 1972, fig. 41/3), suggèrent une date postérieure au Bronze final 2 a (B.F. 2 b dans les contextes cités). Un rapprochement plus sûr est proposé avec l'urne de la tombe 1 de la nécropole de Webenheim (Sarre : Kolling, 1968, pl. 37/4) indiquant une origine extra-régionale.

Ces 8 formes autorisent à placer le dépôt des couches E 5 à E 3 antérieurement au Bronze final $2 \mathrm{~b}$, ce qui confirme l'absence de coupes coniques, d'écuelle et de gobelet à épaulement.
VII. 3. - Mobilier des fouilles 1986 : niveau E 1 (fig. 5)

Une portion de jarre biconique porte une série d'impressions sur la carène $\left(\mathrm{n}^{\circ} 1\right)$; la partie supérieure polie s'oppose à la base raclée. C'est un modèle du Bronze final $2 \mathrm{~b}$ présent dans la grotte de l'Igue-Blanche à sauliac et sur la station du Roc de Conilhac à Gruissan (Lorblanchet et Genot, 1972, fig. 28/3; Aude : Guilaine, 1972, fig. 89/20 à 22). Un fin rebord $\left(\mathrm{n}^{\circ} 2\right)$ rappelle ceux des écuelles basses (cf. infra et fig. 8/9 à 12).

VII. 4. - Mobilier des fouilles 1946-48 attribué au Bronze final 2 ancien

Une écuelle à méplat se placerait à ce stade (fig. 8/ 15) d'après les documents de la grotte de Vaux-lesPrés (Pétrequin et Urlacher, 1967, fig. 5/10). Elle subsiste au Bronze final $2 \mathrm{~b}$ à Valentigney-Pézoles, mais porte alors un décor incisé (Doubs : Pétrequin, 1966, fig. 5). Un fragment à cannelures orthogonales renvoie aux écuelles basses découvertes en 1986 (supra et fig. 5/7 et 10).

VII. 5. - Mobilier des fouilles 1946-48 attribué au Bronze final $2 b$

Les coupes et les jattes (fig. 7) :

- Une jatte à larges cannelures internes ( $\left.\mathrm{n}^{\circ} 11\right)$ identique à celle de la grotte de l'Igue-Blanche à Sauliac (Lorblanchet et Genot, 1972, fig. 27/1). Formes approchantes dans la grotte du Noyer à Esclauzels, de Roucadour à Thémines et du Gaougnas à Cabrespine (Clottes et Lorblanchet, 1972, fig. 11/7 ; Arnal, Couchard et Lorblanchet, 1969, fig. 11/6 ; Aude : Guilaine, 1972, fig. 14/3). On considèrera que c'est une forme caractéristique du sud-est du Massif Central.

- Une coupe à piédestal et un élément de sustentation isolé ( ${ }^{\text {os }} 1$ et 2 ). C'est une forme du groupe Rhin-Suisse-France Orientale (RSFO. Collectif, 1986, carte 2). Les exemplaires régionaux portent avant tout des cannelures : grotte du Noyer à Esclauzels et grotte de Baume-Sourde à Francillon (Clottes et Lorblanchet, 1972, fig. 11/9 ; Vital, 1986 b, no 5). Le bord épaissi cannelé à ressaut est fréquent : couche F 7 de l'abri de Saint-Étienne-de-Gourgas, grotte de la Baume-des-Anges à Donzère et de Baume-Sourde à Francillon (Arnal, 1972, fig. 40/3, 4, 5 ; Vital, 1984 , pl. $3 / 1 ; 1986$ a, fig. $7 / 10 ; 1986$ b et à paraître). 

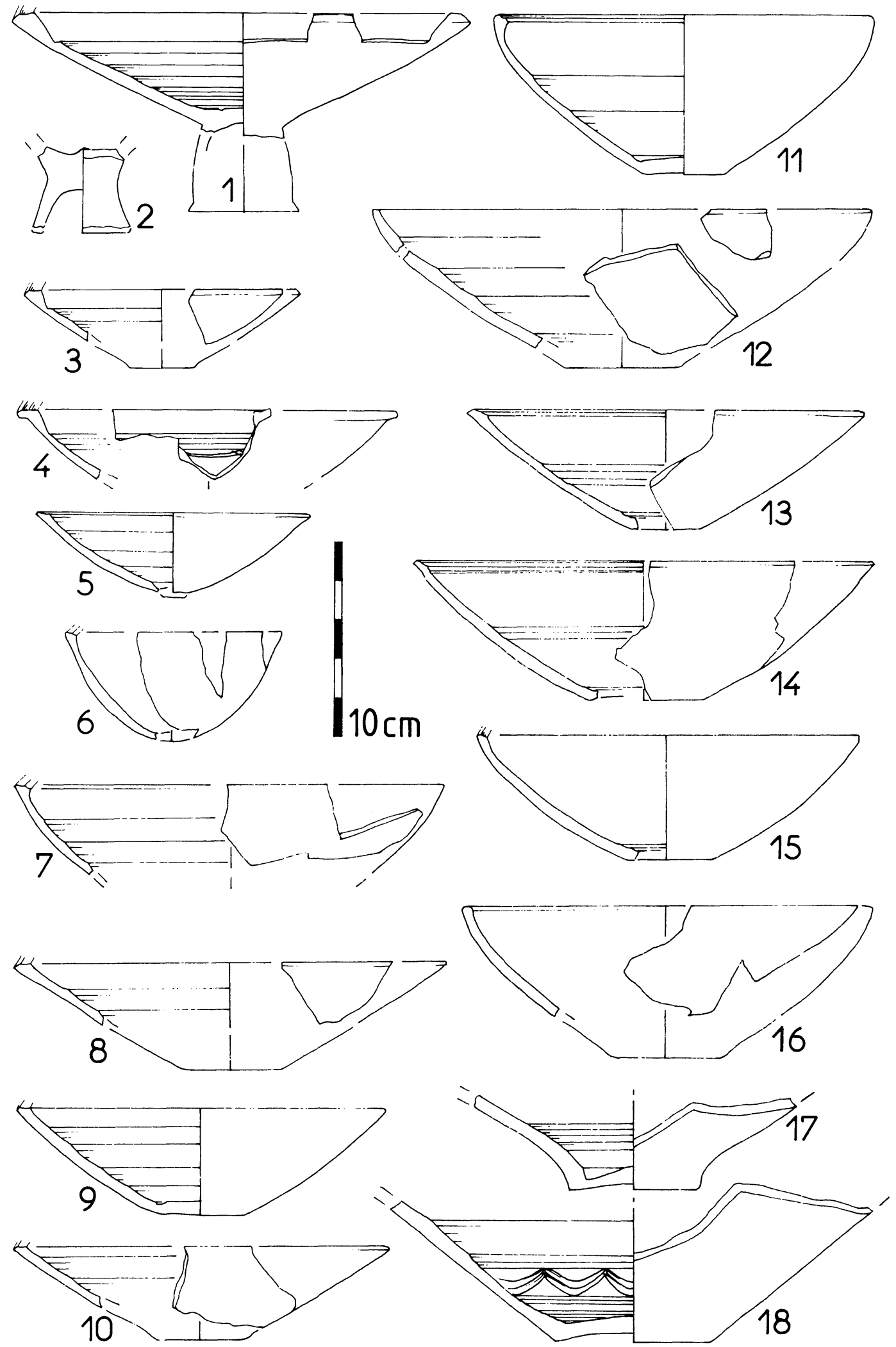

Fig. 7 - Fouilles 1946-48. Coupes et jatte attribuables au Bronze final 2 b et 3 a. 
- Une coupe à ressaut et profil segmenté, à décor interne de cannelures surmontant des arcs tracés au peigne à 2 dents $\left(n^{\circ} 4\right)$. Abondantes dans les régions soumises aux influences RSFO : grotte du Noyer à Esclauzels, à décor entièrement cannelé comme dans la grotte du Gaougnas à Cabrespine, couche 1 de la grotte du Prével Supérieur à Montclus, BaumeSourde à Francillon, tombes 3 et 5 d'Orval (Clottes et Lorblanchet, 1972, fig. 11/5 ; Guilaine, 1972, fig. 94/ 2 ; Roudil, 1972, fig. 66/14 ; Vannier et Abauzit, 1965, fig. 3/1 ; Abauzit, Vannier et Thévenon, 1968, fig. 1/1), ainsi que dans la zone de développement : Ingelheim, Achenheim et Valentigney-Pézoles par exemple (Hesse rhénane : Eggert, 1976, pl. 5/11 ; Schmitt, 1966, fig. 5/28 ; Pétrequin, 1966, fig. 5/6).

- Une coupe à base arrondie $\left(\mathrm{n}^{\circ} 6\right)$ proche de celle de la Cauna de Martrou (Gasco, 1983, fig. 8/3). Une seconde aujourd'hui disparue est figurée par $\mathrm{N}$. Sandars, (1957, fig. 55/1).

- Deux autres coupes connaissent une répartition plutôt large ( $\mathrm{n}^{\text {os }} 5$ et 12) et illustrent la grande fréquence des cannelures larges au Bronze final $2 \mathrm{~b}$. Une réplique à la première provient du tumulus de Maisod (Jura : Combier, 1962, fig. 80/1).

Plusieurs coupes figurent aussi bien dans les inventaires du Bronze final 2 b que 3 a (n ${ }^{\text {os }} 7$ à 10$)$ : grotte du Noyer à Esclauzels et habitat de Pommiers-enForez au B.F. 2 b, station du Baous de la salle à Bize et grotte des Planches-près-Arbois au B.F. 3 a (Clottes et Lorblanchet, 1972, fig. 11/6 ; Loire : Vaginay et coll., 1982, fig. 5/8 ; Aude : Guilaine, 1972, fig. 123/13 ; Pétrequin et coll., 1985, fig. 103/2, $3)$. Un large fragment de base à décor interne entièrement cannelé ( $\left.n^{\circ} 18\right)$ pourrait aussi bien appartenir à l'un ou l'autre de ces deux stades. L'association cannelures larges et étroites serait plutôt un caractère tardif, et les arceaux un motif plus ancien.

En résumé, ces coupes portent la marque du groupe RSFO mais montrent une très nette tendance adaptative au travers de l'usage intensif, et pratiquement exclusif, de la cannelure.

Un micro-vase à pied (fig. 9/13) est modelé dans un matériau localement typique du Bronze final 2 . Une petite coupe à fond rond $\left(\mathrm{n}^{\circ} 11\right)$ est proche de celle évoquée (fig. 7/6). Un tesson à cannelures externes est de datation plus incertaine $\left(\mathrm{n}^{\circ} 12\right)$. Deux jattes présentent une morphologie des plus inhabituelle dans le Sud-Est (fig. 9/10 et 10/13). L'une possède deux languettes horizontales opposées sur la carène et ne déparerait pas en milieu Néolithique Moyen Bourguignon. La seconde montre quatre minuscules pastilles horizontales en limite de la lèvre, sur la moitié de la circonférence seulement, lui conférant un aspect connu dans le groupe de Lüscherz. Pourtant leurs constituants et technologie obligent à les attribuer au début du Bronze final. Elles illustrent un phénomène fréquent, dès que l'on aborde de grandes séries de mobilier, de multiplication de formes sortant du répertoire habituel.

\section{Les écuelles et les gobelets (fig. 8) :}

Beaucoup présentent un épaulement. Les écuelles possèdent un fond plat $\left(n^{\circ} 4\right)$ et un décor associant systématiquement cannelures et incisions triples ou doubles ( $n^{\text {os }} 1$ à 3$)$. Un individu couvert de cannelures séparant des mamelons réhaussés par un cloutage de bronze est connu dans l'aven de Navacelles, mais en position chronologique incertaine, certainement Bronze final 2 a (Gard : Roudil, 1972, fig. 80/3). On doit leur datation aux contextes de Pommiers-enForez, de la grotte des Gitans à Saint-Sorlin-enBugey et du Trou du Fortin à Veyrier (Vaginay et coll., 1982, fig. 6/7 ; Ain : Voruz, 1986, fig. 3/1 ; Haute-Savoie : Oberkampf, 1984, fig. 41/4). Une écuelle non décorée à épaulement court $\left(\mathrm{n}^{\circ} 8\right)$ se compare à celles du Bassin rhodanien : nécropole de Granges, aven d'Espatty à Grospierre et grotte du Hasard à Tharaux, gisement de Camp-Redon à Lansargues, ainsi qu'un exemplaire de La RoqueSaint-Christophe à Peyzac-le-Moustier (Saône-etLoire ; Bonnamour, 1969, n' 171 ; Ardèche : Roudil, 1972, fig. 80/7 et 60/8 ; Prades et coll., 1985, fig. 25/ 3 ; Sandars 1957, fig. 67/2). Comme les précédentes sa diffusion est surtout rhodanienne au sens large, et elle doit être considérée comme une production régionale du Bronze final $2 \mathrm{~b}$.

Des trois gobelets à épaulement l'un $\left(\mathrm{n}^{\circ} 6\right)$ possède un fond pointu. Caractère représenté dès le Bronze final 2 a dans l'horizon de Binningen en BadeWürtemberg et Franche-Comté, un homologue provient de la tombe 1 d'Eberstadt (Grimmer, 1981 ; Richard, 1980 ; Hesse : Müller-Karpe, 1959, pl. 210/ F 1). Un second gobelet proche du précédent $\left(n^{\circ} 5\right)$, s'identifie à celui d'une grotte d'Aurioles, à ceux du Ranc-Pointu $\mathrm{n}^{\circ} 1$ et de la Baume-des-Anges à Donzère (Ardèche : Saumade, 1960, fig. 2 ; Gilles, 1962, fig. 8/3 ; Vital, 1984, pl. 45/7). Connaissant une localisation régionale, ces gobelets appellent les mêmes commentaires que les écuelles. Le troisième $\left(n^{\circ} 7\right)$ trouve des répliques parfaites dans l'aire de développement du groupe RSFO : incinération 21 de la nécropole des Gobillons à Châtenay-sur-seine, dans les tombes de Ballern-en-Sarre (Seine-etMarne : Bontillot, Mordant, Paris, 1975, fig. 18/4 ; Kolling, 1968 , pl. $14 / 7$ et $22 / 6$ et 12 ). Des productions locales à décor cannelé sont connues dans la grotte de la Clapade à Millau et dans celle de thémines à Roucadour (Aveyron : Clottes et Costantini, 1976, fig. 5/6 ; Arnal, Couchard et Lorblanchet, 1969, fig. $10 / 3$ et 11/10). Ce gobelet représente l'un des trois ou quatre types septentrionaux non modifiés, qui souligne les relations nord-sud générant et stimulant les adaptations locales (Vital, 1986 b). 

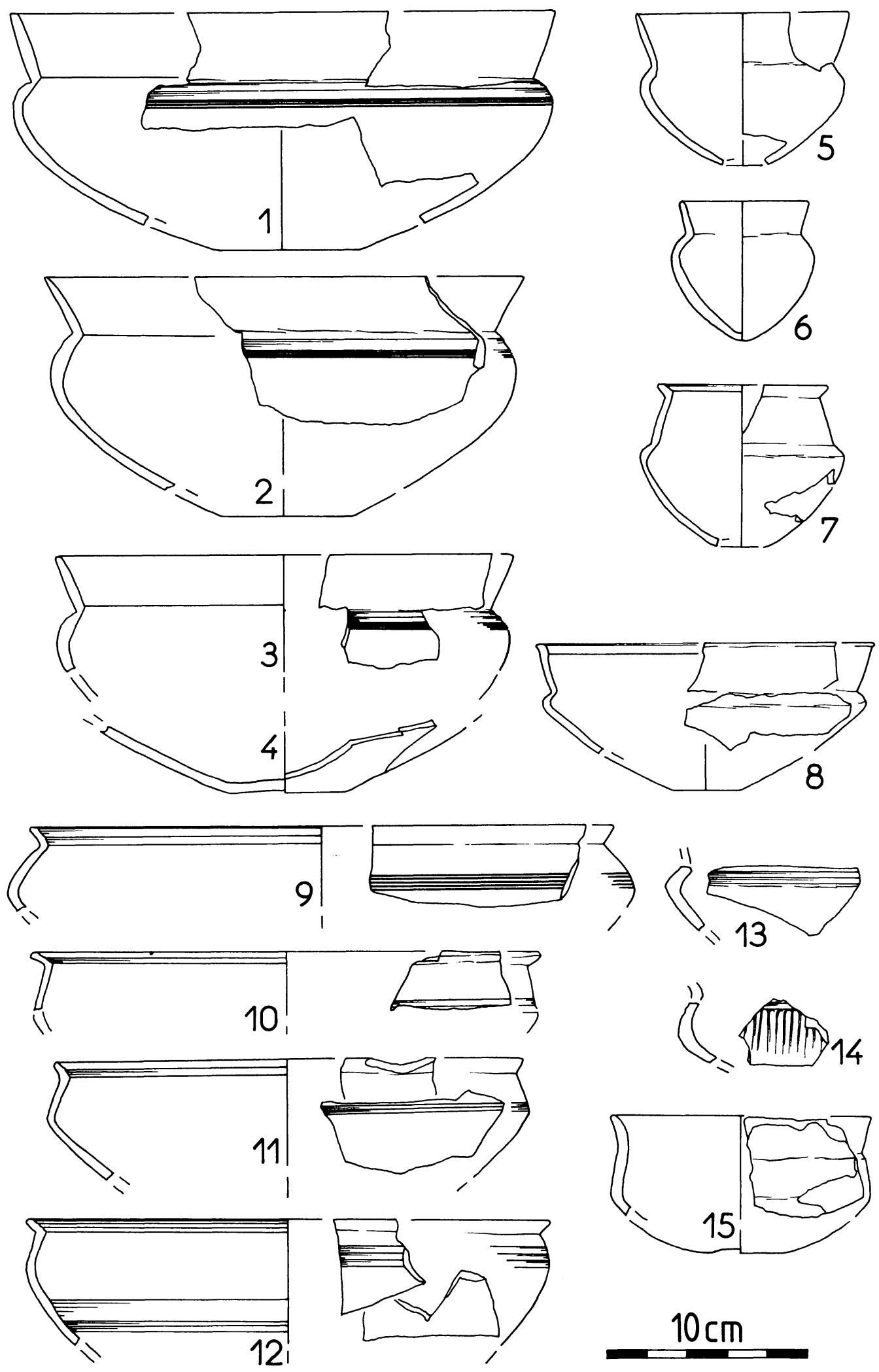

$10 \mathrm{~cm}$

Fig. 8 - Fouilles 1946-48. Écuelles attribuables au Bronze final 2. Le gobelet $\mathbf{n}^{\circ} 6$ est redessiné d'après Huchard et Louis, 1950, pl. 1/8. 
Quatre écuelles basses à rebord court présentent un décor incisé au peigne large $\left(\mathrm{n}^{\circ} 9\right)$, de doubles cannelures ( $\mathrm{n}^{\text {os }} 10$ et 11$)$, complétées par une série de cannelures larges et étroites sur la face interne $\left(n^{\circ} 12\right)$. Le rebord est toujours façonné. La tombe 21 d'Armsheim et la tombe A 9 de Ballern fournissent des comparaisons septentrionales à la première $\left(n^{\circ}\right.$ 9). Elles se présentent en Languedoc oriental dans la grotte du Pontiar à Vallon-Pont-d'Arc et dans celle du Hasard à Tharaux (Hesse rhénane : Eggert, 1976, pl. 17/2 ; Kolling, 1968, pl. 16/7 ; Ardèche : inédit ; Roudil, 1972, fig. 52/7). S'il est impossible d'en déterminer précisément l'origine actuellement, les suivantes $\left(\mathrm{n}^{\text {os }} 10\right.$ à 12$)$ sont abondantes dans le Sud-Est en contexte B.F. $2 \mathrm{~b}$, bien que présentes antérieurement : couche III de la grotte de Labeil à Lauroux, grotte du Prével Supérieur à Montclus, de la Baume-des-Anges à Donzère, du Pontiar à VallonPont-d'Arc, de Peyroche 2 à Auriolles (Bousquet, Gourdiole, Guiraud, 1966, fig. 18 ; Roudil, 1972, fig. $62 / 3$ et 9 ; Vital, 1984, pl. 72 ; 1986 a, fig. 5/10 ; Roudil et Saumade, 1968, fig. 88). Elles sont bien plus rares en Provence : grotte des Fées à Châteauvieux (Var : Lagrand, 1968, pl. 19/2). Le tesson $\mathrm{n}^{\circ} 10$ pourrait correspondre à la forme signalée par $\mathrm{N}$. Sandars (1957, fig. 85/2). L'écuelle à cannelures internes $\left(n^{\circ} 12\right)$ est locale. Cette forme, rarement décorée, figure dans la couche III de la grotte de Labeil, dans la grotte du Noyer et dans celles du Prével Supérieur (Bousquet, Gourdiole, Guiraud, 1966, fig. 19/F 5 ; Clottes et Lorblanchet, 1972, fig. 10/1 ; Roudil, 1972, fig. 87/2). Un exemplaire décoré de la grotte de la Clapade à Millau est identique au nôtre (Louis et Taffanel, 1955, fig. 31/35). Un récipient de forme proche, mais plus tardif, provient de la grotte des Planches-près-Arbois (Pétrequin et coll., 1985, fig. 109/6). Une écuelle à segmentation anguleuse est totalement couverte de cannelures (fig. 9/9). Elle ne paraît pas avoir possédé de fond, à moins qu'il n'ait été façonné avec le piédestal, aujourd'hui absent, qui le supportait. Nous n'en connaissons aucune réplique. Sa technologie est identique à celle des formes $8 / 1$ à 4 et $9 / 1$. Nous avons évoqué la chronologie des piédestals à propos des coupes. Les rares écuelles à cannelures couvrantes et/ ou à profil segmenté anguleux, proviennent de contextes de transition B.F. $2 \mathrm{a} / 2$ b ou B.F. 2 b : Misy-sur-Yonne, fosse F 2 du Bois des Refuges; Bavois-en-Raillon, couche $4 \mathrm{c}$; sépulture 7 de la nécropole du Bois des Hauts à Tigy, station de Kreuznach-Martinsberg (Seine-et-Marne : Mordant et coll., 1977, fig. 33/2 ; Vaud : Vital et Voruz, 1984, fig. 69/1474 ; Loiret : Cordier, 1977, fig. 10/7 e ; Rhénanie-palatinat ; Dehn, 1941). Les prototypes sont peut-être à rechercher parmi les écuelles à fond pointu et cannelures couvrantes de la sépulture 1 de Breitfurt et de la grotte de Courchapon (Kolling, 1968, pl. 34/4 à 6 ; Richard, $1980, \mathrm{n}^{\text {os }} 132$ et 134). P. Pétrequin (Pétrequin et coll., 1985, p. 134) signale l'absence du gobelet ovoïde, dont on possède un exemplaire (fig. 9/5), dans les séries jurassiennes antérieures au Bronze final 3 a. Il se présente pourtant dans l'horizon de Binningen : sépulture 103 de la Colombine à Champlay et Karlsruhe (Yonne : Lacroix, 1957, fig. 61 et 62 ; Bade-Württemberg : Unz 1973, pl. 2/3). La morphologie anguleuse du rebord, les doubles cannelures sur la segmentation externe et un gobelet comparable des séries B.F. 2 b de la Baume Sourde de Francillon autorisent tout de même une attribution (Vital, 1986 b et à paraître).

\section{Les pots et les jarres :}

Deux petits pots, dont un à conservé une anse (fig. 10/4 et 5) montrent un décor digité. Comme un tesson à motif pincé $\left(\mathrm{n}^{\circ} 9\right)$ on doit les rapporter globalement au Bronze final 2, pendant lequel ils sont toujours représentés dans la moyenne vallée du Rhône (Vital, 1984, p. 167). Un grand pot (près de $80 \mathrm{~cm}$ de diamètre) possède un ressaut souligné par une double rangée d'impressions digitales encadrant au moins 8 mamelons horizontaux; le bord est incisé (fig. 11/1). Ces caractères typologiques, ainsi que la dureté de sa pâte de couleur grise, sont éminemment représentés au début du Bronze final dans le Bassin rhodanien : grotte de la Chauve-Souris à Donzère et grotte des Lunettes à Vallon-Pont-d'Arc (Vital, 1984 , pl. 141 et inédit). Un tesson tout à fait identique fut découvert par R. Gilles dans le proche aven de Meunier à Saint-Martin, dont le mobilier protohistorique se classe au Bronze final 2. En dehors de notre secteur, un des vases de la fosse de Civaux mérite une mention (Vienne : Gomez, 1971, fig. $2 / 3$ et pl. 1). Il est attribué à l'extrême fin du Bronze moyen; le traitement de la face externe par modelage de séries de gorges digitées est connu au Bronze final 2 à Donzère (Vital, 1984, pl. 113 et 114 ; 1986 a fig. 5/9). Quelques fragments sont classés au Bronze final 2 sur la base de leur décoration et de leur aspect (fig. 10/7, 8, 11 et 12). La forme et la présence de cannelures sur 3 tessons (fig. 9/6 à 8) permettent la même attribution, par rapprochement avec ceux de la Baume-des-Anges de Donzère et de la grotte de la Rousse à Sainte-Marie-du-Mont (Vital, 1984 ; Isère : Bocquet et Degueurce, 1976, fig. 83). Bien qu'appartenant à deux récipients différents, deux individus permettent d'imaginer la forme originelle de jarre à col cannelée ( ${ }^{\text {os }} 2$ et 3 ), observée dans la grotte du Noyer à Esclauzels, dans l'aven de Sessa à Lagorce, dans la couche $\mathrm{F} 8$ de l'abri de Saint-Étienne-de-Gourgas (Clottes et Lorblanchet, 1972, fig. 11/1 et 11 ; Ardèche : Roudil, 1972, fig. 69/ 2 ; Arnal, 1972, fig. 37). Elle figure dans les séries du groupe RSFO (Brun, 1984, fig. 29/1, 35/7, 38/5). Deux jarres de même facture (fig. $9 / 4$ et 11/5) diffèrent au niveau du col. Les comparaisons nous conduisent à Vaux-les-Prés (Pétrequin et Urlacher, 


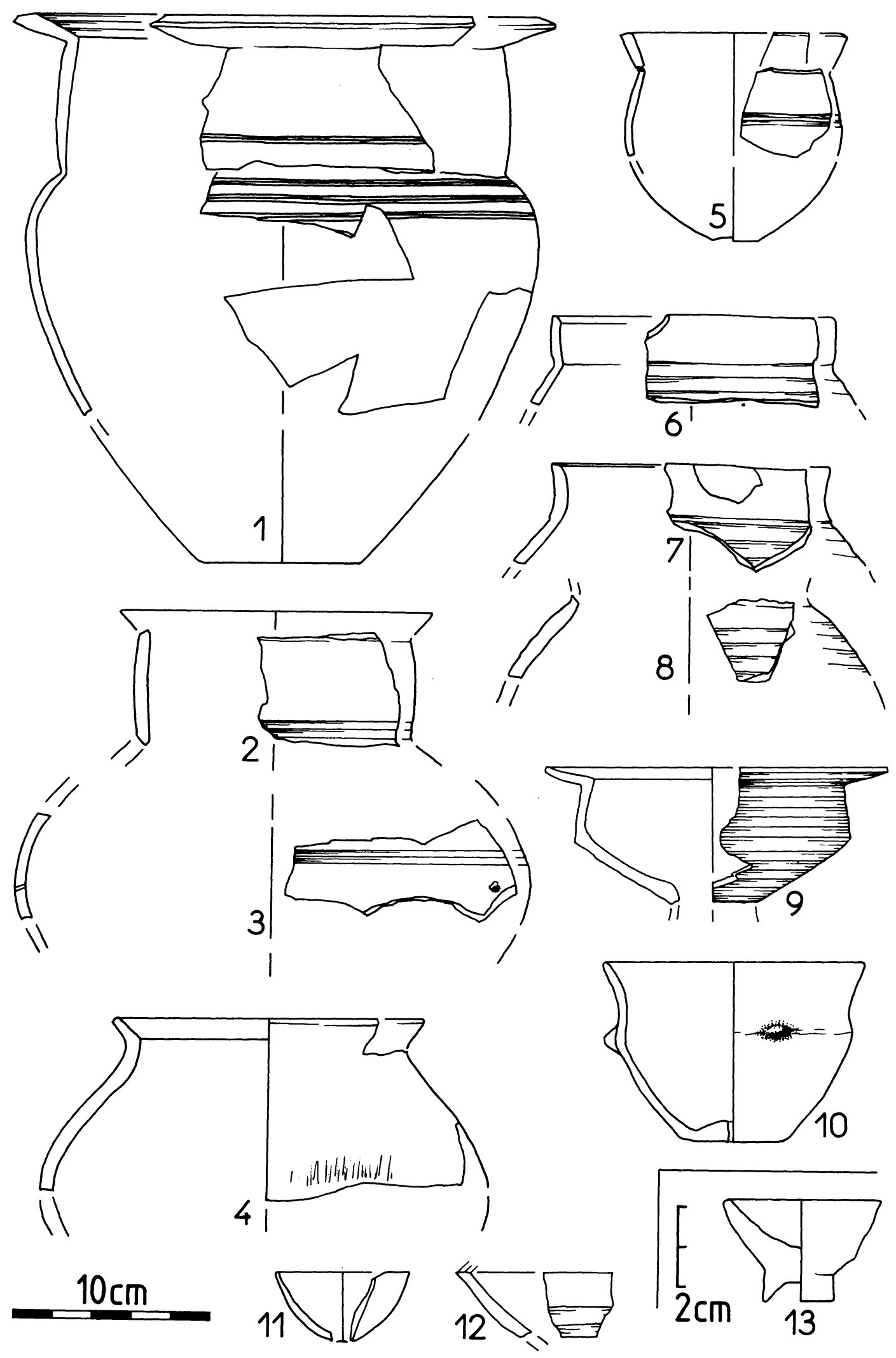

Fig. 9 - Fouilles 1946-48. Céramiques attribuables au Bronze final 2. 

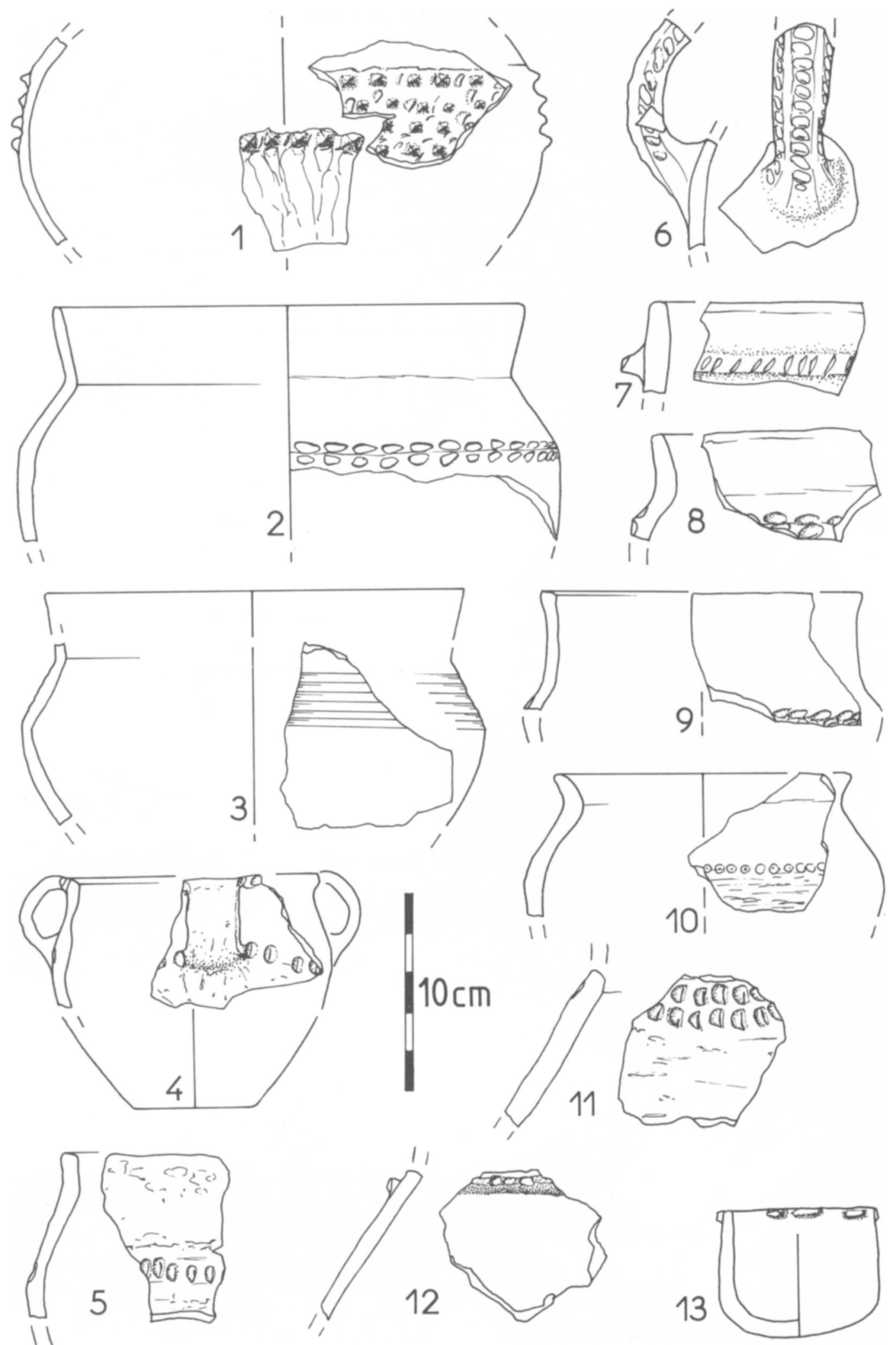

Fig. 10 - Fouilles 1946-48. Céramiques attribuables au Bronze final 2. 

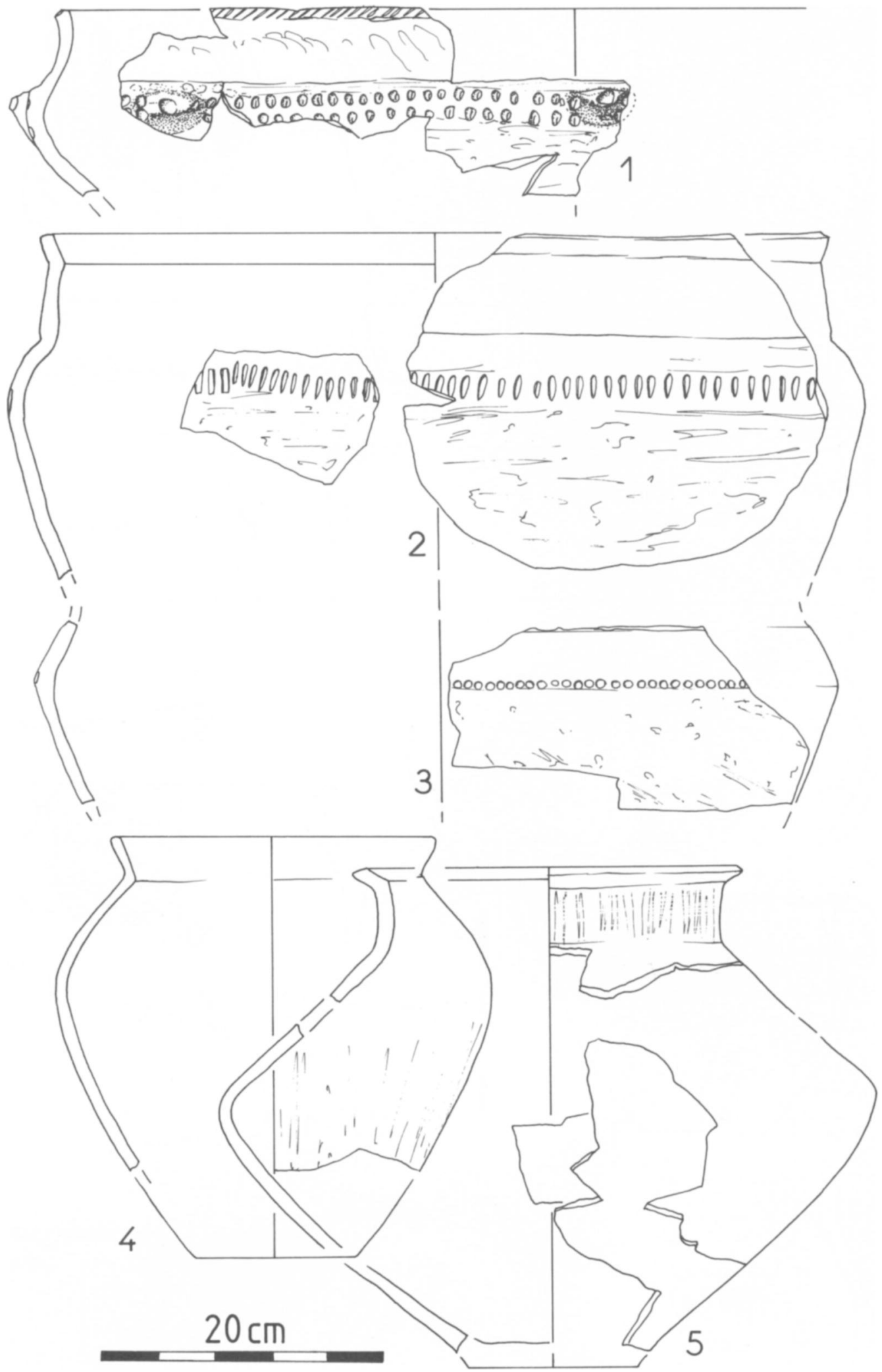

Fig. 11 - Fouilles 1946-48. Jarres et pots attribuables au Bronze final 2. 
1967, fig. 3/3) et dans la nécropole des Gobillons à Châtenay-sur-Seine, dans le tumulus de Maisod, sur la station de Valentigney-Pézole et dans la grotte du Gaougnas à Cabrespine (Bontillot, Mordant, Paris, 1975, fig. 11 ; Combier, 1962, fig. 80/2 ; Pétrequin, 1966, fig. 5 ; Guilaine, 1972, fig. 93/10). La jarre à profil arrondi à segmentation médio-sommitale (fig. 11/4) se rapproche de celle de la couche E 5 (fig. 5/ 12), de la grotte de Labeil à Lauroux et de l'aven des Vouillants à Fontaine (Bousquet, Gourdiole et Guiraud, 1966, fig. 19 ; Bocquet, 1969, fig. 63/1 et 3). Une jarre à carène soulignée par pincement (fig. 10/ 2) est déclarée provenir « du niveau du Bronze " par A. et $P$. Huchard (couche $X)$. On en rapprochera un tesson à décor cannelé ( $\left.n^{\circ} 3\right)$ qui, comme le précédent évoquent des éléments de la Baume-des-Anges à Donzère, de Pommiers-en-Forez, de la grotte de l'Igue-Blanche et de celle de la Tour à La MotteChalançon (Vital, 1986 a, fig. 7/20 ; Vaginay, 1982, fig. 7/2 ; Lorblanchet et Genot, 1972, fig. 27/4 ; Drôme : fouilles Daumas et Laudet inédites). Une jarre à rebord court $\left(\mathrm{n}^{\circ} 10\right)$ montre un décor estampé à l'aide d'une tige creuse, qui souligne la différence de façonnage des parties inférieure et supérieure. Ce motif est fréquent au B.F. 2. Deux fragments permettent de proposer une forme sphérique de jarre $\left(n^{\circ} 1\right)$ offrant la particularité de porter des tétons adjacents modelés en quatre séries superposées. Rares dans le Sud-Est, ces éléments sont fréquents en domaine RSFO, sur la partie inférieure de vases de formes diverses : Zug-Sumpf couche inférieure, Hauterive-Champréveyre zone A couche 3 , incinérations de Vidy, Dampierre-sur-le-Doubs (Zug : Ruoff, 1974, fig. 2 ; Neuchâtel : Borrello et Gross, 1986, fig. 6 a ; Vaud : Weidmann, 1986, et MCAH de Lausanne ; Pétrequin, Urlacher et Vuaillat, 1967, fig. 4/7 et 12). Trois tessons illustrent un type bien représenté dans la moyenne vallée du Rhône (fig. 10/ 2 et 3) : jarres de l'aven de Sessa à Lagorce, de la Baume-des-Anges à Donzère, de l'abri de SaintÉtienne-de-Gourgas (Roudil, 1972, fig. 69/8 ; Vital, 1986 a, fig. 6 ; Arnal, 1972, fig. 38). La première ( ${ }^{\circ}$ 2) est restituée à partir d'un fragment retàillé par polissage et montrant une coloration de recuit, alors que le second est noir. L'absence de traces de frottement sur la face convexe nous interdit d'en faire un " puky » (outil de potier permettant de faire pivoter un récipient pendant le façonnage), mais plutôt un couvercle ou plus sûrement une pièce utilisée près d'un foyer.

VII. 6. - Mobilier des fouilles 1946-48 attribué au Bronze final $3 a$

Deux coupes pourraient bien appartenir à cette phase (fig. 7/13, 14). Dans le Jura, les cannelures étroites ornent aussi bien les coupes du B.F. 2 b à
Dampierre-sur-le-Doubs, que celles du B.F. 3 a au Landeron et à Cortaillod-Est (Pétrequin, Urlacher et Vuaillat, 1969, fig. 15/1 ; Neuchâtel : Ruoff, 1974, pl. 14/1 et 8 ; Rychner et coll., 1986, fig. 5). Elles semblent toutefois moins fréquentes au Bronze final $2 \mathrm{~b}$. Les éléments régionaux vont en ce sens : le Pont du Diable à Aniane et sites lagunaires héraultais (Boudou, Arnal et Soutou, 1961, fig. 6/3 ; Dedet et Py, 1985, p. 19 et fig. 9/6 a). La banalité de deux exemplaires et d'une base (fig. 7/15 à 17) n'autorisent pas un diagnostic sûr. Deux coupes profondes à décor externe d'incisions doubles ou simples (fig. 12/ 10 et 11) figurent dans l'horizon D 2 de la grotte des Planches-près-Arbois (Pétrequin et coll., 1985, fig. 110/3).

Les jattes et les coupelles ont un point de segmentation net (fig. 12/1, 2, 5, 7 à 9,12 et 13), ou diffus ( $\mathrm{n}^{\text {os }}$ $3,4,6,16$ ) et sont caractéristiques du Bronze final $3 \mathrm{a}$; elles demeurent extrêmement rares dans les contextes B.F. $3 \mathrm{~b}$ médio-rhodaniens, mais présentes $\left(\mathrm{n}^{\circ} 3\right.$ par exemple) dès le B.F. 2 avec décor cannelé du pied. La partie supérieure porte des séries d'incisions parallèles et de méandres symétriques : fosse de l'étang de Plazac, plateau du Laouret, le Pont du Diable à Aniane, habitat de Boussecos à Bize, grotte des Planches-près-Arbois, station d'Auvernier-Brena (Dordogne : Chevillot, 1981, pl. 80/1 ; Guilaine, 1972, fig. 119/1 ; Boudou, Arnal et Soutou, 1961, fig. 6, 9, 10 ; Aude : Lauriol, 1963, fig. $3 / 7$ et $6 / 2$; Pétrequin et coll., 1985, fig. 108/1 et $111 / 3$; Neuchâtel : Rychner, 1974, fig. 14/3 à 5). Les jattes à profil continu sont présentes dans la grotte des Planches (Ibid., fig. 110/6, 8). Deux récipients présentent des perforations : une paire sur le $\mathrm{n}^{\circ} 13$, cinq sur le pourtour et une au fond sur le $\mathrm{n}^{\circ} 7$.

Le gobelet $\left(\mathrm{n}^{\circ} 14\right)$ oriente nos comparaisons dans les mêmes directions : Aniane, fosse de Plazac et grotte des Planches (Ibid., fig $7 / 2$; fig. 77/1 ; fig. 91/4 et 92/9). Un gobelet fragmenté montre un profil moins classique (fig. 12/15) ; il se rapprocherait des productions jurassiennes. Une partie supérieure de gobelet biconique, à rebord cannelé, porte des paires d'incisions $\left(\mathrm{n}^{\circ} 17\right)$. On le confrontera à ceux du tumulus de Chaume-les-Baigneux, de la grotte des Planches, de Rouffignac, et à la jarre de l'incinération 0 des Gobillons à Châtenay-sur-Seine (Côted'or : Ratel, 1970, fig. 10 ; Pétrequin et coll., 1985, fig. 116/1, 119/2,... ; Dordogne : Chevillot, 1981, pl. 91/9 et 96/1 ; Bontillot, Mordant et Paris, 1975, fig. 7/4).

Le superbe fragment de jarre à épaulement et décor cannelé léger et incisé (fig. 12/18) est l'un des rares spécimens d'urne proto-villanovienne découverts en France. H. Baills (1979, p. 108) évoque celles de Millas et d'Agullana dans la recherche des comparaisons de l'exemplaire de la tombe 16 de Serralongue. Mais autant à Millas (Aude : Ponsich et De Pous, 1951, fig. 13), à Agullana (Empordà : Pons 

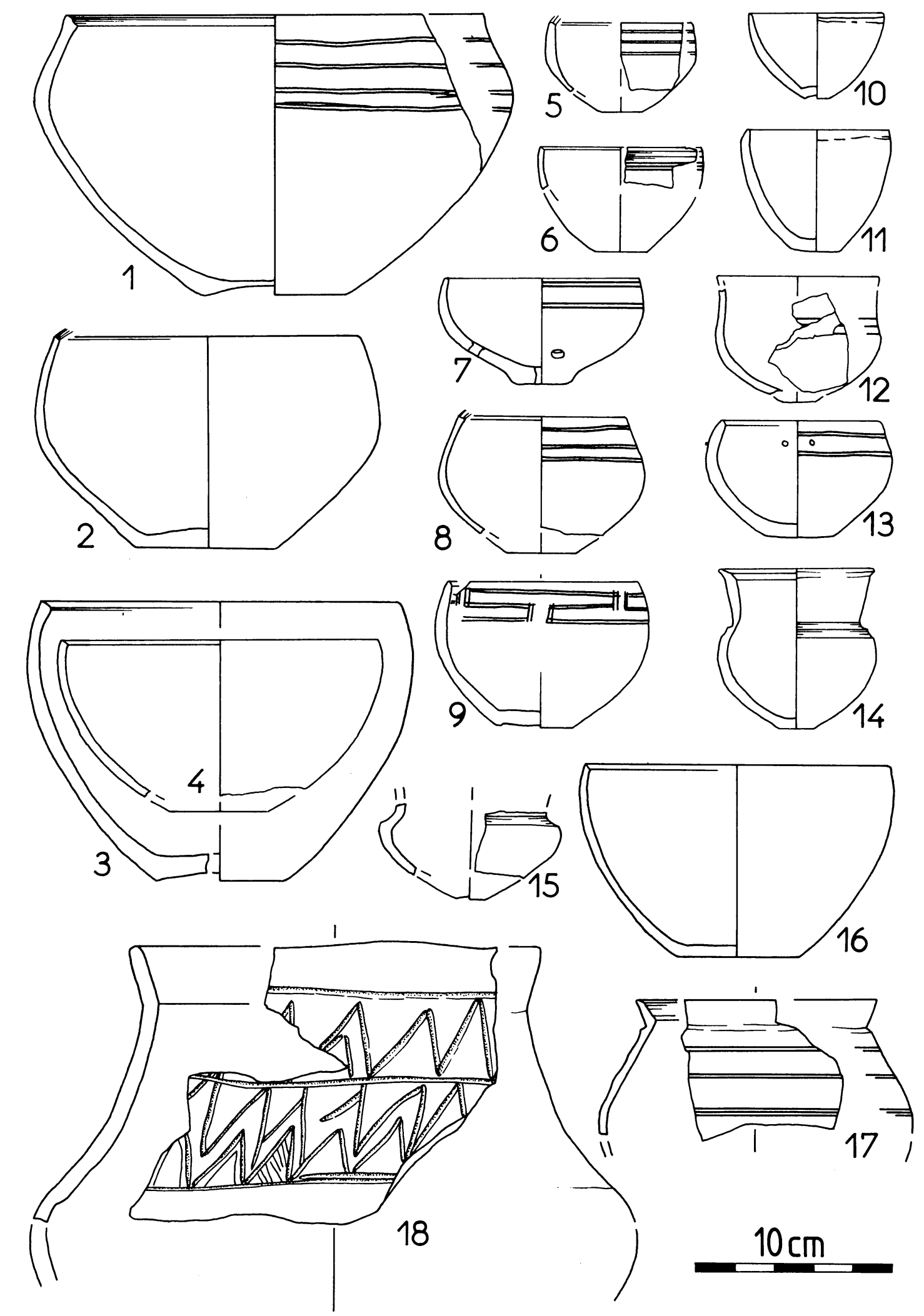

Fig. 12 - Fouilles 1946-48. Récipients attribuables au Bronze final 3 a. 
I Brun, 1984, pp. 194-196) qu'à Serralongue (Pyrénées-Orientales : Baills, 1979, fig. 32/1), elles figurent en milieu du Bronze final $3 \mathrm{~b}$ et du début de l'âge du Fer. Ce n'est pas le cas de notre exemplaire dont les meilleurs parallèles proviennent des tombes 1,2 et 4 de la nécropole de Fontanella et de celle de Pianello-di-Genga, phase II (Lombardie : Salzani, 1978, fig. 3/5, 6 ; 4/1 et 17 ; Marche : Müller-Karpe, 1959, pl. 53/9), rapportées au stade Proto-Golasecca III - Bronze final 3 a (Ibid ; Negroni-Catacchio, Nava et Chiaravalle, 1979).

\section{Les jarres (fig. 13) :}

Une série de jarres, devant accompagner les plus petits récipients, peut être isolée d'après les caractéristiques communes suivantes :

- profil, matériau et coloration proches de ceux du B.F. 2 b (cf. fig. 9/2 et 3),

- absence d'impressions triangulaires, digitées ou ovalaires, de méplat à la base du col, présence d'un rebord divergent, contrairement à leurs homologues du B.F. 3 b (fig. 19),

- emploi de l'incision seule ( $\mathrm{n}^{\text {os }} 1$ et 6 ) ou couplée à des impressions circulaires $\left(\mathrm{n}^{\circ} 2\right)$. On les rapprochera de celles de Boussecos à Bize, de la grotte du Gaougnas à Cabrespine, de celle du Gardon à Ambérieu-en-Bugey, de la grotte du Noyer à Esclauzels, de la fosse de Cormède aux Martres-d'Artières (Lauriol, 1963, fig. 4/3 et 36 ; Guilaine, 1972, fig. 94/ 6 ; Ain : Bornatico, Dumont et Stabile, 1957, fig. 9/ 5 ; Clottes et Costantini, 1976, fig. 5/1 ; Puy-deDôme : Daugas et Vital, 1986, fig. 2/C). A l'énoncé de ces comparaisons on note autant de sites du B.F. 2 b que du B.F. 3, mais les parentés morphologiques doivent être pondérées par la lecture du décor qui marque un changement entre les deux phases, notamment par l'introduction de deux cannelures larges sur la partie supérieure. La petite jarre non décorée $\left(n^{\circ} 8\right)$ se retrouve dans le $\mathrm{S} 2 / \mathrm{C} 4$ du site lagunaire de Tonnerre I à Mauguio (Hérault : Dedet, Py et SavayGuerraz, 1985, fig. 43/9).

VII. 7. - Mobilier des fouilles 1946-48 attribué au Bronze final $3 b$

Le nombre de sites de cette époque étudiés dans les Alpes occidentales s'est accru depuis quelques années, fournissant une image de l'évolution des productions céramiques, en même temps qu'un échantillonnage spectaculaire de plusieurs centaines de formes (et certainement plus d'un millier lorsque les travaux d'élaboration auront pris fin). Nous avons retenu les sites de comparaison suivants : Les Bar- lières à Serrières-de-Briord et le Pré de la Cour à Montagnieu pour le Jura méridional; Le Pas de l'Estang, Les Gandus à Saint-Férréol-Trente-Pas et l'ensemble stratigraphique $8 \mathrm{c} / 9$ de la grotte de la Chauve-Souris à Donzère pour les Préalpes rhodaniennes (Ain : Vital et coll., 1986 b et a ; Drôme : fouilles Héritier inédites, Daumas et Laudet, 198182 ; Vital, 1984). Il convient d'ajouter les séries languedociennes (Garmy, 1981) et provençales (Lagrand, 1968).

Les coupes à rebord montrent fréquemment une différence de façonnage entre les faces interne et externe (fig. 14/1, 2 et 4). Quelques coupes hautes possèdent des échancrures (fig. 15). Les bords convergents sont attestés ( $\mathrm{n}^{\text {os }} 4$ à 7$)$. Les formes banales ( $n^{\text {os }} 1$ à 3,8 à 10$)$ figurent aussi en contexte Bronze final 3 a. Les coupelles (fig. 16) sont une production caractéristique de la région du BasRhône, dont on retrouve de rares exemplaires dans le Bassin parisien et sur le Plateau suisse.

Les gobelets de petite (fig. 17/8 à 13) ou moyenne dimensions ( $\mathrm{n}^{\text {os }} 1$ à 7$)$ renvoient au domaine alpin, tout en consevant des aspects propres : grotte du Ranc-Pointu $\mathrm{n}^{\circ} 1$ à Saint-Martin-d'Ardèche, oppidum du Baou Rous à Bouc-Bel-Air (Gilles, 1962, fig. 3 et 5 ; Bouches-du-Rhône : Boissinot, 1983, fig. 3 et 4). Un gobelet à cannelures et impressions (fig. 17/2) identique à celui du Pont du Diable à Aniane pourrait se classer au Bronze final 3 a (Boudou, Arnal et Soutou, 1961, fig. $25 / 2$ et $4 / 1$ ). Si les récipients à motifs incisés et cannelés sont présents (fig. $17,18 / 2,20 / 4$ à $6,21 / 3$ ), on remarque la représentation importante d'une série de formes de facture moins soignée à décors impressionnés (fig. 18/1 à 5), associés à des cannelures sur des jarres à col droit ou peu divergent (fig. 19 et 21), fréquentes en domaine méridional. Autre différence avec les gisements des Alpes du Nord, c'est la rareté des cordons à la base du col ; un seul est connu (fig. 20/8). L'on s'orientera à nouveau vers le Midi pour une jatte non décorée (fig. 21/3) : couche 5 de l'abri du Capitaine à Montpezat, site de Tonnerre I à Mauguio (AlpesMaritimes : Lagrand, 1968, pl. 34/4 ; Dedet, Py et Savay-Guerraz, 1985, fig. 42/47).

Plusieurs coupes ne peuvent être attribuées à un stade précis du Bronze final (fig. 22/1, 2, 7 à 12). L'une à bord rentrant et anse $\left(n^{\circ} 7\right)$ serait plutôt tardive. Un tesson à décor cannelé $\left(n^{\circ} 6\right)$ reste énigmatique et sans équivalent. Une écuelle présente un décor excisé $\left(\mathrm{n}^{\circ} 5\right)$ comprenant un chevron et des lignes parallèles. Il date aussi bien du Bronze final $3 \mathrm{~b}$ dans sa phase la plus tardive (type ChauveSouris : Vital, 1984, pl. 156/13 et 14) que du début de l'âge du Fer : aven d'Espatty à Grospierre (Gros et coll., 1969, fig. 11/1). Nous excluons de cette étude 5 fragments du $1^{\text {er }}$ âge du Fer, non figurés. 


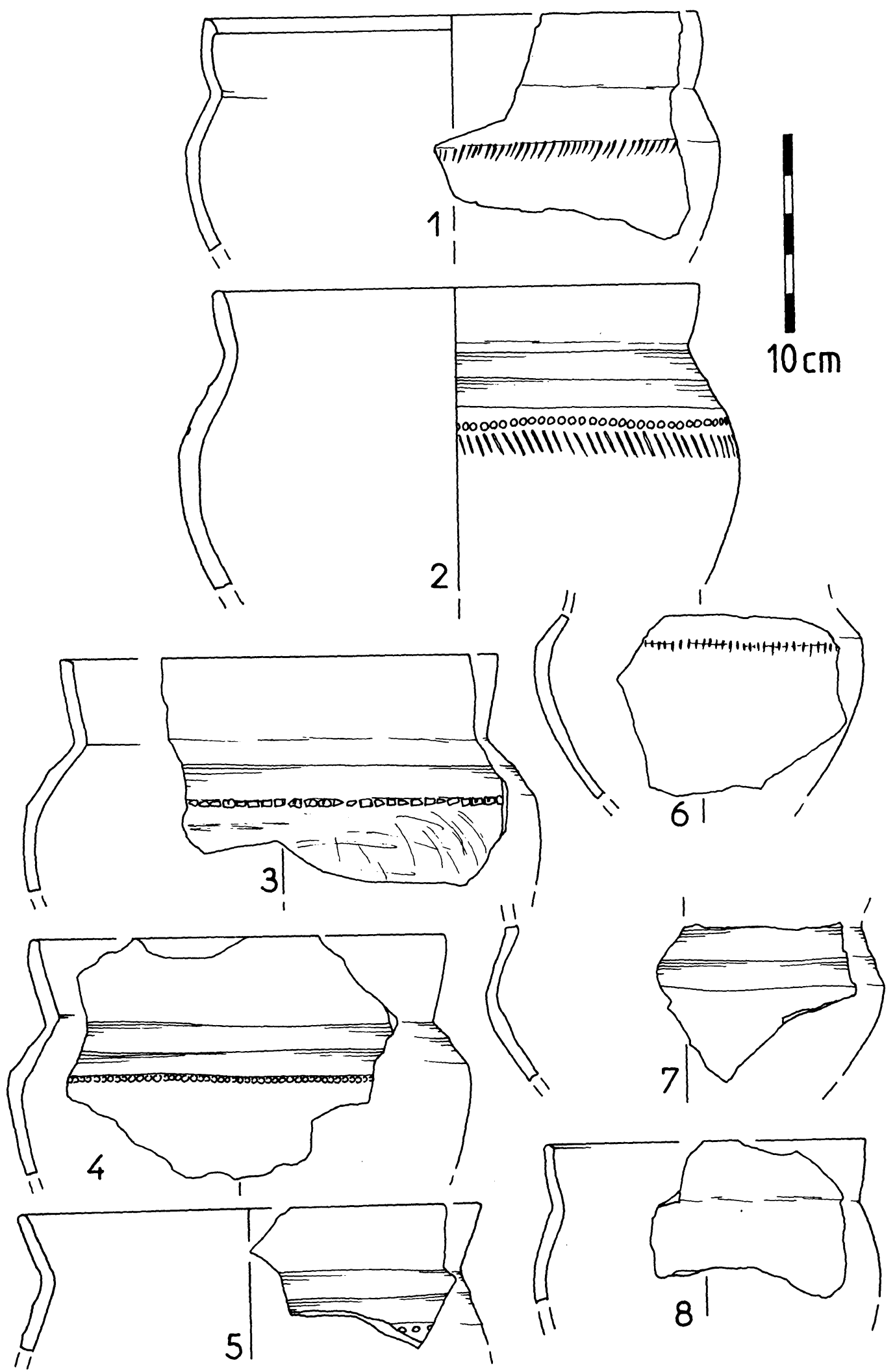

Fig. 13 - Fouilles 1946-48. Récipients attribuables au Bronze final 3 a. 
527
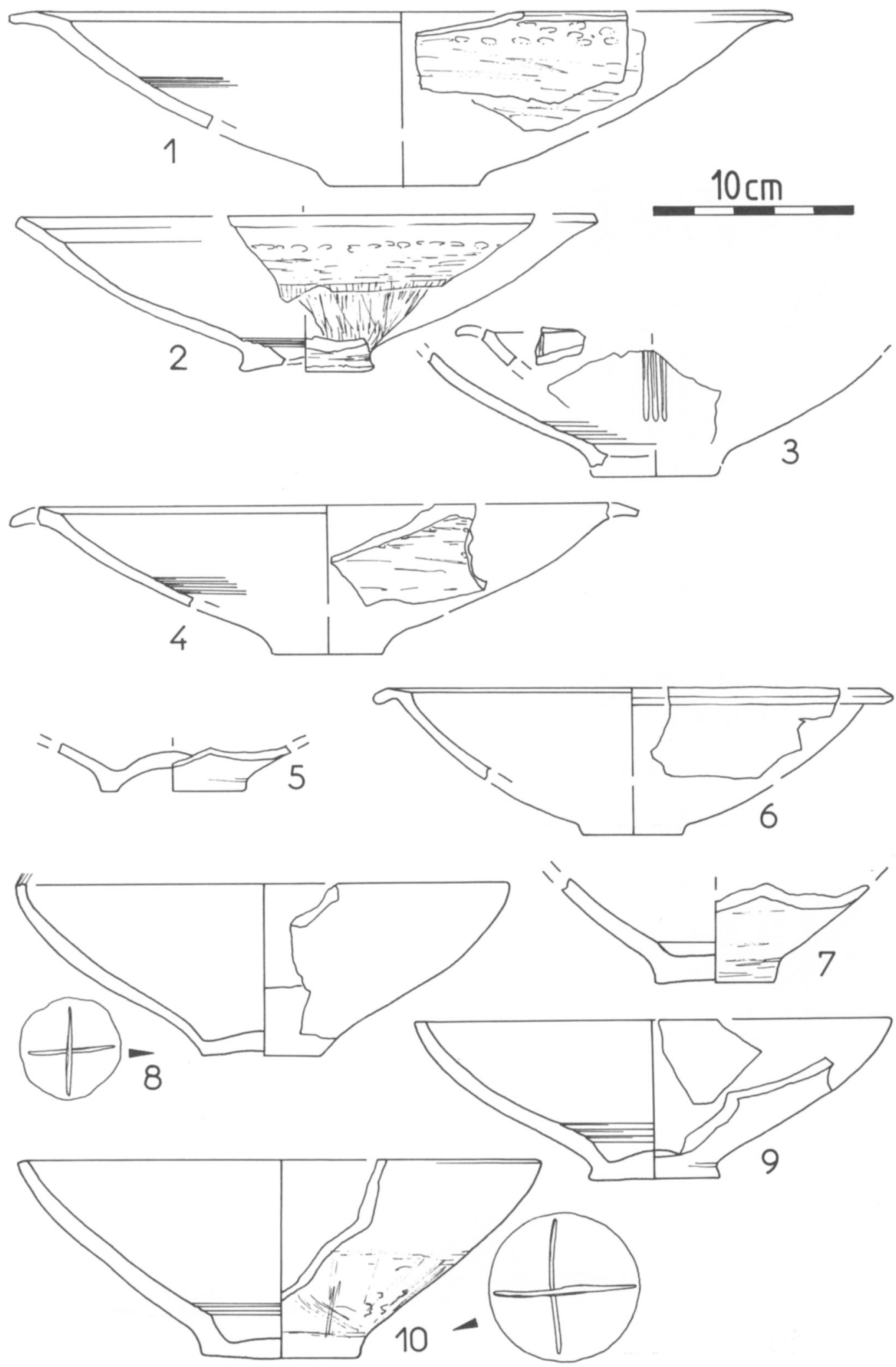

Fig. 14 - Fouilles 1946-48. Coupes attribuables au Bronze final 3 b. 

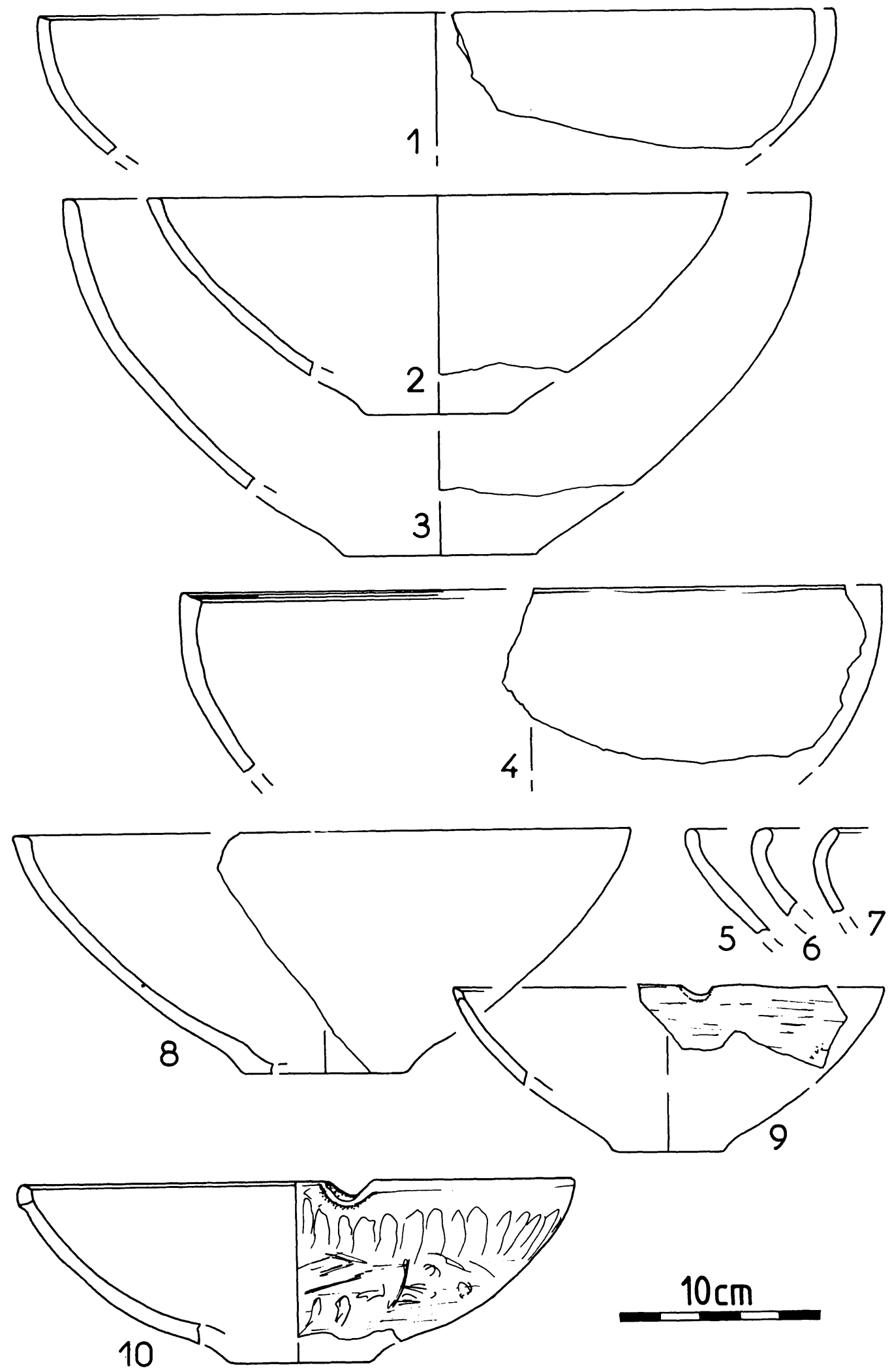

Fig. 15 - Fouilles 1946-48. Coupes attribuables au Bronze final 3. 

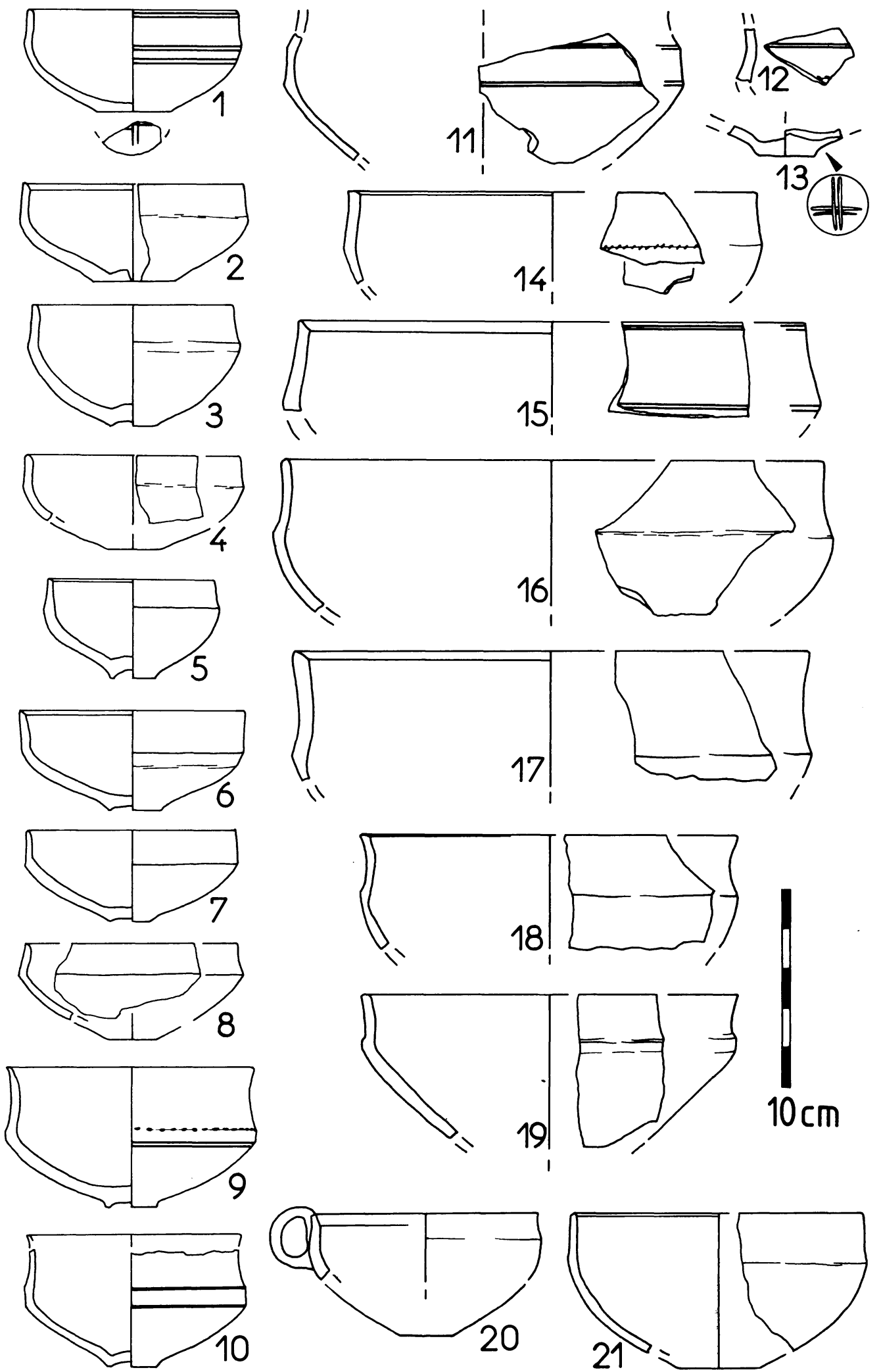

Fig. 16 - Fouilles 1946-48. Coupelles attribuables au Bronze final 3 b. 


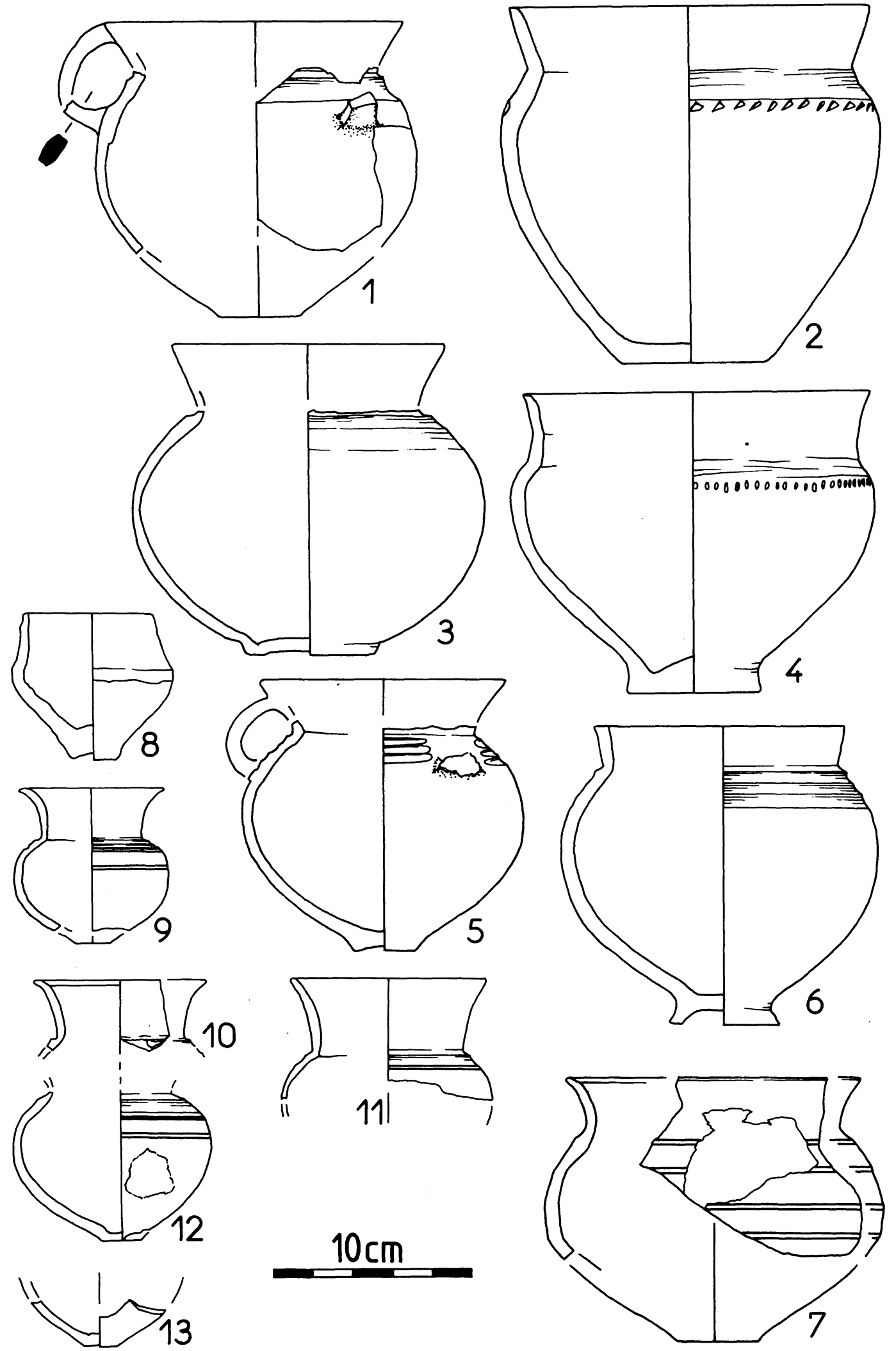

Fig. 17 - Fouilles 1946-48. Gobelets attribuables au Bronze final 3. 

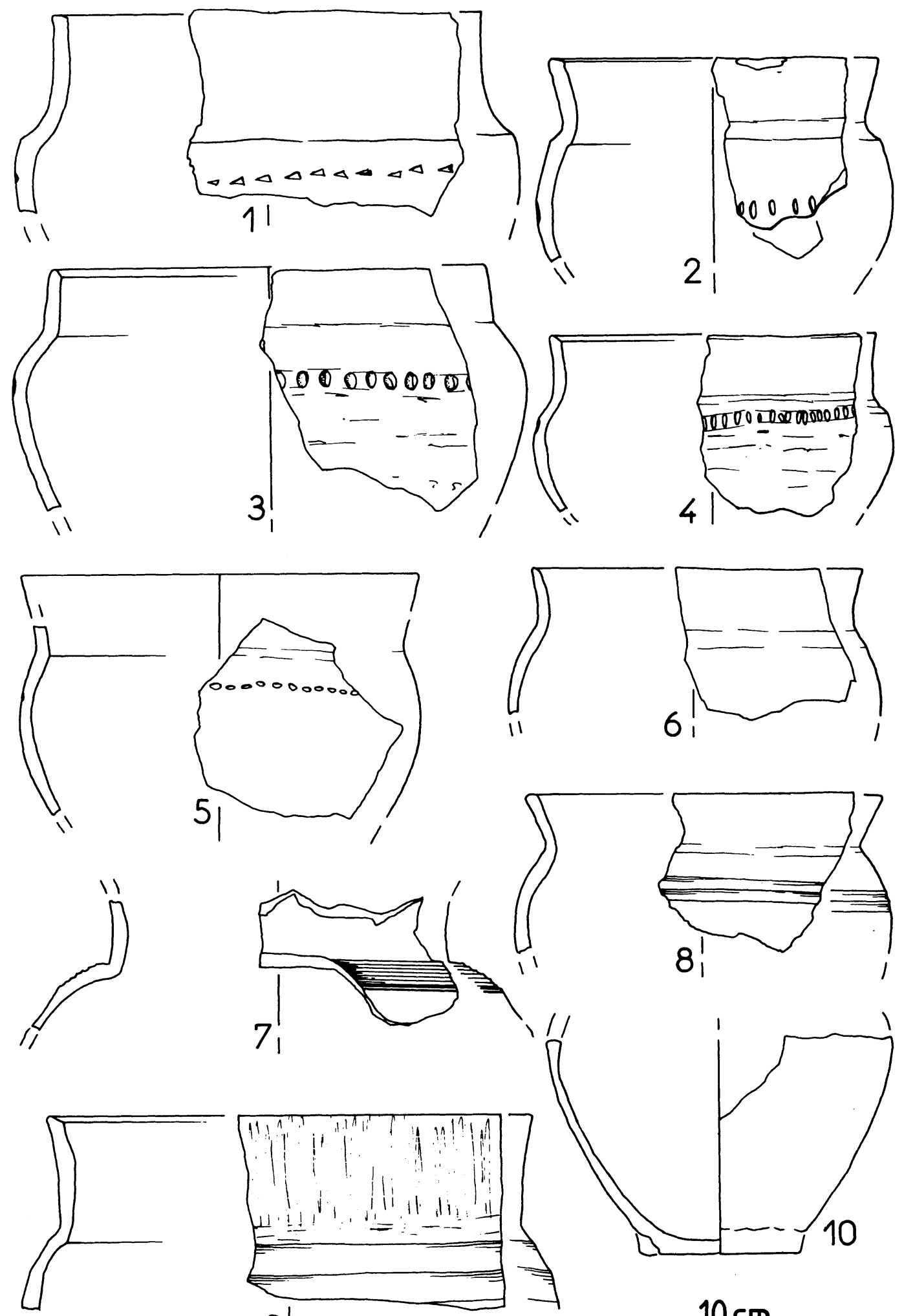

11
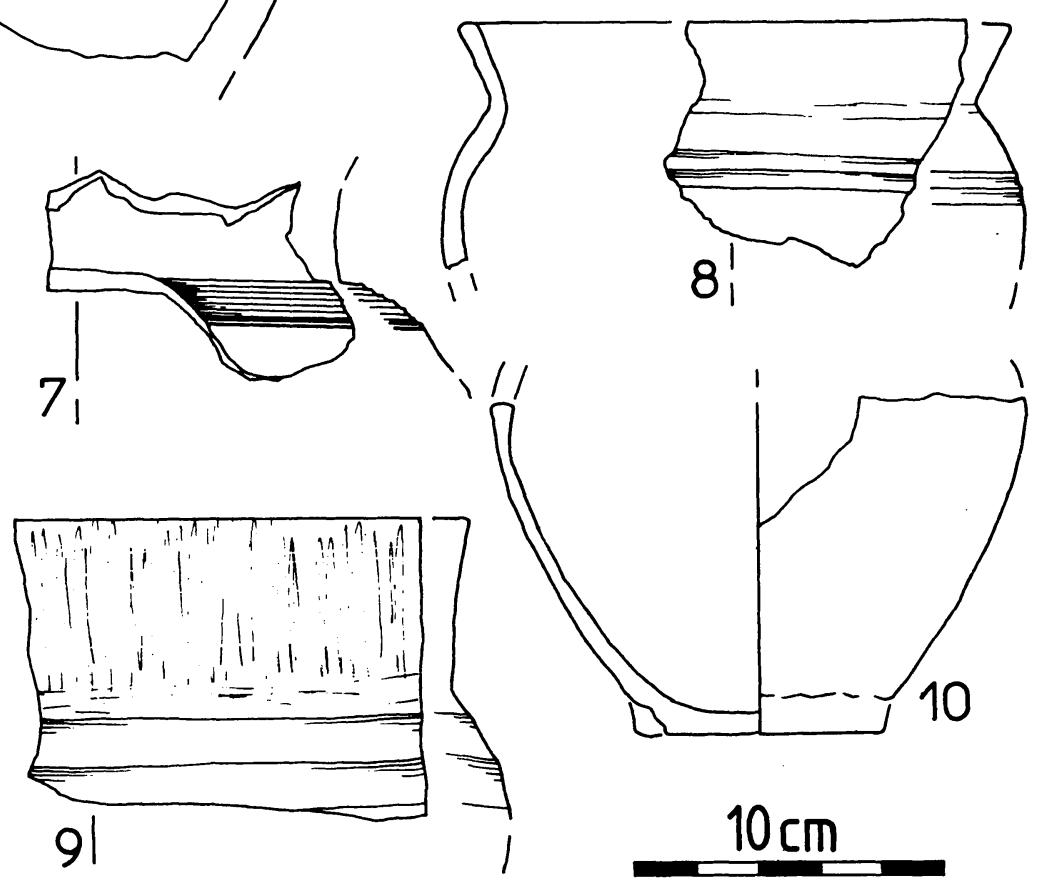

Fig. 18 - Fouilles 1946-48. Céramiques attribuables au Bronze final 3. 

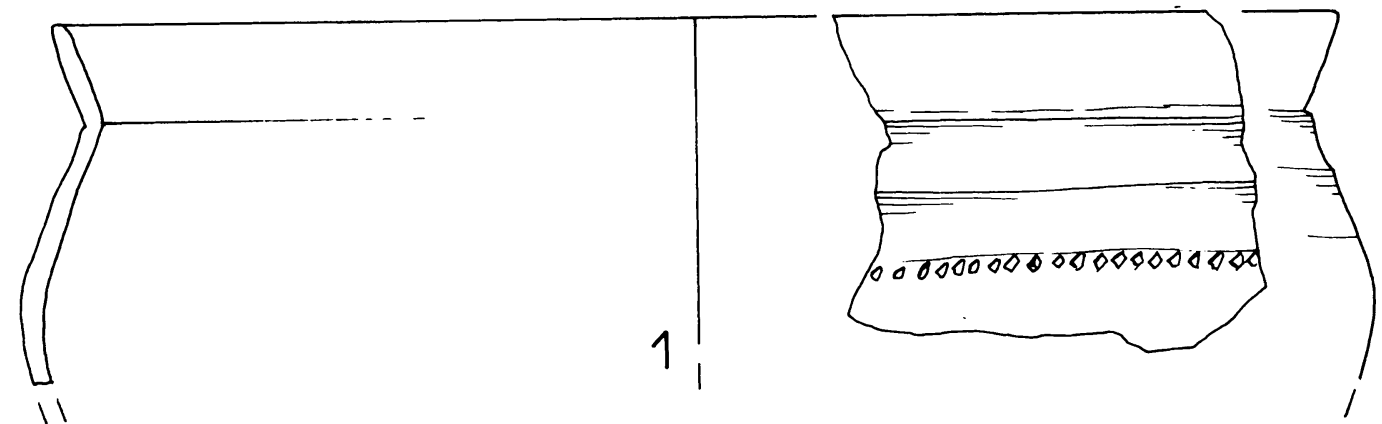

11

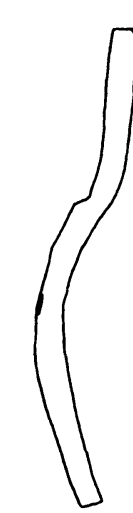

11
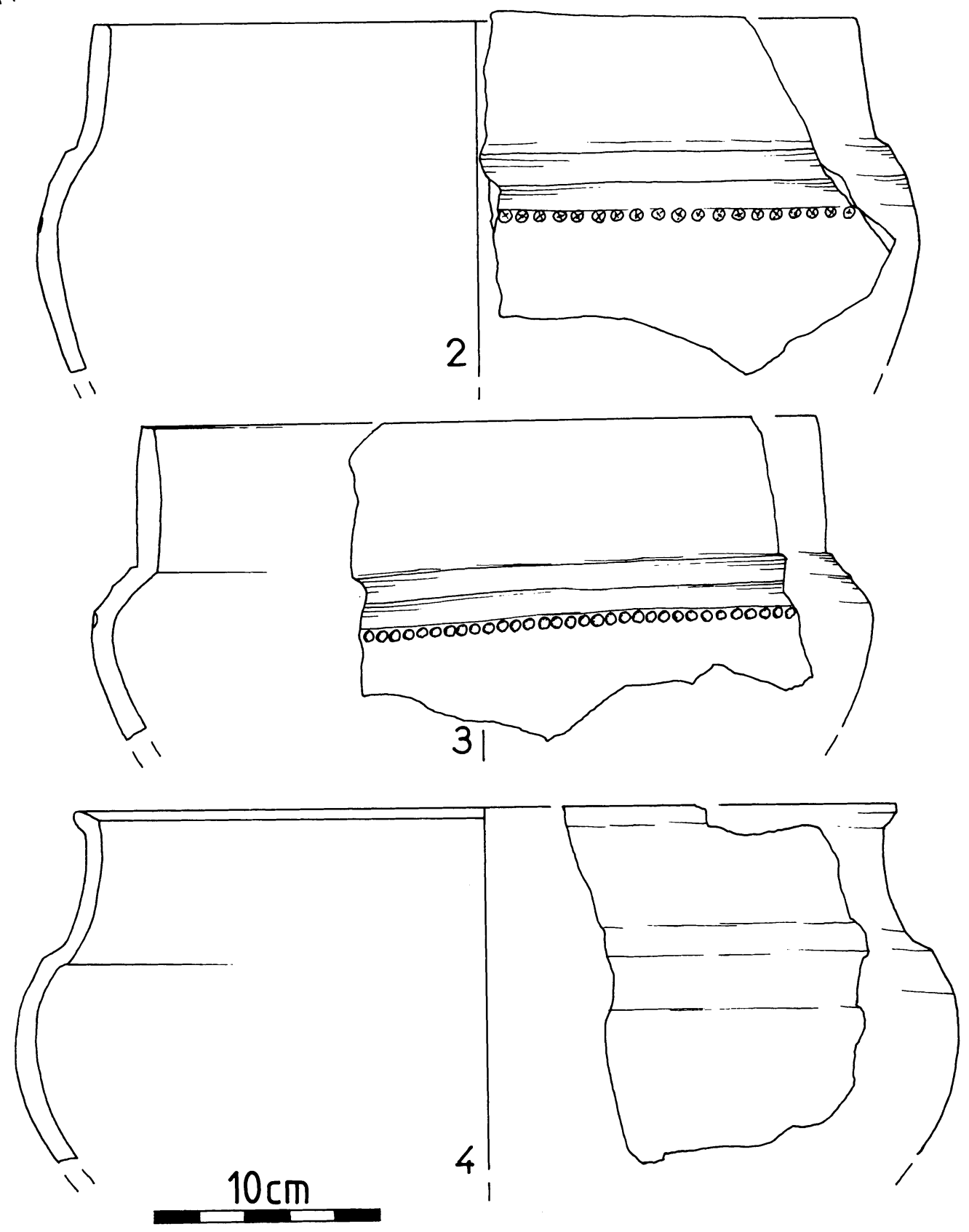

Fig. 19 - Fouilles 1946-48. Jarres attribuables au Bronze final 3 b. 

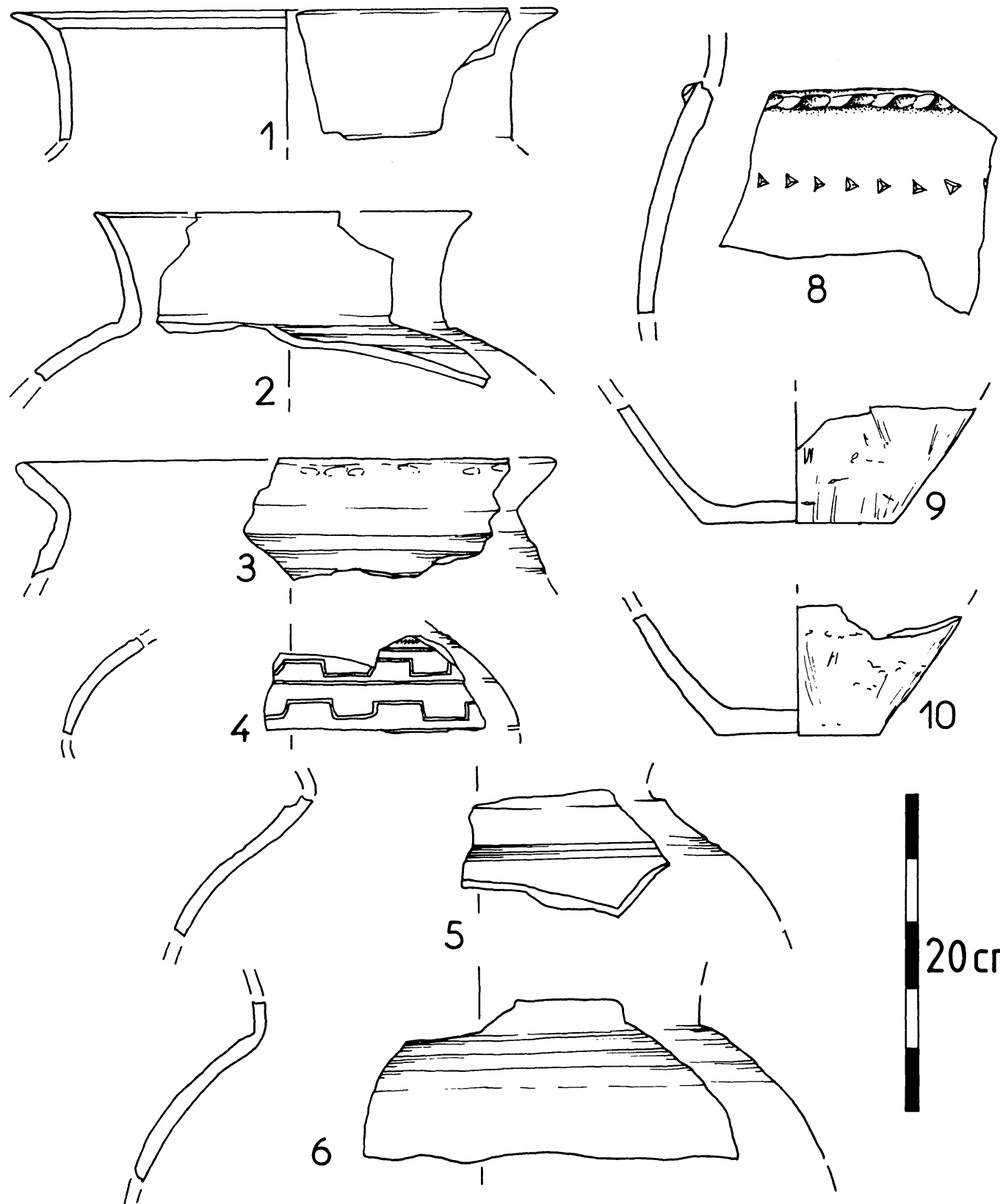

$20 \mathrm{~cm}$
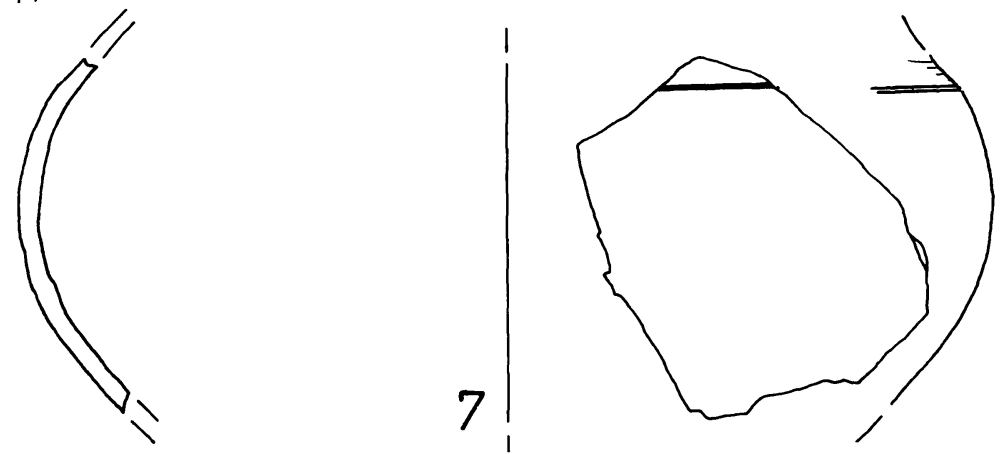

Fig. 20 - Fouilles 1946-48. Jarres attribuables au Bronze final 3 b. 

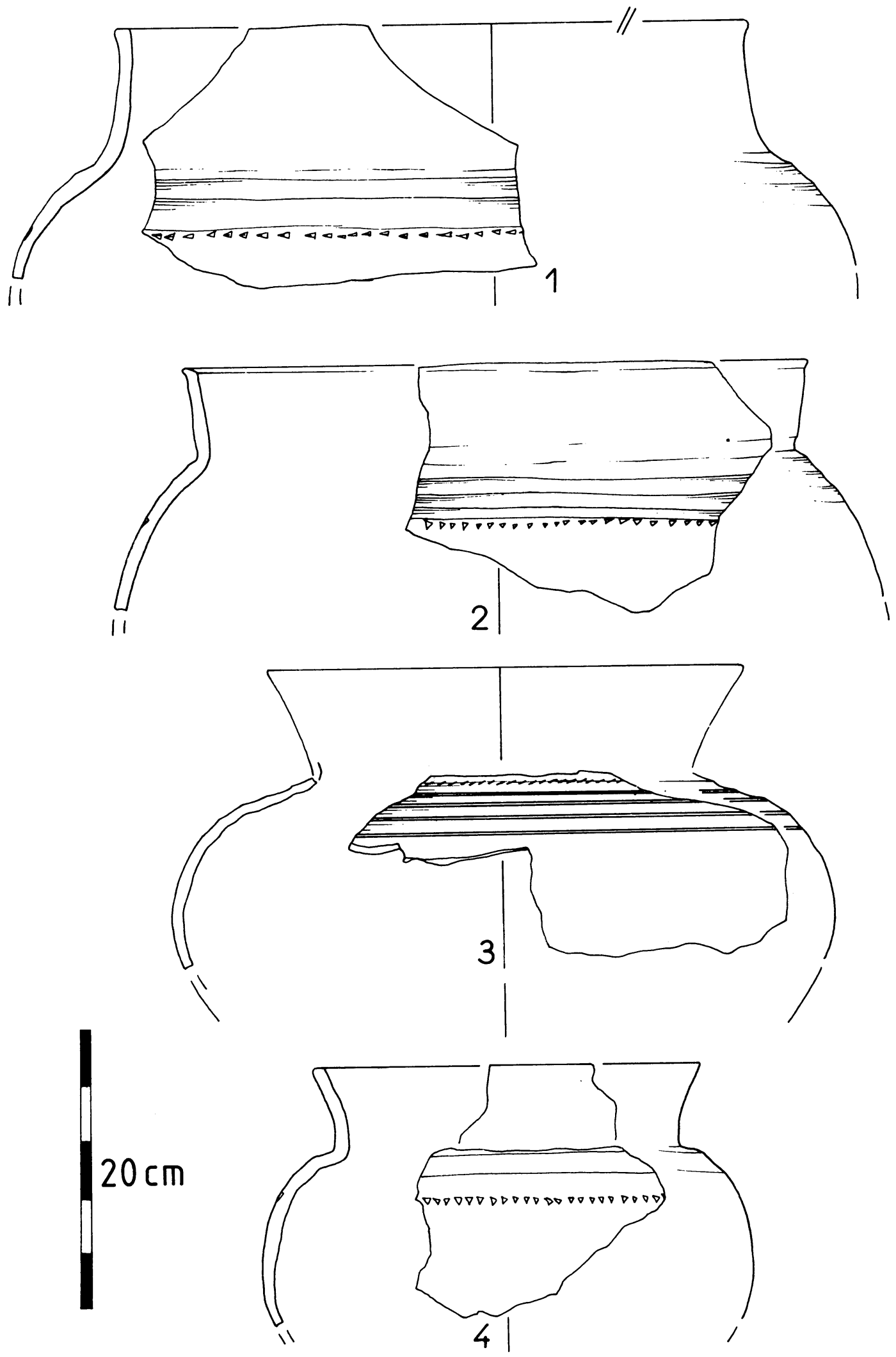

Fig. 21 - Fouilles 1946-48. Jarres attribuables au Bronze final 3 b. 

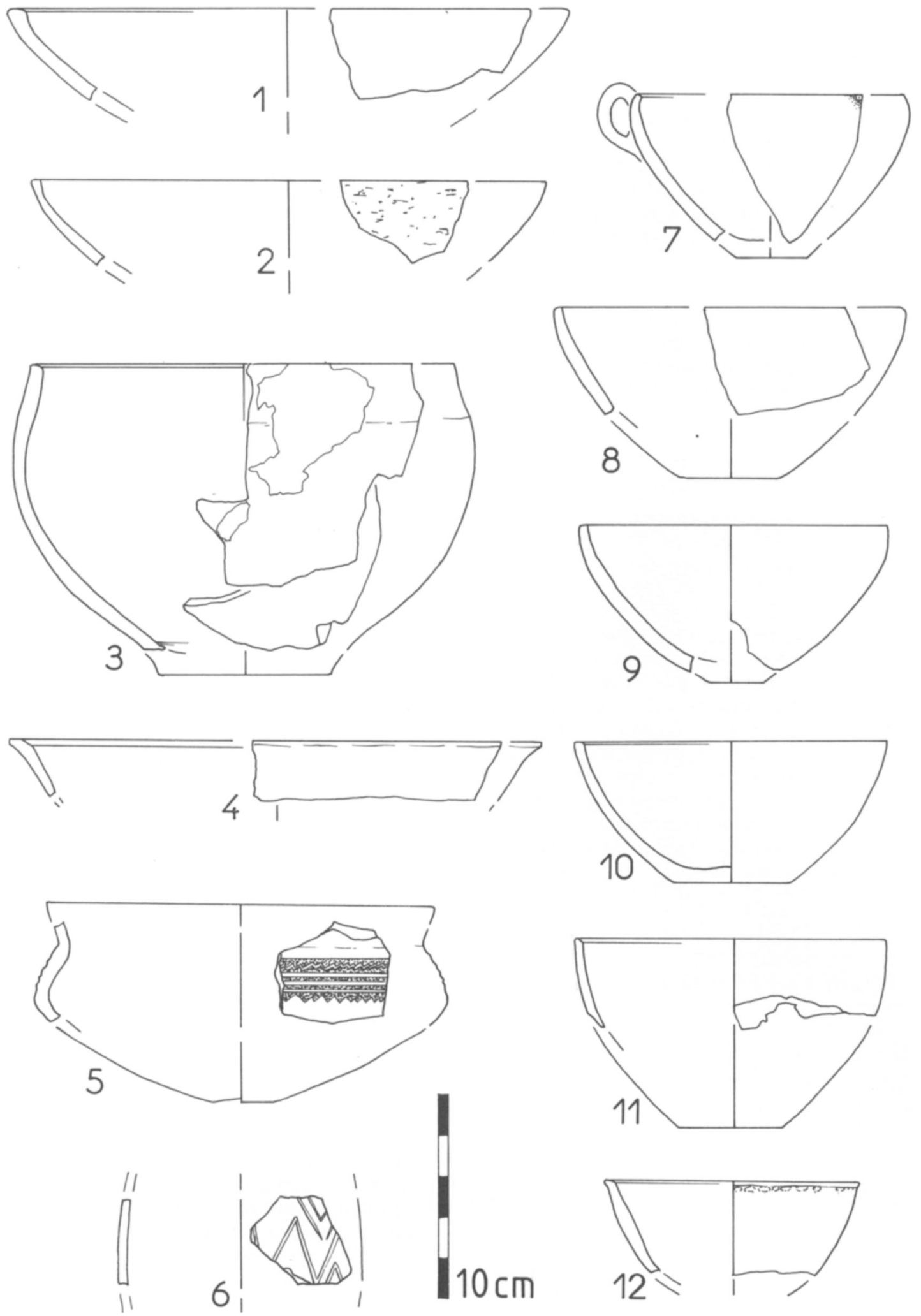

Fig. 22 - Fouilles 1946-48. Céramiques du Bronze final. 
VII. 8. - Les objets divers (fig. 23 et 24)

Outils en matière dure animale :

Un fragment de bois de cervidé poli pourrait être un mors s'il ne possédait une seule lumière rectangulaire (fig. 24/2). La possibilité d'un abandon en cours de façonnage s'oppose à la présence d'un objet identique dans la grotte $\mathrm{n}^{\circ} 1$ du Ranc-Pointu (Gilles, 1962, fig. 10/1). Une épingle à tête aplatie et une fusaïole (fig. 23/24 et 15) furent tirées d'os longs.

\section{Perles:}

Une perle en pate de verre bleu à filet blanc hélicoïdal et une perle annulaire en ambre balte (détermination C.W. Beck), attestées en milieu Bronze final.

\section{Mobilier en Bronze :}

Outre quatre anneaux coulés d'une seule pièce ou obtenu à partir d'un fil de bronze ( $\mathrm{n}^{\text {os }} 16$ à 19), furent extraites une applique à bélière, une alène bipointe et 3 épingles $\left(\mathrm{n}^{\mathrm{os}} 25\right.$ à $\left.27,30,31\right)$. Nous épiloguerons peu sur les épingles à tête cylindro-conique, biconique et en crosse qui, pratiquement absentes à l'ouest du Rhône et offrant un complément aux cartes de répartition, n'en demeurent pas moins difficiles à dater (Audouze et Courtois, 1970, pp. 19 et 21 ; Audouze et Gaucher, 1981). Toutefois l'abondance du mobilier du B.F. 2 dans la grotte des Cloches et l'absence d'association sûre à des contextes du Bronze final autres que des sites lacustres fouillés anciennement et des dépôts, pourraient orienter leur classement vers la première moitié du Bronze final (Mordant, Prampart et coll., 1976, pp. 160 à 162).

VIII. - BILAN ET PERSPECTIVES

Sur 196 fragments céramiques figurés, 166 ont reçu une attribution chronotypologique, soit $85 \%$. Leur répartition au sein des quatre groupes retenus s'effectue ainsi : 12 individus au B.F. 2 ancien (7\%), 51 au B.F. 2 b (31\%; et $38 \%$ au total pour le B.F. 2$), 29$ au B.F. 3 a $(17 \%)$ et 74 au B.F. 3 b (45\%). Une remarque s'impose : si la grotte des Cloches est un site important du Bronze final 3 a, c'est plus par la présence que par la quantité des industries. Ce sont en effet celles du B.F. 3 b et du B.F. 2 qui dominent.

Cette constatation rappelle un phénomène général observable dans le Bronze final médio et bas-rhodanien (Vital, 1984). Plusieurs causes peuvent être à l'origine de la rareté des sites du B.F. 3 a et de la fréquence de ceux le précédant et lui succédant :

- une variation de l'occupation des grottes par rapport à d'autres modes d'implantation, liée ou non à des activités particulières,

- une diminution de la pression démographique,

- un phénomène lié uniquement à la durée relative de chaque phase chronotypologique.

On s'aperçoit que notre jugement ne peut se fonder sans disposer d'outils d'estimation assez fins du facteur temps. La multiplication des dates $14 \mathrm{C}$ confrontées à l'échelle dendrochronologique nordalpine fournira prochainement, espérons-le, un début de réponse. Le fait géographique est aussi important et doit se mesurer dans sa globalité ; c'est le but de l'inventaire des sites de l'âge du Bronze de la moyenne vallée du Rhône en cours de réalisation.

Un des résultats de notre étude est une ébauche de périodisation au sein du Bronze final 2. La présence de types céramiques de tradition Bronze moyen, et d'autres qui appellent des rapprochements avec le Bronze final $2 \mathrm{~b}$, dans le Bronze final 2 ancien, posent deux problèmes :

- Existe-il une phase Bronze final 1 dans la moyenne vallée du Rhône ?

- Ce B.F. 2 ancien est-il synchrone du B.F. 2 ahorizon de Binningen, ou représente-t-il un stade moyen du B.F. 2 ?

J.-L. Roudil constatait en 1972 (p. 143) qu'aucune série céramique ne permettait de dégager un stade Bronze final 1. La situation n'a guère évolué depuis, le critère de perfection technique mis en avant pour les rares types pouvant constituer le B.F. 1, s'applicant aussi au B.F. 2. Les dépôts de bronze régionaux classiques du début du Bronze final se rangent en deux séries : les dépôts de Vers et de Vernaison, rapportés au B.F. 1, pourraient aussi bien se classer à la fin du Bronze moyen comme le suggèrent les travaux réalisés sur des documents similaires (Gard : Roudil, 1972, fig. 43 ; Rhône : Courtois, 1960 ; Osterwalder, 1971 ; Pirling, Wels-Weyrauch et Zürn, 1980, Beck, 1980) ; les dépôts de Reventin-Vaugris et Cabanelle, du début du Bronze final 2 (Isère : Courtois, 1960 ; Gard : Dedet et Bordreuil, 1982 ; Bocquet et Lebascle, 1976). Rien n'interdit donc de s'en tenir actuellement à un système à passage direct Bronze moyen - Bronze final 2 a. Les céramiques de l'ensemble stratigraphique E 5-E 2 caractérisent un stade antérieur au B.F. 2 b qui, avec une jarre à épaulement et une possible coupe à piédestal, représenterait plutôt une phase intermédiaire au sein du B.F. 2, l'aplatissement progressif des écuelles pouvant marquer le passage B.F. 2 a - B.F. 2 moyen. Le nombre de reliques du Bronze moyen dans un tel ensemble à rapide évolution morphologique rend encore plus improbable l'existence du B.F. 1. 

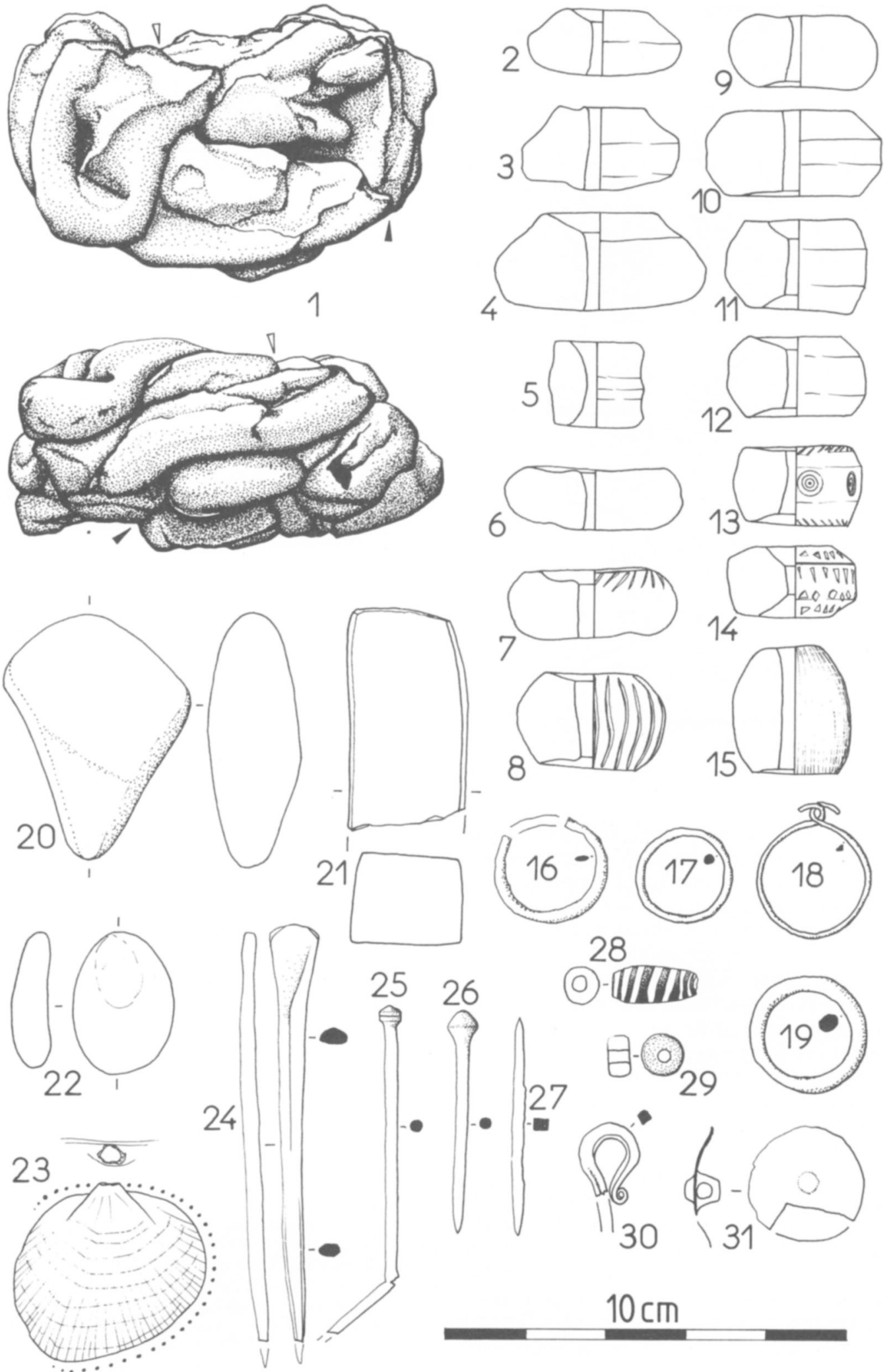

Fig. 23 - Fouilles 1946-48 et 1986. Colombins séchés (1), mobilier céramique (2 à 14), osseux (15 à 24), métallique (16 à 19, 25 à 27,30 et 31$)$, lithique (20 à 22,28 et 29). 


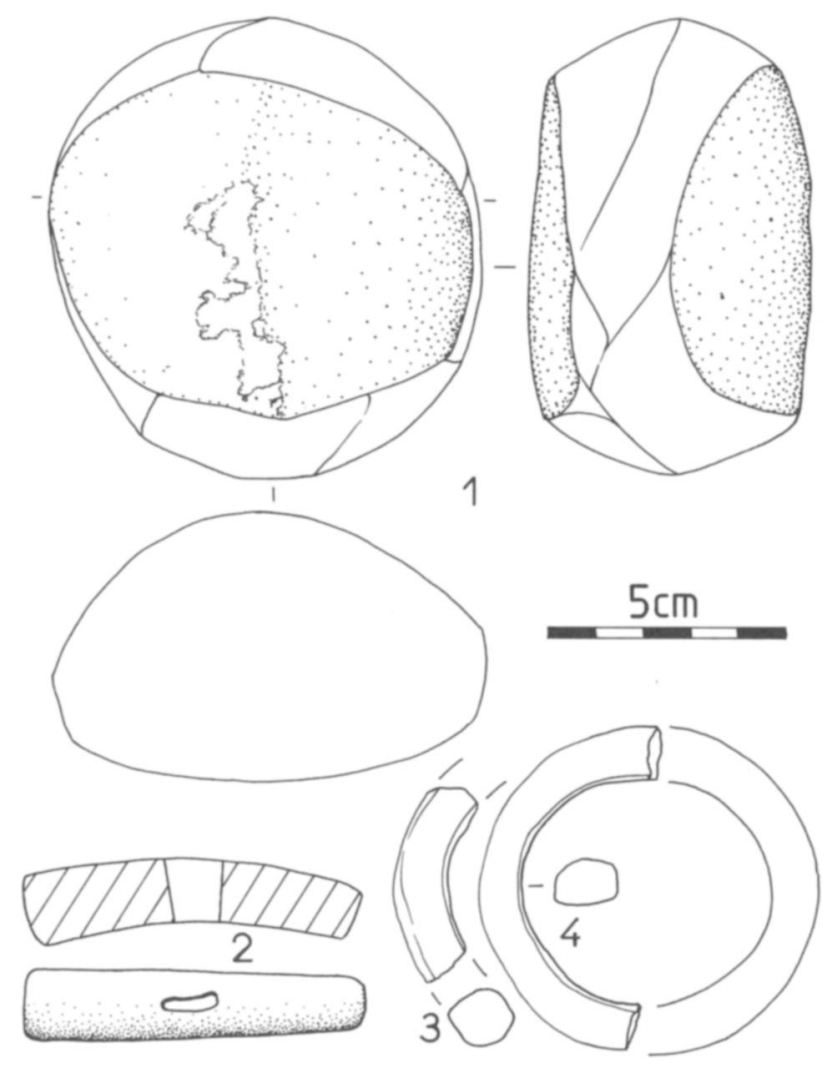

Fig. 24 - Fouilles 1946-48. Mobilier céramique (3 et 4), en bois de cerf (2) et lithique (1).

Dans le domaine des influences, ou des rapports géographiques, deux faits marquent la chronologie du Bronze final. Une diminution des rapports entretenus avec l'Italie du Nord depuis le Chalcolithique, et surtout le Bronze ancien, apparaît au Bronze final $2 \mathrm{~b}$; seuls quelques types céramiques et métalliques ne laissant aucun doute sur leur origine se rencontrent au Bronze final 3, comme si la raréfaction des produits allait de pair avec un renforcement de l'indication de l'origine géographique. La pression du groupe RSFO se fait sentir à la fin du B.F. 2 par l'introduction de plusieurs types de poteries caractéristiques, et par d'autres modèles qui n'en sont qu'une adaptation locale. Sommes-nous face à une tentative de modification du langage sémiotique, enrayée en partie seulement par une tendance locale à conserver la cannelure antérieure sur des formes approchantes ? Les bassins rhodanien et ligérien sont directement soumis aux influences RSFO, qui imprègnent peu le sud des Alpes : un gobelet à épaulement étroit figure sur la station de Viverone VI.1 (Fozzati et Giolitto, 1980, fig. 12) avec un décor spécifiquement alpin.

$\mathrm{Au}$ Bronze final $3 \mathrm{~b}$, les styles céramiques montrent quelques nuances entre le nord, le centre et le sud des Alpes occidentales ; la référence aux modes extérieures devient alors très diffuse au profit des écoles locales (3).

Joël VITAL,

Ampilhac, 43270 VERNASSAL et Institut du Quaternaire, Université de Bordeaux I, 33405 TALENCE CEDEX

(3) Au terme de cette étude, il nous est particulièrement agréable de remercier MM. André et Pierre Huchard, ainsi que René Gilles, des facilités offertes pour l'examen de leurs collections opéré dans des conditions on ne peut plus conviviales.

Abauzit P., Vannier B. et Thevenon R. (1968) - La sépulture $\mathrm{n}^{\circ} 5$ du champ d'urnes d'Orval (Cher). Bull. de la Soc. Préhist. Franç., t. LXV, 4, pp. 103-109.

ARNAL G.-B. (1972) - L'abri sous roche de Saint-Étienne-deGourgas. I. Étude préliminaire du matériel. Gallia Préhistoire, t. 15,2 , pp. 261-308.

Arnal J., Couchard J. et Lorblanchet M. (1969) - La grotte de Roucadour (Thémines, Lot). Archivo de Prehistoria Levantina, t. XII, pp. 55-91.

Audouze F. et Courtois J.-C. (1970) - Les épingles du Sud-Est de la France, Prähistorische Bronzefunde, XIII, 1, 74 p., 30 pl.

Audouze F. et Gaucher G. (1981) - Typologie des objets de l'âge du Bronze en France. Fascicule VI : épingles. Commission du bronze de la Soc. Préhist. Franç., 114 p.

BAILls H. (1979) - La nécropole protohistorique de Serralongue. Centre d'Ét. Préhist. Catalanes, 122 p.

BECK A. (1980) - Beitrage zur frühen und älteren Urnenfelderkultur im nordwestlichen Alpenvorland. Prähistoriche Bronzefunde, XX, 4, $165 \mathrm{p}$.

BLANCHET J.-C. (1984) - Les premiers métallurgistes en Picardie et dans le Nord de la France. Mém. de la Soc. Préhist. Franç., t. 17, 608 p., 251 fig.

Bocouet A. (1983) — Le scialet funéraire du Bois des VouillantsFontaine (Isère). Bull. de la Soc. Préhist. Franç., t. LX, pp. 847 857.

BocouET A. (1969) - L'Isère préhistorique et protohistorique. Gallia Préhistoire, t. XII, 1, pp. 121-258 ; 2, pp. 273-400.

BoCQuet A. (1976) - Les civilisations de l'âge du Bronze dans les Alpes, in : La Préhistoire Française, t. II Paris : Éd. du CNRS, pp. 483-494.

Bocquet A. et Couren J.-P. (1974) - Four trouvé sur la station du Crêt-de-Châtillon à Sévrier. Études Préhistoriques, 9, pp. 1-6.

Bocouet A. et Degueurce P. (1976) - Dépôt de vases de la grotte de la Rousse, Sainte-Marie-du-Mont, in : Livret-guide de l'excursion A9, Néolithique et âges des Métaux dans les Alpes françaises. IX ${ }^{\mathrm{e}}$ Congrès de l'UISPP, Nice, pp. 203-205.

Bocouet A. et Lebascle M.-C. (1976) - Les dépôts et la chronologie du Bronze final dans les Alpes du Nord, in: Colloque XXVI : Les âges des Métaux dans les Alpes, $\mathrm{IX}^{\mathrm{c}}$ Congrès de l'UISPP, Nice, pp. 35-71.

Bocouet A. et ReYmond J. (1976) - La grotte de la Balme (Isère), in : Livret-guide de l'excursion A9, Néolithique et âges des Métaux dans les Alpes françaises, IX ${ }^{\mathrm{e}}$ Congrès de l'UISPP, Nice, pp. 192-199. 
Boissinot P. (1983) - Un habitat de hauteur de l'âge du Bronze en Provence : Les Baou-Roux. L'Anthropologie, t. 87, 3, pp. 425-430.

BoNNAMOUR L. (1967) - Première campagne de fouilles à la grotte du Pontet, commune de La Burbanche (Ain). Bull. mens. de la Soc. Linnéenne de Lyon, 36 ${ }^{\mathrm{e}}$ année, 3, pp. 98-112.

Bonnamour L. (1969) - L'âge du Bronze au Musée de Chalonsur-Saône. Chalon-sur-Saône, 94 p., XXXIII pl.

BonNAmOUR L. (1972) - Première campagne de fouilles sur le site protohistorique des Rives à Saint-Germain-du-Plain (Saône-et-Loire). Comptes-rendus de l'Assoc. rég. de Préhist. et de Paléont. et des Amis du Muséum, Lyon, pp. 34-37.

BonNAmour L. (1973) - Saint-Germain-du-Plain (71). Habitat protohistorique des Rives. Comptes-rendus de l'Assoc. rég. de Préhist. et de Paléont. et des Amis du Muséum, Lyon, pp. 35-40.

Bontillot J., Mordant C. et D. et Paris J. (1975) - La nécropole des Gobillons à Châtenay-sur-Seine (Seine-etMarne). Bull. de la Soc. Préhist. franç., t. 72, pp. 416-456.

Bornatico J., Dumont A. et Stabile H. (1957) - La grotte du Gardon, Ambérieu-en-Bugey. Cahiers Rhodaniens, IV, pp. 2635.

Borrello M.-A. et Gross E. (1986) - Nouvelles approches dans l'étude de la céramique du Bronze final dans la région des lacs du pied du Jura, in : la dynamique du Bronze final en Europe : le groupe Rhin-Suisse-France orientale et la notion de civilisation des Champs-d'Urnes, Colloque international de Nemours, prétirage sous la direction de $\mathrm{P}$. Brun et $\mathrm{C}$. Mordant.

Boudou J., Arnal J. et Soutou A. (1961) - La céramique incisée à méandres symétriques du Pont du Diable (Aniane, Hérault). Gallia, t. XI, 1, pp. 201-218.

Bousquet N., Gourdiole R. et Guiraud R. (1966) - La grotte de Labeil, près de Lauroux (Hérault). Cahiers Ligures de Préhist. et d'Archéol., t. 15, pp. 79-166.

Bouthier A., Daugas J.-P. et Vital J. - La nécropole des Vicreuses à Pougues-les-Eaux. Rétrospective et bilan. $A$ parâेtre.

BRochiER J.-E. (1983) - Bergeries et feux de bois néolithique dans le Midi de la France. Quartär, bd. 33-34, pp. 181-193.

BRÛN P. (1984) - La notion de "Culture des Champs d'Urnes ». Étude critique dans le Bassin parisien. Thèse de $3^{\mathrm{e}}$ cycle, Univ. de Paris 1, 204 p., 81 pl.

Cauvin J. et Nikitine S. (1960) - La grotte de Chazelles, commune de Saint-André-de-Cruzières, Ardèche. Sondage 1958, Cahiers Ligures de Préhist. et d'Archéol., t. 9, pp. 229-236.

CHEVILlot C. (1981) - La civilisation de la fin de l'âge du Bronze en Périgord. Périgueux : Éd. Médiapress, 219 p., 200 pl.

Chiron L. (1896) - La Préhistoire dans le Vivarais. Privas: Imprimerie centrale de l'Ardèche, $57 \mathrm{p}$.

Clottes J. et Costantini G. (1976) - La civilisation de l'âge du Bronze dans les Causses : in : La Préhistoire Française, t. II. Paris : Éd. du CNRS, pp. 470-482.

Clottes J. et Lorblanchet M. (1972) - La grotte du Noyer (Esclauzels, Lot). Congrès Préhist. de France, XIX $X^{e}$ session, Auvergne, (1969), pp. 145-164.

COLLECTIF 1986 - Documentation cartographique annexe, in : La dynamique du Bronze final en Europe : le groupe Rhin-SuisseFrance orientale et la notion de civilisation des Champs-d'Urnes. Colloque international de Nemours, prétirage sous la direction de P. Brun et C. Mordant.

COMBIER J. (1962) - Fouille de sauvetage d'un tertre funéraire de l'âge du Bronze à Maisod (Jura). Rev. Archéol. de l'Est, t. XIII, 3-4, pp. 192-216.

COMBIER J. (1963) - Informations archéologiques. Circonscription de Grenoble. Gallia Préhistoire, t. VI, pp. 275-235.

COMBIER J. (1967) - Le Paléolithique de l'Ardèche dans son cadre paléoclimatique. Mém. $\mathrm{n}^{\circ} 4$, Inst. de Préhis. de Bordeaux, 462 p., 171 fig.
CORDIER G. (1961) - Une nécropole de la civilisation des Champs d'Urnes à Chissay-en-Touraine (Loir-et-Cher). L'Anthropologie, t. 65 , pp. $184-186$.

Cordier G. (1977) - Les Champs d'Urnes en Orléanais. Rev. Archéol. du Loiret, $\mathrm{n}^{\circ}$ 3, pp. 9-39.

CORNET J.-M. (1963) - La grotte de Baume-Sourde à Francillon (Drôme) du Néolithique au Bronze final. Étude stratigraphique, Ogam, t. XV, pp. 17-39.

Courtois J.-C. (1960) - Les dépôts de fondeur de Vernaison (Rhône) et de la Poype-Vaugris (Isère). Cahiers Rhodaniens, VII, pp. 3-24.

Daugas J.-P. et Vital J. (1986). Le groupe Rhin-Suisse dans le Massif Central français, in : La dynamique du Bronze final en Europe : Le groupe Rhin-Suisse-France orientale et la notion de civilisation des Champs d'urnes. Colloque international de Nemours, prétirage sous la direction de P. Brun et C. Mordant.

Daumas J.-C. et LaudeT R. (1981-82) - L'habitat du Bronze final des Gandus à Saint-Ferréol-Trente-Pas (Drôme). Études Préhistoriques, $\mathrm{n}^{\circ} 16,32$ p., 37 fig.

DEBARD E. (1976) - Les remplissages de grottes et abris sous roche en Ardèche et dans le Velay oriental, in : La Préhistoire française, t. 1. I. Paris : Éd. du CNRS, pp. 275-278.

Dedet B. et Bordreull M. (1982) - Le dépôt de fondeur du Bronze final II de Cabanelle à Castelnau-Valence (Gard). Gallia-Préhistoire, t. 25, 1, pp. 187-210.

DEDET B. et PY M. (1985) - L'occupation des rivages de l'étang de Mauguio (Hérault) au Bronze final et au Premier âge du Fer, $T$. III, synthèses et annexes. Cahier $\mathrm{n}^{\circ} 13$ de l'ARALO, Caveirac, $139 \mathrm{p}$.

Dedet B., Py M. et SAVAy-Guerraz H. (1985) - L'occupation des rivages de l'étang de Mauguio (Hérault) au Bronze final et au Premier âge du Fer. T. II, sondages et sauvetages programmés (1976-1979). Cahier no 12 de l'ARALO, Caveirac, 144 p.

DEHN W. (1941) - Kreuznach. Kataloge West-und Süddeutscher Altertumssammlungen, 2 vol. Berlin : Reichsverlagsamt.

De Marinis R. (1980) - Appunti sul Bronzo Medio, Tardo e Finale in Lombardia (1600-900 a. C.), in : Atti del $1^{\circ}$ Convegno archeologico regionale, Milano, pp. 173-204.

Duday H. et Guilaine J. (1975) - Les rites funéraires en Languedoc et Roussillon du Néolithique au Premier âge du Fer. Cahiers Ligures de Préhist. et d'Archéol., t. 24, pp. 140-151.

EGGERT M. (1976) - Die Urnenfelderkultur in Rheinhessen. Geschichtliche Landeskunde, 13. Wiesbaden : Éd. Steiner, 347 p.

Fozzati L. et Giolitto G. (1980) - Lago de Viverone. Preist. Alpina, vol. 16, pp. 157-159.

Gallay A. (1970) - La poterie en pays Sarakolé (Mali, Afrique occidentale). Étude de technologie traditionnelle. Journ. de la Soc. des Africanistes, t. XL, 1, pp. 7-84.

Gallay A. (1981) - Le Sarnyere Dogon. Archéologie d'un isolat. Recherches sur les grandes civilisations, mém. $n^{\circ} 4$, Paris : Éd. ADPF, 242 p.

GARMY P. (1981) - Les habitats de l'âge du Bronze final $3 b$ de Vaunage (Gard) dans leur contexte en Languedoc oriental. Thèse de $3^{\mathrm{e}}$ cycle, EHESS, Paris, 2 vol., 129 p. et fig.

GAsco J. (1983) - L'âge du Bronze final à la Cauna de Martrou, ou grotte de Villemaury (Mas-de-Cours, Aude). L'Anthropologie, t. 87, 1, pp. 99-112.

GAUCher G. et Robert Y. (1967) - Les dépôts de bronze de Cannes-Écluse (Seine-et-Marne). Gallia Préhistoire, t. X, 1, pp. 169-223.

GiLles R. (1962) — Un dépôt céramique funéraire dans une grotte du Ranc-Pointu à Saint-Martin-d'Ardèche (Ardèche). Cahiers Rhodaniens, t. IX, pp. 52-63.

GiLles R. (1984) - L'âge du Bronze dans la basse vallée de l'Ardèche. Ardèche Archéologie, n 1, pp. 19-21. 
Gomez J. (1971) - Céramique de l'âge du Bronze découverte à Civaux (Vienne). Bull. de la Soc. Hist et Archéol. de la Charente, pp. 277-285.

GouRVEST J. (1959) - Les tumulus du quartier de Beauregard à Saint-Remèze (Ardèche). Ogam, t. XI, pp. 243-256.

GRIMMER B. (1986) - Die Urnenferderkultur im südöstlichen oberrheingraben. Thèse, Freiburg-im-Brisgau, 163 p., 110 taf.

Gros A.-C. et coll. (1969) - L'aven d'Espatty à Grospierres (Ardèche). Nouveau site protohistorique du Bas-Vivarais. Grou-Peïro, ${ }^{\circ} 2$, pp. 19-24.

Guilaine J. (1972) - L'âge du Bronze en Languedoc occidental, Roussillon, Ariège. Mém. de la Soc. Préhist. Franç., t. 9, Paris : Klincksieck, $460 \mathrm{p}$.

Guilaine J. et Roudil J.-L. (1976) - Les civilisations de l'âge du Bronze en Languedoc, in : La Préhistoire Française, t. II. Paris : Éd. du CNRS, pp. 459-469.

GUILLIEN Y. (1968) - Informations archéologiques. Circonscription Poitou-Charentes. Gallia Préhistoire, t. XI, 2, pp. 311-335.

HATT J.-J. (1952) - Découverte à achenheim d'un four de potier de la période des Champs d'Urnes. Cahiers d'Archéol. et d'Hist. d'Alsace, 43, $\mathrm{n}^{\circ} 132$, pp. 49-53.

Huchard A., P. et LouIS M. (1950) - La grotte des Cloches, commune de Saint-Martin-d'Ardèche. Rev. d'Et. Ligures, t. XVI, 1-3, pp. 133-139.

JACQUINOT H. et Usquin P. (1878) - Notice sur des sépultures antiques découvertes auprès de Pougues-les-Eaux (Nièvre). Bull. de la Soc. Nivernaise des Sciences, Lettres et Arts, t. VIII, pp. $418-438$.

JEHL M. et BonNet C. (1968) - Un potier de l'époque des Champs d'Urnes au sommet du Hohlandsberg. Cah. Alsacien d'Archéol. d'Art et d'Hist., 12, pp. 5-30.

KIMmig W. (1951 à 1954) — Où en est l'étude de la civilisation des Champs d'Urnes principalement dans l'Est. Rev. Archéol. de l'Est, t. II, 2, pp. 65-81 ; t. III, 1, pp. 7-19 ; t. III, 3, pp. 137172 ; t. V, 1, pp. 7-28; t. V, 3, pp. 209-233.

Kolling A. (1968) - Späte Bronzezeit an Saar und Mosel. Saarbrücker Beiträge zur Altertumskunde, 6, Bonn : Éd. Habelt, 2 vol., 230 p. et pl.

LACROIX B. (1957) - La nécropole protohistorique de la Colombine. Cah. d'Archéol. et d'Hist. et de l'Art, $\mathrm{n}^{\circ}$ 2. Soc. des fouilles archéol. de l'Yonne, $167 \mathrm{p}$.

LAGRAND C. (1968) - Recherches sur le Bronze final en Provence méridionale. Thèse de l'Univ. d'Aix-en-Provence, 2 vol., $394 \mathrm{p}$. et $88 \mathrm{pl}$.

LAGRAND C. (1976) - Les civilisations de l'âge du Bronze en Provence, in : La Préhistoire Française, t. II, Paris : Éd. du CNRS, pp. 452-458.

LAURIOL J. (1963) - Trois nouveaux gisements du Bronze final à Bize. Cahiers Ligures de Préhist. et d'Archéol., t. 12, pp. 131141.

Laville H., Nikitine S. et Thibault C. (1969) - Étude géologique du remplissage de la grotte de Chazelles (commune de Saint-André-de-Cruzières, Ardèche). Quaternaria, t. II, pp. 161-188.

LAVOINNE M.-L. et PARISI S. (1981) - Atlas préhistorique du Midi méditerranéen. Feuille d'Orange. Paris : Éd. du CNRS, 273 p., 33 fig.

Leroi-Gourhan A. (1971) - L'Homme et la matière. Paris : Albin-Michel (1 ${ }^{\text {re } e ́ d ., ~ 1943), ~} 348$ p., 577 fig.

L'HelgouACH J. (1979) - Informations archéologiques. Pays de la Loire. Gallia Préhistoire, t. 22, 2, pp. 569-572.

LORBLANCHET M. et GENOT L. (1972) - Quatre années de recherches préhistoriques dans le Haut-Quercy (1967-1971). Bull. de la Soc. des Études Litt. Scient. et Art. du Lot, t. XCIII, pp. 71-153.

Louis M., TAfFanel O. et J. (1955) - Le Premier âge du Fer languedocien. 1. Les habitats. Inst. Int. d'Études Ligures, Bordighera-Montpellier, $208 \mathrm{p}$.
Millotte J.-P. (1959) - Deux vases du Bronze final au musée Rolin à Autun. Rev. Archéol. de l'Est, t. X, 3, pp. 192-196.

Mordant C. (1975) — La nécropole de la Colombine à Champlay (Yonne) d'après les fouilles et la collection de P. Jacquelin. Rev. Archéol. de l'Est, t. XXVI, 2, pp. 423-441.

MoRdant C. et D. (1970) - Le site protohistorique des Goursaux-Lions à Marolles-sur-Seine (Seine-et-Marne). Mém. de la Soc. Préhist. Franç., t. 8, Paris : Klincksieck, 139 p.

Mordant C., D., Prampart J.-Y. et coll. (1976) - Le dépôt de bronze de Villethierry (Yonne). IX ${ }^{\mathrm{e}}$ suppl. à Gallia Préhistoire, Paris : Éd. du CNRS, 237 p., 190 fig.

MORDANT C., D. et coll. (1977) — Le Bois des Refuges à Misy-surYonne (Seine-et-Marne). Bull. de la Soc. Préhist. Franç., t. 74, pp. 420-462.

MÜLLER-KARPE H. (1959) - Beiträge zur Chronologie der Urnenfelderzeit nördlich und südlich der Alpen. Römisch-Germanische Forschungen, 22, Berlin : Éd. W. de Gruyter et Co., 334 p. et $221 \mathrm{pl}$.

Negroni Catacchio N., Nava M.-L. et Chiaravale M., (1979) - Il Bronzo finale nell'Italia nord-occidentale, in : Atti della XXI Riunione Scientifica (1977). Firenze : Istituto Italiano di Preistoria e Protostoria, pp. 47-116.

Nicolardot J.-P. (1968) - Protohistoire de la montagne beaunoise. Thèse de $3^{\mathrm{e}}$ cycle, Dijon, 4 vol., $496 \mathrm{p}$.

Oberkampf M. (1984) - L'âge du Bronze en Haute-Savoie. Mém. de Maîtrise. Fac. des Lettres et des Sciences Humaines, Besançon, 156 p., 42 fig.

OSTERWALDER C. (1971) - Die mittlere Bronzezeit im Schweizerischen Mitteland und Jura. Monographien zur Ur- and Frühgeschichte der Schweiz, 19, Bâle : Soc. Suisse de Préhist. et d'Archéol., 97 p., 61 Pl.

Petrequin P. (1966) - L'âge du Bronze final dans la région de Montbéliard. Rev. Archéol. de l'Est, t. XVII, 1-2, pp. 28-46.

Petrequin P. et Urlacher J.-P. (1967) - La grotte de Vaux-lesPrés (Doubs). Bull. de la Soc. Préhist. Franç., t. LXIV, pp. 761772 .

Petrequin P., Urlacher J.-P. et Vuaillat D. (1969) - Habitat et Sépultures de l'âge du Bronze à Dampierre-sur-le-Doubs (Doubs). Gallia Préhistoire, t. XII, 1, pp. 1-35.

Petrequin P. et coll. (1979) - Le gisement néolithique et protohistorique de Besançon-Saint-Paul (Doubs). Ann. Litt. de l'Univ. de Besançon, vol. 228, arch. 30, 232 p.

Petrequin P., Chaix L., Petrequin A.-M. et Piningre J.-F. (1985) - La grotte des Planches-près-Arbois (Jura). ProtoCortaillod et âge du Bronze final. Paris : Éd. de la MSH, 273 p., 216 fig.

Piccoli A. (1982) - Saggio esplorativo nell'insediamento perilacustre di castellaro Lagusello (MN), in : Studi in onore di Ferrante Rittatore Vonwiller. Como : Soc. Arch. Comense, Parte prima : Preistoria e Protostoria, vol. II, pp. 443-486.

Pirling R., Wels-Weyrauch U. et Zürn H. (1980) - Die mittlere Bronzezeit auf der Schwäbischen Alb. Prähistorische Bronzefunde, XX, 3, 105 p., $69 \mathrm{pl}$.

Ponsich P. et De Pous A. (1951) — Le Champ d'Urnes de Millas. Études roussillonnaises, t. 1, pp. 1-94.

Pons I BRUn E. (1984) - L'Empordà de l'Edat del Bronze à l'Edat del ferro 1100-1600 a.C. Girona : Centre d'investigacions arquelògiques de Girona, 366 p., 66 fig.

PADES H. et coll. (1985) - L'occupation des rivages de l'étang de Mauguio (Hérault) au Bronze final et au Premier âge du Fer. T. 1., les recherches du Groupe Archéologique Painlevé (19691976). Cahier $\mathrm{n}^{\circ} 11$ de l'ARALO, $135 \mathrm{p}$.

RATEL R. (1961) - Le tumulus de la Rente-Neuve à Couchey (Côte-d'Or). Rev. Archéol. de l'Est, t. XII, 3, pp. 177-192.

RATEL R. (1970) - Le tumulus à incinération de Chaume-lesBaigneux (Côte-d'Or). Rev. Archéol. de l'Est, t. XXI, 1-2, pp. 181-199. 
RichARD A. (1980) - Typologie des céramiques Bronze final de la grotte de la Roche à Courchapon. Mém. de Maîtrise, Fac. des Lettres de Besançon, 2 vol., 131 p., et pl.

RIEgger H. - La poterie primitive. Paris : Dessain et Tolra, $120 \mathrm{p}$.

Roudil J.-L. (1972) - L'âge du Bronze en Languedoc oriental. Mém. de la Soc. Préhist. Franç., t. 10. Paris : Klincksieck, $302 \mathrm{p}$.

Roudil J.-L. et SAUMAde H. (1968) — La grotte de Peyroche II à Auriolles (Ardèche). Gallia Préhistoire, t. XI, 1, p. 147-203.

Roudil J.-L. et Soulier M. (1976) - La grotte du Hasard à Tharaux (Gard). I. La sale IG et le commerce de l'ambre en Languedoc oriental. Gallia Préhistoire, t. 19, 1, pp. 173-200.

Roussot-LARRoQue J. (1986) - Le « Rhin-Suisse-France orientale " et l'Aquitaine, in : La dynamique du Bronze final en Europe : Le groupe Rhin-Suisse-France orientale et la notion de civilisation des Champs d'Urnes. Colloque international de Nemours. Prétirage sous la direction de P. Brun et C. Mordant.

Ruoff U. (1974) - Zur Frage der Kontinuität zwischen Bronzeund Eisenzeit der Schweiz. Bâle : Soc. Suisse de Préhist. et d'Archéol., 137 p., 54 pl.

RyChNER V. (1974) - L'âge du Bronze final à Auvernier NE. Notes préliminaires sur le matériel des fouilles de 1969 à 1973. Ann. de la Soc. Suisse de Préhist. et d'Archéol., vol. 58, pp. 4365.

RYCHNER V. et coll. (1986) - Dendrochronologie du groupe Rhin-Suisse dans la région neuchâteloise. In : La dynamique du Bronze final en Europe : le groupe Rhin-Suisse-France orientale et la notion de civilisation des Champs d'Urnes, Colloque international de Nemours. Prétirage sous la direction de P. Brun et C. Mordant.

SAlZANI L. (1976) - La stazione preistorica di Cop Roman. Preist. Alpina, vol. 12, pp. 155-162.

Salzani L. (1978) - La necropoli dell'età del Bronzo a Fontanella Mantovana. Preist. Alpina, vol. 14, pp. 115-162.

SANDARS N.-K. (1957) - Bronze Age cultures in France. Cambridge University Press, $412 \mathrm{p}$.

Saumade H. (1960) - Découverte de deux vases du Premier âge du Fer dans le Bas-Vivarais. Cahiers Rhodaniens, VII, pp. 123124.

Schmitt G. (1966) - Une fosse de l'âge du Bronze final à Achenheim-Oberschaeffolsheim. Cah. Alsacien d'Archéol. d'Art et d'Hist., 10, pp. 35-42.

Temple P. (1936) - La Préhistoire du département de l'Aveyron. Nîmes : Larguier, 159 p.
UNZ C. (1973) - Die spätbronzezeitliche Keramik in Südwestdeutschland, in der Schweiz und in Ostfrankreich. Praehistorische Zeitschrift, vol. 48, 1, pp. 1-124.

VAGINAY M. et coll. (1982) - L'âge du Bronze dans la Loire à la lumière des fouilles récentes. Cahier Archéol. de la Loire, $\mathrm{n}^{\circ} 2$, pp. 17-37.

VANNIER B. et ABAuZiT P. (1965) - Découverte d'une nécropole de la civilisation des Champs d'Urnes à Orval, près SaintAmand-Montrond (Cher). Rev. Archéol. du Centre, t. IV, 2, pp. 124-140.

VICHERD G. (1986) - Château-Gaillard (Ain). Gisement protohistorique de La Laya. Rapport de sauvetage programmé, Direction des Antiquités de Rhône-Alpes, 99 p.

Vicherd G., BAUdrand M.-N. et De KliJN H. (1981) Béligneux (Ain). Fouille de sauvetage sur le site protohistorique et gallo-romain du " camp de Chanes » ou " combe Héret ". Rapport de fouille, DAH de Rhône-Alpes.

Vital J. (1984) - Sites et industries de l'âge du Bronze dans le Défilé de Donzère (Drôme). Thèse de $3^{\mathrm{e}}$ cycle, Univ. de Bordeaux 1, no 1957, 386 p., 166 pl.

ViTAL J. (1986 a) - Une fosse du Bronze final dans la grotte de la Baume-des-Anges à Donère (Drôme). Bull. de la Soc. Préhist. Franç., t. 83, 1, pp. 17-27.

VITAL J. (1986 b) - Le groupe Rhin-Suisse-France orientale dans la moyenne vallée du Rhône, in : La dynamique du Bronze final en Europe : le groupe Rhin-Suisse-France orientale et la notion de civilisation des Champs d'Urnes. Colloque international de Nemours. Prétirage sous la direction de P. Brun et C. Mordant.

VITAL J. et coll. (1986 a) - Le site protohistorique et gallo-romain du Pré de la Cour à Montagnieu (Ain). Rapport de fouille de sauvetage. Directions des Antiquités de Rhône-Alpes, 236 p. et 209 fig.

VITAL J. et coll. (1986 b) - Le site littoral protohistorique des Barlières à Serrières-de-Briord (Ain). Rapport de fouille programmée. DAP de Rhône-Alpes.

VITAL J. et VORUZ J.-L. (1984) - L'habitat protohistorique de Bavois-en-Raillon (Vaud). Cahiers d'Archéol. Romande, $\mathbf{n}^{\circ} 28$, 231 p. et 115 fig.

VORUZ J.-L. (1986) - Un habitat-refuge à la grotte des Gitans (Saint-Sorlin). Spéléo 01, ${ }^{\circ}$ 10, pp. 28-43.

Weidmann D. (1986) - Chronique archéologique. Ann. de la Soc. Suisse de Préhist. et d'Archéol., vol. 69, pp. 231-232.

Wells P. (1984) - Trois fermes du Premier âge du Fer en Europe centrale. Pour la Science, fév. 1984, pp. 46-53. 


\title{
Annexe 1 \\ Grotte des Cloches (Ardèche) Etudes des vestiges humains
}

\author{
par Jean-Luc Gisclon
}

I. - INVENTAIRE : FOUILLES 1986, COUCHE E 5

Phalange proximale de main d'adulte, fragment diaphysaire d'ulna (?) d'adulte.

II. - INVENTAIRE : FOUILLES 1986, HORS STRATIGRAPHIE

Atlas d'adulte, $\mathrm{M}^{2}$ droite d'adulte. Phalange proximale main (R 11) droite d'adulte, Humérus gauche d'adulte, Calcaneum gauche d'adulte, Clavicule droite de jeune adulte, deux hemi-arcs neuraux d'une Thoracique et d'une Lombaire d'enfant, fragment distal d'un fémur gauche d'adulte, six fragments osseux d'adulte brûlés, fragment de diaphyse fémorale d'adulte, fragment de diaphyse humérale (?) d'adulte (?), fragment de S I d'enfant (sous réserve), plusieurs fragments de côtes d'adulte et quelques-uns d'enfant, fragment de diaphyse tibiale, fragment diaphyse humérus d'enfant, scapula gauche fragmentée d'adulte, fragment d'arc postérieur de vertèbre Thoracique d'adulte (T 6 ou T 7), C 7 d'adulte. Extrémité proximale de fibula droite d'adulte, Phalange proximale (III) main droite, Phalange proximale (?) main (IV ?) fragmentée, $1^{\text {er }}$ métacarpe gauche d'adulte, $M_{I}$ droite d'adulte, $I_{I}$ droite d'adulte, deux fragments de diaphyse tibiale (?) d'enfant (?), fragment diaphyse femorale (?) d'enfant (?). Radius droit d'enfant, fibula fragmentée d'enfant, fragment diaphysaire indéterminé d'enfant, fragment d'hemimandibule droit d'enfant, $3^{\mathrm{e}}$ métatarse droit d'adulte, $2^{\mathrm{e}}$ métacarpe gauche d'adulte fragmenté. Vertèbre L 5 d'adulte (sous réserve) (arc post. non soude : pathol. ou faune ?) Arc vertébral postérieur non soudé d'adulte (sous réserve, pathologique ou faune).
Restes incinérés d'un adulte : 4 fragments d'un pariétal droit d'adulte, aspect criblé de la surface exocranienne, couleur noire en surface, plus claire sur les bords ; sur la face endocranienne, partie noire et non brûlée. Présence de sortes de cupules d'éclatement thermique sur la face exocranienne et de stries entrecroisées sur un des fragments; présence de deux incisions parallèles sur la face exocranienne d'un second fragment.

Le crâne a été incomplètement brûlé, partiellement et à basse température (environ $330^{\circ} \mathrm{C}$ ). Il a certainement été exposé au feu entier puis, ayant éclaté, a légèrement subi le feu sur la face endocranienne.

III. - IDENTIFICATION

N.M.I. : 3 individus inhumés : un enfant d'environ 6 mois au maximum (entre 3 et 6 mois), un jeune adulte ( 23 ans en moyenne) peut-être de sexe féminin et devant correspondre à la sépulture de la couche $\mathrm{X}$, et un adulte d'environ 40 ans.

Notons la présence d'un individu incinéré adulte.

IV. - OBSERVATIONS SUR LES CRÉMATIONS

La coloration des os brûlés craniens permet d'estimer la température de chauffe (Susini, 1984) à environ $350^{\circ} \mathrm{C}$. Trois fragment diaphysaires, dont un fragment huméral blanc à l'ext. et int. de l'os compact, noir/gris bleuté au centre de l'os compact chauffé à environ $600{ }^{\circ} \mathrm{C}$, et un fragment fémoral ou tibial marron chauffé à environ $300^{\circ} \mathrm{C}$. Un fragment de côte gris-bleu et un autre gris-bleu/noir chauffés à 
environ $500{ }^{\circ} \mathrm{C}$. Un fragment de scapula (?) noir en surface et en épaisseur chauffé à environ $350^{\circ} \mathrm{C}$.

Une analyse plus poussée que la simple observation est indispensable si l'on veut connaître réellement la température de chauffe (phénomènes pédologiques possibles).

Nous retiendrons une combustion à haute température (au moins $600{ }^{\circ} \mathrm{C}$ ) de cet individu, ayant détruit la majorité du squelette. L'ustion différentielle, habituelle et normale pour cette époque, peut être due "à une combustion incomplète à cause d'une mauvaise maîtrise des techniques de crémation, ou au manque de carburant » (Susini, 1984). Il s'agit vraisemblablement d'un dépôt funéraire secondaire constitué par les résidus de la combustion.

\section{V. - OBSERVATIONS SUR LES INHUMA- TIONS}

En ce qui concerne la taille, un seul os long entier nous a intéressé. Il s'agit d'un Humérus qui nous a permi d'estimer la stature de l'individu (une jeune femme certainement) à 1,54 m (Manouvrier corrigé par Sauter). S'il s'agit d'un homme, les tables de Manouvrier modifiées par Olivier, permettent d'estimer la stature à $158 \pm 4,25 \mathrm{~cm}$.

\section{VI. - ANTHROPOMÉTRIE}

\section{A. Enfant}

- Fragment diaphyse humérale : diamètre max. 11,5 et min. 10 .

- Radius droit (diaphyse) : L = 54,3 Age d'environ 5 mois (selon Johnston). Stature estimée (méthode Telka, Palkama) à $57,6 \pm 0,31 \mathrm{~cm}\left(\sigma^{7}\right)$ ou à 54 $\pm 0,38 \mathrm{~cm}(q)$.

- L'hemi-mandibule droite ne porte aucune dent (alvéoles vides).

\section{B. Jeune adulte}

- Calcaneum g. : L max 72,7, larg. min. 26,9, Haut. 35,8, saillie du sustentaculum tali 8 (approximatif)

I. de larg. $=37$, I. de $\mathrm{H}=49,25$
- Phal. prox. main (III) droite : $\mathrm{L}=40,7$

n. b. face latérale externe colorée en vert par oxyde métallique (bague ?)

- Phal. prox. main (II) droite : $\mathrm{L}=37,8$

n. b. diaphyse colorée en vert par oxyde métallique sur tout son pourtour (bague ?).

- Humérus gauche : L max. $=295,6 \mathrm{~mm} ; \mathrm{L}$ physio $=293$ angle d'inclinaison du col $=21^{\circ} ;$

Périmètre au milieu de l'os $=61$; périmètre minimum $=58$

Diamètre max. diaphysaire $=20,4$; diamètre transv . tête : $37 ; \mathrm{I}=89,59$

Diamètre min. diaphysaire $=16$; long de l'ext. prox. $=45,5$

Diamètre sagittal de la tête $=41,3$; I de robustesse $=19,62$

Largeur de l'extrémité distale $=57$; poids : 105 gr.

I. diaphysaire $=78,43$ (eurybrachie).

Observations : gouttière bicipitale bien marquée, $\mathrm{V}$ deltoïdien apparent mais pas très prononcé, pas de perforation olécranienne mais paroi osseuse très mince au-dessus de la trochlée, pas d'épine susépitrochléenne, le trochin est saillant avec une dépression sur la face interne parallèle à l'axe sagittal de la tête articulaire. Donc humérus d'apparence assez gracile, pédomorphe, eurybrachique, de jeune individu peu développé musculairement, caractère que l'on peut interpréter comme sexuel, avec prudence néanmoins, étant donné la jeunesse relative du sujet. Nous considérons que cet humérus appartient à une femme de 23 ans, de petite taille $(1,54 \mathrm{~m})$.

- Scapula g. fragmentée (cavité glonoïde) : Haut de la cavité $=35,9$, larg. $=25, \mathrm{n}$. b. cavité piriforme, I. glénoïdien $=69,64$.

- Extrémité prox. de Fibula droite : périmètre $\min .=35,5$

- Clavicule droite (extrémité externe fragmentée) $:$ poids $\simeq 20 \mathrm{gr}$.

$\mathrm{L}$ max. $=120$ environ $(q)$ périmètre au milieu $\sigma^{7}$ $34,5\left(\sigma^{7}\right)$

diamètre max. au milieu $=11,7$; long. ext. env. 19,6 (O)

diamètre min. au milieu $=9 ;$ I de robustesse $=28,75$

$\left(\sigma^{7}\right)$

courbe horiz. int. $=12 ;$ courbe horiz. ext. $=17,8$

indice de largeur externe $=16,3\left(\sigma^{\prime}\right.$ ou $\left.q\right)$

largeur au tubercule conoïde $=18,8$ (plus près de $\sigma^{7}$ que de )

tubercule conoïde très marqué formant saillie sur le bord postérieur du corps. I diaphysaire $=85,4\left(\sigma^{\prime \prime}\right.$ ou o)

diamètre au milieu horizontal $=10$

diamètre au milieu vertical $=11,7$

n. b. facette du ligament costo-claviculaire (face inf.) très déprimée (pathologie?). Présence d'exostoses 
sur face sup. près de l'extrémité interne et traces d'incisions juste à côté. L'extrémité interne n'étant pas soudée à la diaphyse cet os ne peut avoir plus de 24 ans si $\sigma^{\prime}$, plus de 23 ans si $q^{*}$.

- Phal. prox. (?) main (IV ?) fragmentée non mesurable. 39,6 .

- $1^{\text {er }}$ métacarpe $\mathrm{g}:$ Long. $=41,6, \mathrm{~L}$. physio $=$

- $\mathrm{I}_{\mathrm{I}}$ droite : légère pointe de cément à l'apex

Hauteur totale $=21,6 ;$ hauteur couronne $=8$

diamètre $\mathrm{m}-\mathrm{d}$ de la couronne $=4,8$

diamètre $v-l$ de la couronne $=5,9$

diamètre $\mathrm{m}$-d au collet $=3,4$

diamètre $\mathrm{v}-\mathrm{l}$ au collet $=5,5$

usure presque nulle, \pm horizontale (degré A 1,5 de Gustafson), légèrement oblique, du mésial vers le distal.

60,5

$3^{\mathrm{e}}$ métatarse droit : $\mathrm{L} \max =62,1, \mathrm{~L}$ physio $=$

- Phal. prox. main (E 5) : $\mathrm{L}=30,5$

- Atlas : diamètre transversal $=70,4$

diamètre sagittal $=43,4$

diamètre trans. canal rachidien $=26,4$

diamètre sagittal canal rachidien $=28,6$

épaisseur de l'arc ant. $=4,3$

épaisseur de l'arc post. $=7$

I. de largeur $=61,65$

- $\mathbf{M}^{2}$ droite : $\mathrm{H}$. tot $=19,2$

H. couronne $=6$

diamètre $\mathrm{m}-\mathrm{d}=9,3$

diamètre $\mathrm{v}-\mathrm{l}=10$

diamètre $\mathrm{m}$ - $\mathrm{d}$ collet $=7$

diamètre $\mathrm{v}$-l collet $=9,6$

usure faible (dentine apparente au protocône) (degré A 1,5 de Gustafson).

- Côtes fragmentées non mesurées, ainsi que 2 fragments de diaphyses.

\section{Adulte}

$2^{\mathrm{c}}$ métacarpe gauche non mesurable (n. b. couleur rougeâtre), fragment d'arc post. de $\mathrm{T} 6$ ou $\mathrm{T} 7$ non mesurable (n. b. couleur rougeâtre).

- $\mathrm{M}_{\mathrm{I}}$ Droite : $\mathrm{H}$. tot $=20$

H. de la couronne $=5,7$

diamètre $\mathrm{m}-\mathrm{d}-\mathrm{=}=11$

diamètre $\mathrm{v}-\mathrm{l}=10,2$

diamètre $\mathrm{m}-\mathrm{d}$ au collet $=9$

diamètre $\mathrm{v}-\mathrm{l}$ au collet $=8,9$

usure importante (A 2, 5, cuspides abrasées laissant place à des trous par où apparaît l'intérieur de la couronne) ; résorbtion (R 2), selon Gustafson, n. b. la dent (surtout la racine) a une patine rougeâtre.

- Fragment d'une trochlée fémorale non mesurable avec une patine marron-rougeâtre.

Observation : la patine de ces os et l'état dégradé de leurs surfaces laisse supposer qu'ils ont séjourné un certain temps à l'air libre durant lequel ils ont subi une altération chimique (ruissellement). Tous viennent d'ailleurs des déblais anciens.

- Un fragment d'apophyse transv. de vertèbre thoracique.

- Un fragment diaphysaire de fémur (?) d'adulte.

VII. - CONCLUSIONS

- Présence de 3 individus (au moins) inhumés (ensembles ?) et d'un individu incinéré non daté. L'adulte féminin proviendrait de la couche $X$.

- Cellule familiale nucléique (un homme, une femme et un enfant) ?

- Jeune femme avec une bague sur la $1^{\text {re }}$ phalange de l'index droit.

Jean-Luc GisCLON, Laboratoire d'Anthropologie, Université de Bordeaux I 33405 TALENCE CEDEX 


\title{
Annexe 2
}

\section{Une approche de la végétation au Bronze final $2 \mathrm{~b}$ à la grotte des Cloches (Ardèche) : les résultats de l'analyse anthracologique}

\author{
par Stéphanie Thiébault
}

Dans cette étude, nous avons pu identifier quelques 129 charbons de bois, issus d'une vidange de foyer probable de la couche E 1-BF 26.

Cet exposé, rapide par nécessité, se limitera à une liste d'espèces reconnues, accompagnée de quelques remarques d'ordre général.

Dénombrement et pourcentages des essences carbonisées:

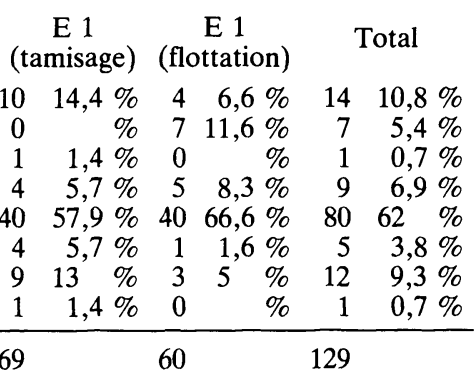

Les deux colonnes (tamisage et flottation) correspondent à deux ensembles de charbons de bois. L'un provient d'un prélèvement par tamisage à sec, l'autre par flottation.

\section{Quelques remarques}

La position de la grotte des Cloches, à SaintMartin-d'Ardèche est intéressante car elle se trouve partagée entre de fortes influences méditerranéennes, qui se remarquent dans la végétation du Bronze final, avec des essences telles que le Filaria et surtout le Chêne vert et des influences plus « médioeuropéennes » qui se traduisent par la présence des Chênes à feuillage caduc, de l'Aubépine, de l'Érable champêtre, de l'Orme et du Hêtre. Soulignons la présence de ce dernier, bien que représenté en très faible quantité $(0,7 \%)$. Dans l'histoire classique de la végétation, cette essence aurait quitté ses zones refuges depuis le début du Subboréal, à la faveur d'un rafraîchissement et d'une légère augmentation de l'humidité du climat.

Le Chêne vert, avec $62 \%$ du total des essences est largement majoritaire. Or, depuis une quinzaine d'années, les études de paléobotanique (Pons et Vernet, 1971) ont peu à peu démontré que son développement postglaciaire serait en partie dû à l'influence de l'homme sur la végétation, influence déterminante en région méditerranéenne, notamment à partir du Néolithique.

En définitive, cette étude montre qu'aux environs de la grotte des cloches, au Bronze final $2 \mathrm{~b}$, se cotoyaient deux types de végétation : - l'une méditerranéenne avec Filarias et Chênes verts, mais d'où le Buis est totalement absent (traditionnel compagnon du Chêne vert dans les diagrammes anthracologiques, cette espèce se développe sur les terres dégradées ; les anthracologes tendent à donner à ces deux essences une valeur de marqueur de l'anthropisation pour les époques postglaciaires. Vernet, Thiébault, Heinz, 1983). L'autre plus médioeuropéenne, indique une chênaie mixte. Nous pouvons ici poser le problème du retour des Chênes à feuillage caduc au Bronze final. Celui-ci a déjà été évoqué dans un gisement plus septentrional (Les Sarrazins, Isère : Thiébault, 1983) ou même suggéré à la Baume-desAnges (Drôme). En effet, après une régression très importante de la courbe des Chênes caduc, au Néolithique, celle-ci se développe à nouveau à partir du Bronze final.

Toute remarque supplémentaire serait prématurée, les analyses de couches supérieures et inférieures du gisement nous faisant défaut.

Stéphanie THIEBAULT

Centre de Recherches Préhistoriques, Paris I

Pons A., Vernet J.-L. (1971) - Une synthèse nouvelle de l'histoire du Chêne vert (Quercus ilex). Bulletin de la Société botanique de France, $\mathrm{n}^{\circ} 118$, pp. 841-850.

Thiebault S. (1983) - L'homme et le milieu végétal à la fin du Tardiglaciaire et au Postglaciaire : analyses anthracologiques de six gisements des Préalpes sud-occidentales. Thèse III $^{\mathrm{e}}$ cycle, Université de Paris I, 215 p., 74 fig., 12 tabl., 5 pl.

Vernet J.-L., Thiebault S., Heinz C. (1983) - Essai de zonation préhistorique postglaciaire méditerranéenne : données nouvelles d'après les analyses anthracologiques du Sud de la France. Actes du colloque : " premières communautés paysannes en Méditerrannée occidentale », Montpellier, avril 1983, actes à paraître en 1986 . 